\title{
Discussion Paper No. 08-119 \\ Geographical and Multi-product \\ Linkages of Markets: \\ Impact on Firm Equilibrium Interactions \\ (Some Evidence from the \\ European Car Market)
}

Nina Leheyda

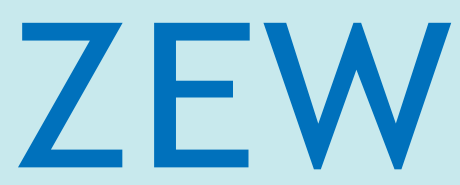

Zentrum für Europäische Wirtschaftsforschung $\mathrm{GmbH}$

Centre for European

Economic Research 
Discussion Paper No. 08-119

\title{
Geographical and Multi-product Linkages of Markets: Impact on Firm Equilibrium Interactions (Some Evidence from the European Car Market)
}

\author{
Nina Leheyda
}

Download this ZEW Discussion Paper from our ftp server:

ftp://ftp.zew.de/pub/zew-docs/dp/dp08119.pdf

Die Discussion Papers dienen einer möglichst schnellen Verbreitung von neueren Forschungsarbeiten des ZEW. Die Beiträge liegen in alleiniger Verantwortung der Autoren und stellen nicht notwendigerweise die Meinung des ZEW dar.

Discussion Papers are intended to make results of ZEW research promptly available to other economists in order to encourage discussion and suggestions for revisions. The authors are solely responsible for the contents which do not necessarily represent the opinion of the ZEW. 


\section{Non-technical Summary}

The European car market is characterized by extensive multimarket contact (i.e., the firms are present in many geographic and product markets), a high degree of interfirm linkages, and presence of several global automotive manufacturer groups. The impact of these factors on the firm behaviour has not been considered in the previous studies, which could explain more precisely the firm conduct in the European car market and shed more light on the pricing behaviour differences across markets, thus, possibly contributing to understanding better the price dispersion pattern in the European car market. Multiple market presence is generally argued to foster collusive firm behaviour. The major objective of this paper has therefore been to test the game-theoretic predictions about the impact of multimarket contact on the firm behaviour by Bernheim and Whinston (1990) for the European car market.

The results of the study reveal the existence of the effect of multimarket contact on the firm behaviour in the European car market. The impact of multimarket contact on the firm behaviour is economically (quantitatively), however, rather insignificant. The impact of concentration on prices is found to be more considerable. For the mutual forbearance to hold, it may be, however, not just enough to be present in several markets. It could be important for firms to have "spheres of influence" in those markets. The effect of the multimarket on the firm behaviour is stronger in the more concentrated market. Concentration alone also contributes to higher prices. The strategic effects of the multimarket contact could be observed in the European car market, i.e., the redistribution of the market power from the more collusive to the more competitive markets. The result is that multimarket contact may lead to lower prices in the more concentrated markets.

To sum up, the results of the study reveal some weak quantitative effect of multimarket contact on pricing/market conduct in the European car market as well as provide some evidence on designing strategic policies by the automotive firms and shifting their market power across the markets, in which they operate. 


\section{Das Wichtigste in Kürze}

Der europäische Automobilmarkt ist charakterisiert durch den hohen Grad an Multi-MarktKontakt (d.h. die Unternehmen begegnen sich in vielen geographischen und ProduktMärkten), den hohen Grad an zwischenbetrieblicher Verflechtung (,linkages') und die Präsenz globaler Automobilherstellergruppen. Die Auswirkung dieser Faktoren auf das Verhalten der Unternehmen wurde in früheren Studien nicht untersucht. Sie könnte jedoch dabei helfen, das Unternehmensverhalten auf dem europäischen Automobilmarkt präziser zu erklären und die Preisverhaltensdifferenzen auf den Märkten zu erläutern, und dadurch möglicherweise zu einem besseren Verständnis der beobachteten Preisunterschiede auf dem europäischen Automobilmarkt beizutragen.

Die Ergebnisse dieser Studie zeigen die Existenz eines Effektes des Multi-Markt-Kontakts auf das Unternehmensverhalten auf dem europäischen Automobilmarkt. Dieser Effekt ist aber wirtschaftlich (quantitativ) nicht signifikant. Der Effekt der Konzentration auf die Preise ist höher. Um die ,mutual forbearance' Hypothese zu unterstützen, ist es nicht ausreichend nur auf verschiedenen Märkten präsent zu sein. Es könnte wichtig sein, Einflussbereiche auf diesen Märkten zu haben. Der Effekt des Multi-Markt-Kontakts auf das Unternehmensverhalten ist stärker auf den höher konzentrierten Märkten. Die Konzentration allein trägt auch zu höheren Preisen bei. Die strategischen Effekte des Multi-Markt-Kontakts können auf dem europäischen Automobilmarkt beobachtet werden: Die Neuverteilung der Marktmacht von den mehr kollusiven zu den wettbewerblicheren Märkten. Das Ergebnis ist, dass der Multi-Markt-Kontakt zu niedrigeren Preisen auf den mehr konzentrierten Märkten führen könnte.

Zusammenfassend zeigen die Ergebnisse dieser Studie einen schwachen quantitativen Effekt des Multi-Markt-Kontakts auf das Preisverhalten und das „market conduct“ Verhalten auf dem europäischen Automobilmarkt. Sie liefert auch einige Evidenzen zum Design der strategischen Politik bei den Automobilherstellern und zur Verschiebung der Marktmacht zwischen verschiedenen Märkten. 


\title{
Geographical and Multi-Product Linkages of Markets: Impact on Firm Equilibrium Interactions (Some Evidence from the European Car Market) ${ }^{1}$
}

\author{
Nina Leheyda*
}

\begin{abstract}
This paper aims to study geographical and multi-product linkages of markets (multiple market presence) and firm behaviour interdependence as a result of such linkages existence. In particular, it attempts to answer whether the multimarket linkages lead to more cooperative behaviour among the firms, which results in higher prices and profits, and whether the degree of collusive/cooperative behaviour varies across markets. These issues are investigated within a structural oligopoly model for differentiated products for the European automobile market on the basis of the aggregate product-level data for 1970-1999. The results of the study reveal weak (quantitative) effect of multimarket contact on market conduct/pricing in the European car market as well as provide some evidence on the redistribution of the market power from the more collusive to the more competitive markets due to multimarket contact.
\end{abstract}

Keywords: multimarket contact, collusion, automobile industry, test for non-nested hypothesis, menu test, structural oligopoly models, conjectural variations

JEL-Classification: L13, L25, L62

* Centre for European Economic Research (ZEW), Department of Industrial Economics and International Management, P.O. Box 1034 43, D-68034 Mannheim, Germany, phone: +49621-1235-172, fax: +49-621-1235-170, leheyda@,zew.de

I am thankful for the financial support to the German Research Foundation (Deutsche Forschungsgemeinschaft (DFG)) and the Center for European Economic Research (ZEW) during my PhD studies at the Center for Doctoral Studies in Economics (CDSE), University of Mannheim. I am very grateful for the comments to Konrad Stahl and for the discussion to Frank Verboven at the early stage of the paper. Enormous thanks to my sister Tetyana Romanchenko for data assistance. The comments of the participants of 2007 CDSE Doctoral Seminar, 2007 9th INFER annual conference, 2008 Spring Meeting of Young Economists, 2008 North American Summer Meeting of the Econometric Society, 2008 EEAESEM conference and 2008 EARIE conference are appreciated. 


\section{Introduction}

Most of the existing on the European car market ${ }^{2}$ studies has been devoted to the investigation of significant price dispersion in the European car market (e.g., Verboven, 1996, Degryse and Verboven, 2000, Goldberg and Verboven, 2001) $)^{3}$. Empirical studies find the following reasons for the price dispersion in the European car market: differences in demand elasticities, concentration, import quota constraints, lack of uniform taxation, incomplete pass-through of exchange rates, differences in local costs ${ }^{4}$, etc. Verboven (1996) mentions considerable crossborder arbitrage costs, which result in geographical car market fragmentation ${ }^{5}$. The volume of parallel imports is very low. Ginsburgh (1996) and Lutz (2000) point out the "block exemption" to be the most important factor that has hindered competition in the European car market. Additional obstacles to purchase a car abroad are national type approval rules (harmonized only in 1995) and national registration systems (Goldberg and Verboven, 2001). This leads to significant artificial trade barriers.

The European car market is characterized by extensive multimarket contact (i.e., the firms are present in many geographic and product markets), a high degree of interfirm linkages, and presence of several global automotive manufacturer groups ${ }^{6}$. The impact of these factors on the firm behaviour has not been considered in the previous studies, which could explain more precisely the firm conduct in the European car market and shed more light on the pricing behaviour differences across markets, thus, possibly contributing to understanding better the price dispersion pattern in the European car market.

Multiple market presence is generally argued to foster collusive firm behaviour (e.g., Bernheim and Whinston, 1990, Spagnolo, 1999). The major objective of this paper has been to test the game-theoretic predictions about the impact of multimarket contact on the firm behaviour by Bernheim and Whinston (1990) for the European car market. First of all, I have aimed to test for the general effect of the multimarket contact presence, i.e., the extent of the markets overlap, on the firms' equilibrium behaviour pattern. Furthermore, the firms should "forbear" from retaliating more, the larger shares they have in those markets. For them there is more to lose in the concentrated markets if they choose to deviate from collusive prices, and there will be lower coordination costs in those markets. That is why, I have attempted to investigate whether the multimarket contact effect on collusion is stronger in the more concentrated markets. In empirical studies it is usually difficult to measure the effect of multimarket contact on competition and to differentiate between the impact of multimarket contact and concentration on pricing, which I have intended to address in this paper. I have also aimed to test directly for the presence of the "spheres of influence" that would foster collusive behaviour (this term has been introduced by Edwards (1955) and has been discussed

2 In Introduction I refer to European car market as a whole Western European car market. In my estimations later, however, under the European car market the new car sales in the following five countries are meant: Belgium, France, Germany, Italy and the UK.

3 A detailed survey and major findings of these studies can be in particular found in Degryse and Verboven (2000). A number of studies on the price differentials in the European car market have been published by the European Commission. Questions being addressed in the other European car market studies have been in particular the effects of the reform of the car distribution system in Europe (Brenkers and Verboven, 2006a), and defining a relevant car market (e.g., Brenkers and Verboven, 2006b).

4 Manufacturing cost differences across countries in the European car market have been found to be important (e.g., Kirman and Schueller, 1990). The highest-cost producer is the UK, followed by Italy and Germany, with Belgium and France being the least-cost producers.

5 The possibility of arbitrage trade between markets and the degree of market segmentation have been addressed in Lutz (2004).

At present there are about 13 global independent automotive manufacturer groups. These manufacturer groups own several car brands (e.g., VW Group). The notion of interfirm linkages comprises equity and contractual as well as horizontal and vertical relationships among the firms. This issue will be discussed in more detail later in the paper. 
by Bernheim and Whinston (1990)). That is, I have tested for collusion among "influential rivals", which could respect each others' "spheres of influence" (e.g., these could be the markets where they have cost advantages). Finally, I have intended to test for the presence of the strategic effects of the multimarket contact as specified by Bernheim and Whinston (1990), namely, the redistribution of the market power from the more collusive to the more competitive markets in case of differentiated products due to the multimarket contact in the European car market.

The previous empirical evidence on multimarket contact effects has been rather inconclusive concerning the existence, sign and significance of the effect on the tacit collusion (e.g., Heggestand and Rhoades, 1978, Scott, 1982, Evans and Kessides, 1994, Parker and Röller, 1997). In Leheyda (2007a) I could find some evidence about the possible existence of the multimarket contact effects on the firm behaviour in the US light vehicles market. However, some additional evidence could have been worthwhile to get to argue firmly about the relevance of these effects for the automobile markets. In particular, it was difficult to differentiate that effect from the possible concentration effect on collusive pricing. As compared to that study, in this paper the longer period of time and a greater number of markets allow me to study a richer number of the research objectives (including the existence of the strategic effects of the multimarket contact) and apply other approaches to study the multimarket contact (as well as concentration) effects on the firm behaviour. Geographical aspect of the multimarket contact is added to the multi-product context of the automotive industry, which increases the number of markets, across which the automotive firms interact.

Evidence for collusive behaviour found in the other studies, or facts observed in reality ${ }^{7}$ could serve as an additional motivation to investigate the multimarket contact hypothesis. The empirical evidence on the multimarket contact effects existence, if found, might be another potential explanation/motive for cooperative/collusive behaviour among the firms. Verboven (1996) could not reject the hypothesis of the presence of collusive behaviour in Germany and United Kingdom in 1990. Goldberg and Verboven (2001) attribute the higher prices in Italy to the presence of the strong bias towards domestic brands, higher prices in the UK to "the better equipped cars and/or differences in the dealer discount practices". Brenkers and Verboven (2006a) find that the firm behaviour in the UK is slightly more collusive than the Bertrandtype behaviour, and that the behaviour in France, Germany and Italy is slightly less competitive than the multiproduct behaviour as compared to Belgium. As compared to the above three studies ${ }^{8}$, I am using other approaches to identify the collusive firm behaviour ${ }^{9}$. In addition, I try to link it to the presence of the extensive multimarket contact and high concentration in the European car market. That is, I attempt not only to report the existence of the collusive behaviour in the European car market, but point out some factors behind its existence if found. Jaumandreu and Moral (2006) find support for the price coalition by domestic and European firms in the Spanish car market during 1990-1996, notwithstanding the increased competition starting 1993 (connected with tariffs dismantling for foreign firms, demand downturn, and high entry of new models).

\footnotetext{
The UK has been, e.g., mentioned as the only European country where a legal investigation for collusive behaviour has been initiated by Monopolies and Merger Commission (Goldberg and Verboven, 2001). These are the only studies that estimate structural oligopoly models with product differentiation for the total European car market. The other studies apply mostly the reduced-form approach to study the price dispersion in the European car market, or they concentrate on specific country markets developments. For the demand side, I take the similar demand specification. I am not interested in the demand specification as such in this paper. The most important for me has been to get the reliable estimates of price and correlation parameters that could have been used to estimate substitution patterns, markups and market conduct parameters.
} 
Absence of the consistent and considerable evidence and no targeted study on the firm behaviour in the European car market has served as an additional motivation for doing this study. For example, Verboven (1996) argues that there could be differences in the degree of collusive behaviour across countries and calls for a more detailed analysis of the differences in the firm behaviour across the countries. My study has been meant to be a contribution to the market conduct literature using new empirical approaches in the IO. In this paper the emphasis is on different demand and cost conditions in geographical markets and also product markets, which could lead to different degrees of collusion/cooperative behaviour in these markets due to multimarket contact, which has been pointed out by Bernheim and Whinston (1990). The idea of this paper is to extend the empirical approach of structural oligopoly model with product differentiation by Verboven (1996), Goldberg and Verboven (2001) and Brenkers and Verboven (2006a, b) for geographical markets to study the impact of the degree of geographical and multiproduct market linkages on the firm behaviour in the European car market. To sum up, this study attempts to systematize the previous evidence on the firm behaviour in the European car market and draw some new inferences by going further into the methodology on the firm equilibrium interactions.

The major contribution of this paper in terms of the methodology to study the impact of multiple market presence on the firm behaviour is to estimate conjectural variation parameters (in case of differentiated products) and test the impact of concentration and multimarket contact within this market conduct equation. These effects are tested directly within the hedonic pricing equation as well. To measure the degree of multimarket linkages, I construct several multimarket contact measures at the firm and market level. I also discuss different "spheres of influence" for the car producers at geographic, market segment and geographicproduct market levels. In addition, the likelihood of a number of multimarket contact firms coalitions as candidates for a potential equilibrium outcome in the European car market is being tested on the basis of the menu approach. In particular, the test for non-nested hypotheses by MacKinnon, White, and Davidson (1983) and the model selection test by Rivers and Vuong (2002) are applied to test for different modes of market conduct.

The results of the study reveal the existence of the effect of multimarket contact on the firm behaviour in the European car market as well as provide some evidence on the redistribution of the market power from the more collusive to the more competitive markets. The impact of multimarket contact on the firm behaviour is economically (quantitatively), however, rather insignificant. The impact of concentration on prices is found to be more considerable. The multimarket contact effect on the market conduct and prices may be also stronger in the more concentrated markets. It has been challenging to choose the best model specification for the supply side on the basis of the menu approach that has been aimed to test directly for the "spheres of influence" version of the mutual forbearance hypothesis.

The paper proceeds in the following way. First, the literature review is presented. In the next section I describe the structural characteristics of the European car market as well as observed in the market multimarket contact and inter-firm linkages. After that empirical framework for testing the mutual forbearance hypothesis is discussed. Then data, estimation procedure and results are described. The paper ends with some conclusions.

\section{Literature review}

The literature on multimarket contact theory has been more extensively discussed in the paper on the multimarket contact effects in the US light vehicles market (Leheyda, 2007a). In this section I would like to highlight some empirical studies that are more relevant for this study and have not been discussed in detail in the paper earlier. 
As I have already mentioned, the existing empirical studies (e.g., Heggestand and Rhoades, 1978, Scott, 1982, Evans and Kessides, 1994, Parker and Röller, 1997), which are mostly done for airlines and banking industry, have failed to give conclusive evidence about the existence, sign and significance of the multimarket contact effect on facilitating and maintaining collusion. These are mainly the cross-sectional studies. They may rather identify correlations between multimarket contact and competition, while prices, concentration and multimarket contact are rather endogenously determined. One of the sources of endogeneity is the unobserved heterogeneity across markets, which can be captured by introducing market fixed effects in panel-data models.

Most existing empirical studies concentrate on testing the multimarket contact effect, based on the construction of some multimarket contact measure, on the firm's performance (i.e., the so-called reduced-form approach), while there have been virtually no studies done about the multimarket contact effect on collusion within a structural model of firm behaviour. The only exceptions are the papers by Jans and Rosenbaum (1996) and Parker and Röller (1997) for homogenous products. The existing empirical studies have a major problem to distinguish between internal (e.g., concentration, demand conditions, barriers to entry) and external effects (e.g., multimarket contact) upon the firm performance (Bernheim and Whinston, 1990).

Most of the existing empirical studies on the multimarket contact effects focus on geographical markets (for banking, airlines, mobile telephony markets, etc.). The only exception there seems to be a paper by Scott (1982), where the study is done for the lines of businesses.

Some studies find that the effect of multimarket contact on prices is stronger in the more concentrated markets (e.g., Scott (1982), Jans and Rosenbaum (1996)). Scott (1982) and Jans and Rosenbaum (1996) find a more pronounced effect of multimarket contact on collusion in the more concentrated markets, and higher impact of concentration on collusion in the markets characterized by the more extensive multimarket contact. Fernandez and Marin (1998) find lower prices in the markets where it is easier to collude, and higher prices in the markets where it is more difficult to reach collusive agreements. They attribute this effect to the presence of the so-called strategic effects of the multimarket contact, i.e., the redistribution of the market power from the more collusive to the more competitive markets.

The focus of many empirical studies are the general conditions of the existence of the multimarket contact effects (i.e., studying the impact of the overlap of the markets in which the firms are present), while not so many studies focus explicitly on the different effectiveness of multimarket contact when the firms differ in their territorial interests (in other words, "spheres of influence"). This idea of the "spheres of influence" version of the mutual forbearance hypothesis has been discussed in detail by Gimeno (1999). He argues that firms under multimarket contact competition tend to recognize different "territorial interests" that the firms may have in different markets. They may use their market shares in the markets that are important for their rivals to reduce the competition in those markets that are important for them and sustain their dominant positions. The benefit for the firms from multimarket retaliation threats is not equal across all their markets. These threats of multimarket retaliation are rather used by the firm to defend its position in those markets, where the firm has "spheres of influence". The empirical literature on this aspect of the multimarket competition is not extensive, which may serve as an additional argument to investigate this issue more profoundly in this study.

In addition to the construction of multimarket contact measures and testing their impact on the firm performance, the estimation of the so-called conjectures has been another approach used in the literature to study the firm strategic interdependence as a result of multiple market 
presence. Feinberg (1985) argues that the theory of the mutual forbearance could be treated as an extension of traditional oligopoly theory, which foresees the possible existence of crossmarket conjectural variations. When firms meet each other in several markets, a firm can conjecture a possible reaction of another firm in all the markets where they meet each other to an action by anyone of them. The estimation of own- and cross-market effects is in tradition of the empirical industries with market power (survey by Bresnahan (1989)). Feinberg (1985) and Gelfand and Spiller (1987) estimate "conjectures", i.e., own- and cross-market reactions, and interpret them in terms of the mutual forbearance hypothesis ${ }^{10}$. But what is actually rather being tested in these papers, that is the notion of strategic interdependence (introduced by Areeda and Turner, 1979), or the presence of multiproduct oligopolistic strategies, which may be not actually the evidence for the cooperative behaviour of firms. When firms recognize this mutual interdependence, the mutual forbearance behaviour can evolve, which led to the hypothesis formulated by Edwards (1955) and formalized by Bernheim and Whinston (1990) (i.e., collusive behaviour as strong interdependence across markets).

The number of studies that estimate the conjectural variation parameters for differentiated products industries is rather limited (as compared, e.g., to those that estimate homogenous goods demand and marginal cost). Thus, any contribution in this field could be welcome, despite some criticisms of this approach (e.g., identification problem, conjectures interpretation). Both $\mathrm{menu}^{11}$ and conjectural variation approaches to identify the market conduct have their weaknesses, so it is worthwhile to apply both of them in order to come up with the reliable results at the end. This has been the strategy pursued in this paper.

\section{European car market}

\subsection{Structural characteristics}

The European car market, although less concentrated than the US car market, is characterized by significant cross-country differences in concentration ratios. The markets are especially concentrated in France and Italy, followed by Germany and the UK, with the lowest concentration ratio for Belgium (see Graph B1, Appendix B). The most concentrated market based on the one-firm (C1)-concentration ratio is Italy, while the most concentrated market on the basis of the four-firm (C4)- and seven-firm (C7)-concentration ratios is France in 1999. During the considered period of time, i.e., during 1970-1999, the concentration ratios have declined in Italy. The concentration ratios for the total European car market have stayed on average at the same level, while the multimarket contact, which will be discussed in more detail below, has increased.

The number of producers in geographic markets has increased in 1999 as compared to 1970. In particular, several foreign producers have entered the European car market (e.g., Mazda (1972), Mitsubishi (1976), Daihatsu (1979), Hyundai (1980), Suzuki (1981), Seat (1983), Skoda (1993)). The share of the non-European firms is the highest in Belgium, where there are no domestic producers.

The European car market is also characterized by different tax levels (see Table B2, Appendix B) and import quotas (3.0\% in France, $15.0 \%$ in Germany, $1.0 \%$ in Italy, and $11.0 \%$ in the UK (Goldberg and Verboven, 2001)).

The above mentioned differences in concentration ratios as well as in the number of car producers across geographic-product markets imply that the markets that I consider could be

\footnotetext{
10 Their analysis is based upon the investigation of the "conjectures" values and their change as a result of some regulatory actions.

11 The menu approach to identifying the firm behaviour has been in particular described by Gasmi et al. (1990).
} 
quite different. As Bernheim and Whinston (1990) state (among other possible conditions), the effect of the multimarket contact on cooperative behaviour can be facilitated in case of different markets, or in case of a different number of firms in those markets.

A few words should be mentioned about the international price dispersion in the European car market. International price differences are the lowest for the luxury car market segments, while the highest international price differentials are observed in segments C and D (Degryse and Verboven, 2000). In general in the smaller car market segments the price differentials are found to be higher. The highest price differentials are observed by Japanese and Italian brands (that have most models in the smaller car market segments). As for international price differentials across brands, Degryse and Verboven (2000) find the highest price differentials by Fiat, Alfa Romeo, Nissan, Honda, Toyota, Subaru, Mazda and Ford, and the lowest by Mercedes, BMW, Lancia, Peugeot, Citroen and Renault. Lutz (2000) finds that among European car producers Peugeot/Citroen, Fiat and Ford Groups price-discriminate more than GM Opel, VW, and Renault. The lowest absolute price differentials have been found for BMW, Mercedes, Audi and Volvo. Japanese producers are not found to price-discriminate more than other producers but Nissan, Daihatsu, Suzuki and Subaru price-discriminate more than Honda, Toyota, Mitsubishi and Mazda. At the country level the most expensive models are found in the UK, followed by Germany, France, Austria, Finland and Greece.

\subsection{Multimarket and multi-firm linkages}

This sub-section is built in the following way. I start with a definition of a geographic-product market in the European car market, while the exact definition of a market is important for identifying the effect of the multimarket contact on the firm behaviour. After that I present a general picture of multimarket contact across markets, namely describe the overlap of the markets, in which the automobile companies are present, and describe the "territorial interests", the presence of which could make the automotive companies respect each other's "spheres of influence" and, thus, behave cooperatively. This discussion is presented at the geographic, market segment, and geographic-product market for the European car market. Next the descriptive statistics for the constructed multimarket contact measures and concentration ratios is presented. The sub-section ends with some discussion of interfirm relationships between the automobile companies.

\subsubsection{Definition of a geographic-product market}

The European car market is characterized by considerable multimarket contact both within geographic and product-level dimensions. Geographic-product market, i.e., the overlap of geographic and product markets (e.g., Belgium subcompact, Germany luxury, etc.), is a main unit upon which the multimarket contact effects are investigated in this paper.

Geographic-product market is used as a market to define the number of multiple contacts among the firms and to construct the multimarket contact and concentration measures. The major question is how distinct these markets are so that one could discuss them separately and investigate the multimarket contact effects. The major criteria used in the literature to delineate the market boundaries ${ }^{12}$ is to consider the cross-price elasticities of demand (econometric tests for the delineation of market boundaries have been developed by Sheffman

12 Candidates for markets are different products or services within an industry, geographical demand for a product or service, different industries (Gimeno and Woo, 1999). Market definition is partially determined by the level of aggregation as there could be multiple products in any industry, or a country market can be divided into regional, or local markets. 
and Spiller (1996)), or to investigate the co-movements in prices across markets ${ }^{13}$ (e.g., Kay, 1990).

Brenkers and Verboven $(2006 \mathrm{~b})^{14}$ find the existence of distinct product markets in the European car market: the segments are the relevant markets for all classes (subcompact, compact, intermediate, standard/luxury, and sports), except for minivan, for which the relevant market definition should be the aggregate country level, i.e., all new cars. They recommend the competition authorities to investigate the impact of their policies for each car market segment separately. The cross-price elasticities of demand are usually found to be low with respect to the cars in the other market segments (e.g., Berry, Levinsohn and Pakes, 1995, Brenkers and Verboven, 2006a). Demand linkages if any are likely to be stronger across adjacent than across more remote market segments. Different price dispersion across market segments is also observed in the European car market (e.g., Degryse and Verboven, 2000). To sum up, industry analysts and academic researchers support the view that the car market segments constitute distinct sub-markets, which differ in consumer demand, technology, and competitors' type (e.g., Requena-Silvente and Walker, 2005).

Geographical European car market fragmentation is taken as a standardized fact: there is very little, or no cross-price elasticity of demand across country markets. There is no single European car market: the European car market consists of many national markets with quite distinct characteristics.

Automotive firms are multinational firms that are present in a lot of geographic-product markets. The mutual forbearance foresees that there is a company-level decision-making process coordinated across geographic-product markets ${ }^{15}$. It has been argued that the European car market fragmentation prevents from exploiting the economies of scale ("plantscale") (European Commission, 2004).

At the product market level the economies of scale ("product-scale", large numbers of more or less the same product) and scope (ability to make many different and new products; not one car for different markets, but different cars for different markets and types of customers; the number of market segments and niches has been continuously increasing) have been important for the automotive firms. The VW Group is an example of the company that relies a lot on scale and scope economies.

\subsubsection{General picture of multimarket contact across markets}

In addition to a just simple market overlap between multipoint competitors (i.e., presence of the same competitors in several markets), the "spheres of influence" of firms could play an even more important role in sustaining collusive outcomes between multimarket firms as the firms may tend to respect each other's "spheres of influence" and behave less competitively.

The "spheres of influence" of firms could be defined on the basis of the "market share dominance" and "market dependence"16. "Market share dominance" is measured by the largest shares the firms hold in different markets. It is defined for every firm, that is why, the

13 If there is a high positive correlation between the prices of two potentially competing products, that would mean that the products are likely to be substitutes, and, thus, they could be in the same relevant market.

Brenkers and Verboven (2006b) apply the SSNIP (a small but significant and non-transitory increase in prices) test to delineate relevant markets.

15 Gimeno and Woo (1999) argue that the decisions should be coordinated at the organization level if the managers want to exploit the scope economies.

16 This has been first suggested by Gimeno (1999). He actually uses three criteria to define asymmetric territorial interests of firms: market share dominance, market dependence, and resource centrality. Under "resource centrality" the firms have different territorial interests because of different competitive advantage, which is linked to "underlying resources and capabilities of the firm". 
share of a firm may not be the largest one if it is not a large car producer, especially this can hold for premium producers, or foreign producers. "Market dependence" ("importance" of the market) is measured by the percentage of the firm's total sales (revenue) represented by that market ${ }^{17}$. Domestic car markets could be considered as "spheres of influence" of the automobile producers at the geographical level. In addition, there are "spheres of influence" for producers at the product level.

Below I concentrate on the descriptive analysis of the multimarket presence of the automotive manufacturers at geographical, product and geographic-product market level as well as discuss the presence of the "spheres of influence" for the automotive manufacturers in the European car market. This is used later to define the possible coalitions of the multimarket contact firms. I start with the description of the multimarket presence of the automotive firms and their "spheres of influence" at the geographical level.

Table B3 (Appendix B) gives an idea of the most important country markets for the car producers (comparison of 1999 to 1970). The simple market overlap can be inferred from this Table: many of the OEMs, especially large volume ones like VW, are present in almost all countries. In 1999 France is the most important country market for Peugeot and Renault. Germany is the most important country market for BMW, Daihatsu, Kia, Mazda, Mercedes, Mitsubishi, GM, Suzuki, Toyota, VW and Smart. Italy is the most important country market for Fiat, Hyundai and Daewoo. The UK is the most important country market for Ford, Honda and Nissan. As for the largest European volume car producers that could be seen as the primary candidates to recognize and respect each other's "spheres of influence", to sum up, it can be seen that Italy is the most important market for Fiat, Germany is the most important market for VW and GM, France is the most important market for Peugeot and Renault, and the UK is the most important market for Ford. The large players are likely to be uninterested in forming implicit collusive arrangements with small players like Daihatsu. Mercedes and BMW are premium producers that will rather compete with each other. Audi is also a premium brand, but it is considered as a part of the volume car producer VW Group.

Table B4 (Appendix B) shows the share of a firm in the total country market sales in 1999 as compared to 1970 and gives some picture of "market share dominance". The "spheres of influence" defined on the basis of this criterion are France for Peugeot and Renault, Germany for BMW, Mercedes and VW, Italy for Fiat, the UK for GM and Ford, which actually reflect the "domestic origin" of a producer, except for the UK ${ }^{18}$. The largest share in Belgium belongs to VW, in France - to Peugeot, in Germany - to VW, in Italy - to Fiat, in the UK - to Ford. The largest shares in the total European car market (Belgium, France, Germany, Italy and the UK) belong to VW (20.1\%), Peugeot (13.1\%) and GM (12.2\%).

Now I move to the discussion of the multimarket contact presence of the automotive producers and the determination of the "spheres of influence" at the market segment level for the European car market.

Table B5 (Appendix B) gives the largest car manufacturers in each market segment and for the whole European car market in 1999 as compared to 1970 ("market share dominance"). In general, the structure of the European car market in 1999 is as follows: subcompact (37.8\%), compact (30.2\%), intermediate (19.7\%), standard (6.7\%) and luxury (5.6\%). As for the simple overlap of markets, a fewer number of firms are present in almost all markets, which are

17 As compared to the "market share dominance" criterion, the "market dependence" criterion takes into account the size of the market and the size of the firm. For example, a large firm may have a dominant share in a small market, but this may be strategically unimportant for this large firm.

18 As for the non-European firms, the so-called "spheres of influence" in 1999 are Belgium for Suzuki, FujiHI, Mitsubishi and Toyota, the UK for Honda, and Nissan, and Germany for Daihatsu, Kia, and Mazda. The shares of these firms in these countries are, however, very small. 
defined here to be the market segments, as compared to the overlap of geographical markets. There are some firms like Mercedes and BMW that are present in one or two market segments, here standard and/or luxury market segments, or e.g., Kia is present only in the smaller car market segments. Subcompact market segment is a "sphere of influence" for Daihatsu, Fiat, Hyundai, Renault, Daewoo and Smart. Compact market segment is a "sphere of influence" for Ford, Mitsubishi, GM and VW. Intermediate market segment is a "sphere of influence" for Kia, Mazda, Nissan, Peugeot, Suzuki, Toyota and VW. Standard market segment is a "sphere of influence" for BMW and Honda. Luxury market segment is a "sphere of influence" for Mercedes. Except for Fiat, Renault, Peugeot, VW, GM, Ford, BMW, Mercedes, the other firms have small shares. The collusive arrangements of the influential players with small automotive players are highly unlikely. The most important markets ("market dependence") are subcompact for Daihatsu, Fiat, Hyundai, Nissan, Peugeot, Renault, Suzuki, Toyota, Daewoo, and Smart, compact for Ford, Honda, Mazda, GM, and VW, intermediate for Kia and Mitsubishi, standard for BMW, and luxury for Mercedes. This can be inferred from Table B6 (Appendix B).

The combination of geographic and product market presence leads to geographic-product market linkages, which is actually the level of my analysis. The below discussion is important to define the "spheres of influence" and "influential rivals" at the geographic-product market level, among whom later the assumption of collusive behaviour could be tested. Geographicproduct market linkages are described in Table B7 (Appendix B). The firms that are present in all 25 geographic-product markets in the European car market in 1999 (5 countries and 5 market segments) are Fiat, Ford, GM, and VW. Peugeot and Renault are present in almost all market segments ${ }^{19}$. BMW has also increased its presence across markets as compared to 1970. For Fiat, Ford and Renault the three most important "spheres of influence" (based on "market share dominance") are the respective domestic markets, while for GM and VW the "spheres of influence" may lie outside of the domestic country market. For Fiat these are subcompact, standard and luxury market segments in Italy. For Ford these are subcompact, compact and intermediate market segments in the UK. For Renault these are subcompact, compact and standard market segments in France. GM has the largest market shares in the subcompact market segment in Germany, and in the intermediate and standard market segments in the UK. As for VW, it has the largest market shares in the compact and intermediate market segments in Germany and in the intermediate market segment in Italy.

Table B8 (Appendix B) presents the picture of the most important geographic-product markets for firms ("market dependence"). As for the largest car volume producers, the most important market for Fiat is Italy's subcompact market segment, for Ford - the compact market in Germany, subcompact and compact markets in the UK, for GM - the compact market in Germany, for Peugeot - the subcompact market in France and intermediate market segment in France, for Renault - the subcompact market in France, for VW - the compact market segment in Germany. These firms might behave rather collusively if they would like that their competitors respect their "spheres of influence" in return for that they themselves respect the "spheres of influence" of their competitors.

The biggest geographic-product markets in Europe are subcompact market segment in France (the most important for Peugeot and Renault), compact market segment in Germany (the most important market for GM and VW) and subcompact market segment in Italy (the most important for Fiat). For Ford the subcompact market segment in the UK is the most important. These firms could be interested in respecting each other's "spheres of influence", as the stakes in the markets are rather high.

19 As for non-European firms, Toyota and Nissan are the firms that are most frequently present in the geographic-product units of the European car market. 


\subsubsection{Multimarket contact and concentration measures for the European car market}

To measure the impact of multimarket contact on the firm behaviour in the European car market, I consider the construction of several multimarket contact measures. These measures can be constructed at the firm and market level. Quite a large number of geographic-product markets in which the automobile firms are present in the European car market allows me to construct these measures, which have not been considered for the automobile markets before (also a long period of time allows me to get variation in these measures (cross-sectional and within-group variation)). I consider four measures of the multimarket contact: number of geographic-product markets, in which a firm is present, number of multiple contacts of a particular firm with other firms, simple and market-share weighted multimarket contact measures ${ }^{20}$.

Two simple count measures of the multimarket contact presence have been constructed at the firm level: the number of geographic-product markets in which a firm is present and the number of multiple contacts (see Table C1, Appendix C).

The number of geographic-product markets in which a firm is present is a simple count measure. Its interpretation can be twofold: multiple market presence (the larger the number of markets in which a firm is present, the greater is the probability that the firm will meet the same competitors in those markets, the more cooperatively the firm should then behave) and economies of scope (large producers are more likely to be present in several markets).

The number of multiple contacts is constructed as the sum of pairwise contacts in a year: e.g., for Ford: the number of contacts between Ford and GM in all geographic-product markets where they are both present, plus the number of contacts between Ford and Mercedes, etc., i.e., the number of pairwise contacts in all contact markets for the particular firm with its competitors. The larger the number of these multiple contacts, the more cooperatively the firm should behave with its multiple competitors and the more collusively it will tend to set its prices (for the mutual forbearance hypothesis to hold).

As compared to 1970, in 1999 the automotive firms are characterized by even greater multiple market presence and higher number of multiple contacts (in particular, due to the expansion of their product line, movement to new geographic and product markets, the entry of Asian competitors into the European car market). The average number of geographicproduct markets in which a firm is present increased from 14.02 in 1970 to 19.37 in 1999 . The average number of multiple contacts for a firm went up from 93.49 in 1970 to 228.43 in 1999 . The number of multiple contacts is also constantly being influenced by changes in the corporate ownership, which contributes to the variation in the multimarket contact measures.

Simple and market-share weighted multimarket contact measures at geographic-product market level have been constructed (see Appendix A for details on the methodology of these measures construction, see Table C2, Appendix C for the descriptive statistics of these measures).

The intuition behind the simple multimarket contact measure construction is as follows: to proxy the degree of multimarket contact in a particular geographic-product market $k=1, \ldots, K, I$ take every automotive manufacturer $n=1, \ldots, N$ in a market $k$ (which is defined to be a focal market, or market under consideration) and aggregate all the contacts this firm

20 These measures have been previously used in the literature, which may allow me to compare the results of this paper with the results of the other studies as well as derive some implications in terms of the use of such measures for the automobile industry. In Leheyda (2007a) these measures have not been constructed as there would have been little variation in these measures to identify their impact on prices due to a short period of time as well as a small number of markets has been observed. 
has in $K$ markets (which are defined to be contact markets) with its $N_{k}$ competitors (i.e., the number of competitors in the market under consideration). The number of contacts is aggregated for all firms that are present in the market under consideration and then divided by the number of firm pairs in the focal market. Thus, the firm's average multimarket contact with its rivals in the given market is calculated. As compared to the above considered number of multiple contacts with other firms calculated at the firm level, this measure is calculated as a market average for a pair of firms.

In addition, the contact markets may have different importance for the firm, thus, the contacts need to be weighted taking into account different characteristics of the contact markets. I weight each contact by the market shares of the firms. This reflects that the higher the market shares (and, thus, the firms' stakes in those markets) are, the more likely the firms will try to compete less aggressively (to avoid punishments, which are likely to be more severely felt by the firm, when it has a large market share in that market), and the higher the profits the firms may expect to get. Then all the contacts are aggregated and divided by the number of firm pairs in the market under the consideration to get the average share-weighted multimarket contact measure at the market level. As compared to the simple multimarket contact measure, the share-weighted measure may show more variation (as there is large variation in the market shares over time).

The higher the simple and market-share weighted multimarket contact measures for a market, the more cooperatively the firms should behave (for the mutual forbearance to hold) and the higher prices should be observed.

The average simple multimarket contact measure increased from 8.07 in 1970 to 14.41 in 1999, while the average market-share weighted multimarket contact measure somewhat decreased from 1258.53 in 1970 to 1021.11 in 1999 . The highest simple count multimarket contact measure is found for the intermediate market segment, while the lowest value is found in the luxury market segment. In case of the share-weighted multimarket contact measure, the highest value is found for the luxury car market segment, which is related to the high market shares of luxury car producers and a small number of such producers in this market segment (BMW, Mercedes, and Fiat in Italy).

Concentration measures $(\mathrm{C} 1, \mathrm{C} 4$, and $\mathrm{C} 8)$ have been constructed at the country (see Graph B1) and geographic-product market level. Some descriptive statistics for these concentration measures at the geographic-product market level can be found in Table C3 (Appendix C). The average concentration ratios have decreased: C1 ratio from 47.38 in 1970 to 34.40 in 1999, $\mathrm{C} 4$ ratio from 89.68 to $77.15, \mathrm{C} 8$ ratio from 99.53 to 94.45 . On the basis of the $\mathrm{C} 1$ ratio, the most concentrated markets are the luxury car market segment of Belgium, France and Germany and the subcompact market segment of Italy. Except for the luxury car market segments, the most concentrated markets on the basis of $\mathrm{C} 4$ ratios are intermediate, standard and subcompact market segments in France, standard market segment in Germany, and standard and subcompact market segments in Italy. Higher concentration is generaly expected to result in higher prices.

\subsubsection{Some picture of interfirm linkages}

The discussion in this Section is important as I aim to test for the mutual forbearance hypothesis among the multimarket firms, and it should be decided whether these effects should be evaluated at brand (e.g., Mercedes), or manufacturer group (e.g., DaimlerChrysler) level.

As it has been already mentioned, the automobile industry is characterized by a lot of interfirm linkages. By interfirm linkages I mean both contractual and equity arrangements of firms. By contractual arrangements first of all non-traditional contracts are implied (e.g., joint 
R\&D, joint product development, long-term sourcing agreements, joint manufacturing, joint marketing, shared distribution service). Equity agreements may generally take up different forms, in particular with or without new equity creation. The picture of international linkages between automotive manufacturers (in particular, contractual arrangements) can be found in Automobile Production (Automobil Produktion) (2005) that has been originally prepared by WardsAuto.

The automobile industry has gone through a period of tremendous consolidation. This consolidation has influenced the degree of external multimarket contact and decreased the number of the independent automotive manufacturers. At present there are about 13 global independent automotive manufacturer groups. Table B9 (Appendix B) gives the picture of the presence of global manufacturer groups that own several car brands. These brands within a group may directly compete with each other especially if they are very similar and belong to the same market segment. For example, Opel and Saab are both present in the standard market segment. Or Rover and Volvo compete in the standard market segment, Ford and Rover both have car models in the compact market segment.

Table B10 (Appendix B) gives the picture of the cross-ownership in the automobile industry $^{21}$. Cross-ownership arrangements between manufacturers and suppliers (i.e., vertical interfirm linkages) are not considered in this paper. As for the overlap of the market shares, for example, Ford and Mazda are present together in the three market segments: subcompact, compact and intermediate, Mazda has, however, much lower market segment shares than Ford. As for GM (Subaru, Suzuki, Isuzu) and Fiat constellation, Suzuki has very small market shares, Opel's shares are higher than Fiat's in the UK, Germany and Belgium, while Fiat's shares are higher in Italy and somewhat more comparable in France.

The multimarket contact effects in this paper are discussed at the level of automotive manufacturers, which may own several brands. The possible cross-ownerships are not taken into account. It could be worthwhile to find out about the interbrand competition within an automotive manufacturer group (e.g., VW Group). It is interesting to analyze whether groups (no brands) develop products to compete with rival firms, or they suffer more from "cannibalization". The analysis could be more of relevance for only volume brands, or only premium brands. This could be a subject of future research.

\section{Structural oligopoly model for the European car market}

In this section of the paper an empirical oligopoly model for the European car market is presented. This is a model with multiproduct firms that sell differentiated products in geographically segmented markets.

\subsection{Demand side}

The demand equation is derived from a two-level nested logit where the price coefficient is interacted with income, and, thus, enters the demand equation in a non-linear way ${ }^{22}$.

The general utility function can be written down in the following way:

\footnotetext{
21 Partial ownership arrangements as it has been mentioned have been in particular discussed by Davis and Alley (2004) and Alley (1997). It has been found that even small partial ownership arrangements may lead to collusive behaviour.

22 In the exposition below, I follow Berry (1994), Verboven (1996) and Brenkers and Verboven (2006a), after McFadden (1978) and Ben-Akiva and Lehrman (1985). The demand-side derivation on the basis of restricted two-level nested logit (i.e., without consumer heterogeneity) can be also found in Leheyda (2007b). The interaction of consumers' individual characteristics with products' characteristics is generally expected to allow getting more reasonable substitution patterns.
} 
$U_{i j}=V_{i j}+\varepsilon_{i j}$

$V_{i j}$ is the deterministic part of the utility function and can be expressed by $V_{i j}=\delta_{j}+\alpha \ln \left(y_{i}-p_{j}\right)$. The error term $\varepsilon_{i j}$ follows the assumptions of a two-level nested logit distribution. The common part to all consumers in the utility function is $\delta_{j}=x_{j} \beta+\xi_{j}$. The individual-specific part is $-\alpha_{i} p_{j}+\varepsilon_{i j}$, where $\alpha_{i}=1 / y_{i} \cdot \alpha_{i}$ is the consumers' distaste for price increases. It is assumed that the distribution of $\alpha_{i}$ varies with income. Price sensitivity is modelled as inversely proportional to income. Income effects are one of the most important sources of consumer heterogeneity in the automobile markets.

It is assumed that there are $G+1$ exhaustive and mutually exclusive groups, $g=0, \ldots, G$, where 0 is an outside good. In each group there are further subgroups $H_{g}, h=1, \ldots, H_{g}$. Utility $u_{i j}$ of household $i$ for product $j$ in subgroup $h$ of group $g$ is given by:

$u_{i j}=x_{j} \beta-\alpha_{i} p_{j}+\xi_{j}+\varepsilon_{i g}+\left(1-\sigma_{g}\right) \varepsilon_{i h g}+\left(1-\sigma_{h g}\right) \varepsilon_{i j}, j \in h_{g} \subset g, \forall i, \forall j$

where $\varepsilon_{i j}=\varepsilon_{i g}+\left(1-\sigma_{g}\right) \varepsilon_{i n g}+\left(1-\sigma_{h g}\right) \varepsilon_{i j}$ and $\alpha_{i}=1 / y_{i}$. Variation in consumer tastes enters through $\alpha_{i}$ and $\varepsilon_{i j}$.

The error term $\varepsilon_{i j}$ is decomposed into an iid shock, a group-specific component and a subgroup specific component. $\varepsilon_{i g}, \varepsilon_{i h}, \varepsilon_{i j}$ are standard for the nested logit distributions, $\varepsilon_{i g}$, $\varepsilon_{i g}+\left(1-\sigma_{g}\right) \varepsilon_{i h g}$ and $\varepsilon_{i g}+\left(1-\sigma_{g}\right) \varepsilon_{i h g}+\left(1-\sigma_{h g}\right) \varepsilon_{i j}$ are assumed to have an extreme value distribution. It is assumed that $\varepsilon_{i j}$ are uncorrelated across customers; for a particular customer, $\varepsilon$ 's, which belong to the same group, will be more correlated with each other than with the $\varepsilon$ 's that belong to any other group $\left(\varepsilon_{i g}{ }^{23}\right)$; and for a particular customer, $\varepsilon$ 's, which belong to the same subgroup, will be more correlated with each other than with the $\varepsilon$ 's that belong to any other subgroup $\left(\varepsilon_{i h g}\right)$. That is, the products of the same sub-group or group share common features, and consumers' preferences for these features may be correlated. Nesting parameters $\sigma_{h g}$ and $\sigma_{g}$ can be interpreted as random coefficients on discrete dummies for subgroups and groups rather than on variables that are continuously measured (e.g., performance or size). It should be noted that correlation parameters $\sigma_{h g}$ and $\sigma_{g}$ here are allowed to be different across groups and subgroups. In such a way additional consumer heterogeneity is introduced into the model.

$\sigma_{h g}$ measures the degree of substitutability of products in a subgroup, and $\sigma_{g}$ is the degree of substitutability of products in a group. The following $0 \leq \sigma_{g}<\sigma_{h g}<1$ should hold to be consistent with random utility maximization. That is, consumer preferences will be more correlated across all products of the same subgroup than across products of the same group but a different subgroup. Consequently, more plausible substitution patterns can be obtained, and localized competition among the products from the same group or subgroup can be allowed.

23 For consumer $i$, the variable $\varepsilon$ is common to all products in a group $g$ and has a distribution function that depends on $\sigma_{g}$. Similar interpretation is for a subgroup. 
The above mentioned assumptions upon the aggregation of choices across all consumers result in the well-known formulas of the nested logit model for the conditional choice probabilities. The mean utility for the outside good is normalized to zero, $\delta_{0}=0$.

The choice probability of a consumer $i$ for a car $j$ in a subgroup $h$, group $g$ can be written down as:

$$
S_{i j}(p)=\frac{e^{\left(\delta_{j}-\alpha_{i} p_{j}\right) /\left(1-\sigma_{h g}\right)}}{e^{I_{i h g} /\left(1-\sigma_{h g}\right)}} \frac{e^{I_{i h g} /\left(1-\sigma_{g}\right)}}{e^{I_{i g} /\left(1-\sigma_{g}\right)}} \frac{e^{I_{i h g}}}{e^{I_{i}}}
$$

where $I_{i h g}, I_{i g}$ and $I_{i}$ are called "inclusive values" for consumer $i$, which are defined in the following way:

$$
I_{\text {ihg }}=\left(1-\sigma_{h g}\right) \ln \sum_{j=1}^{J_{h g}} e^{\left(\delta_{l}-\alpha_{i} p_{j}\right) /\left(1-\sigma_{h g}\right)}, I_{i g}=\left(1-\sigma_{g}\right) \ln \sum_{h=1}^{H_{g}} e^{I_{i h g} /\left(1-\sigma_{g}\right)}, I_{i}=\ln \sum_{g=1}^{G} e^{I_{i g}}
$$

The individual probabilities over the number of individuals are averaged into the predicted aggregate market share for product $j$ below:

$$
s_{j}(p)=\sum_{i=1}^{N} s_{i j}(p) / N
$$

where $N$ is the number of individuals drawn from an empirical income distribution.

\subsection{Cost side and multimarket contact equilibrium interactions}

The firm $\mathrm{f}$ maximizes its profits over all markets in period $t \pi_{f t}$ :

$$
\pi_{f t}=\sum_{m=1}^{M} \sum_{j \in F_{f m t}}\left(e_{f m t} p_{j m t}^{w}-e_{f s t} c_{j m t}\right) L_{m t} s_{j m t}\left(p_{m t}\right)+\sum_{m=1}^{M} \sum_{j \notin F_{f m t}} \varphi_{j m t}\left(e_{f m t} p_{j m t}^{w}-e_{f s t} c_{j m t}\right) L_{m t} s_{j m t}\left(p_{m t}\right)
$$

where $M$ is the number of markets, $F_{f m t}$ is the set of products of firm $f$ in market $m$ in period $t, p_{j m t}^{w}$ are wholesale prices for product $j$ in market $m$ in period $t, p_{m t}$ are list prices (includes prices of products that are in market $\mathrm{m}$ in period $t$ ), $c_{j m t}$ is the constant marginal cost of producing product $j$ in market $m$ in period $t, e_{f m t}$ is an exchange rate between the registration country of firm $f$ and the destination market, $e_{f s t}$ is an exchange rate between the registration country of firm $f$ and the production location of model $j, L_{m t}$ is market size in market $m$ in period $t$, and $s_{j m t}$ is the share of product $j$ in market $m$ in period $t$.

$\varphi_{j m t}$ is the weight on competitors' products for product $j$ in market $m$ in period $t$ : a positive value means cooperative behaviour relative to Bertrand, while a negative value can be interpreted as aggressively competitive behaviour relative to the Bertrand behaviour. The value of zero implies just multi-product Bertrand pricing assumption. The value of one is the case of perfect collusion. But generally these parameters are allowed to take on any values in a broad range. If the product is sold in all five geographic markets, there will be five values of the market conduct parameter for this product.

Demand linkages across geographical markets are assumed away: the sales of each car model in market $m$ depend on the prices only in that market and not on the prices for that model in the other markets (prohibitive arbitrage costs to the consumers are assumed, this also follows from considerable artificial trade barriers). 
The relationship between consumer (list) $p_{j m t}$ and wholesale $p_{j m t}^{w}$ prices is modelled as exogenous and takes up the following functional form:

$p_{j m t}^{w}=\frac{p_{j m t}}{\left(1+t_{j m t}\right)\left(1+\tau_{j m t}\right)}$

where $t_{j m t}$ is a value added tax in market $m$, period $t$ for product $j$, and $\tau_{j m t}$ is a dealer markup in market $m$, period $t$ for product $j^{24}$.

The first-order conditions can be written down in the following way ${ }^{25}$ :

$$
\sum_{k \in F_{f m t}}\left(e_{f m t} p_{k m t}^{w}-e_{f s t} c_{k m t}\right) \frac{\partial s_{k m t}}{\partial p_{j m t}^{w}}+\sum_{j \notin F_{f m t}} \varphi_{j m t}\left(e_{f m t} p_{k m t}^{w}-e_{f s t} c_{k m t}\right) \frac{\partial s_{k m t}}{\partial p_{j m t}^{w}}+e_{f m t} s_{j m t}=0
$$

The $J_{m t}$ pricing equations can be further expressed in matrix form for all models that are sold in period $t$ in market $m$ as:

$$
p_{m t}=c_{m t}+\left[\Delta \cdot *\left(\Xi^{o w n}+\Theta^{\text {comp }}\right)\right]^{-1} S_{m t}
$$

where $\Xi^{\text {own }}, \Theta^{\text {comp }}$ are ownership matrices: $\Xi_{i, j}^{\text {own }}=1$, if $i$ and $j$ are produced by the same firm, and zero otherwise, and $\Theta_{i j}^{\text {comp }}=\varphi_{j}$ if the products $i$ and $j$ are produced by different firms. This value will be an average value for product $j$ with respect to the products of its competitors in market $m$ in period $t$. The vector $\varphi$ for $J$ products is obtained ${ }^{26}$. $\Xi^{\text {own }}, \Theta^{\text {comp }}$ are the matrices of the same dimension $J_{m t}$ (i.e., the number of products in market $m$ in period $t$ ). $\Delta$ is a matrix of own- and cross-price elasticities, also of dimension $J_{m t}$. Thus, I have got an element-by-element multiplication of two matrices of the same dimension.

The marginal cost for product $j$ in market $m$ in period $t$ takes up the following form:

$$
c_{j m t}=\exp \left(\omega_{j m t} \phi+w_{s}+w_{f}+w_{m}+w_{t}+w_{j m t}\right)
$$

where $\omega_{j m t}$ are the product characteristics other than price, $\varphi$ is the vector of parameters to be estimated, $w_{s}, w_{f}, w_{m}, w_{t}$ are the fixed effects for production locations, firms, markets and time, respectively, and $\omega_{j m t}$ is an iid error term.

In addition, to examine the roots for why a firm takes into account the behaviour of other firms while setting prices in a particular market, I allow $\varphi$ depending upon firm, geographic and product market characteristics $Z_{j m t}$ that may help explain the deviation in prices across the same products across different markets, including concentration and multimarket contact:

24 Some information on the dealer discounts in the European car market can be found in Verboven (1996). In particular, in 1990 the maximum dealer markups were $11 \%$ in Belgium, $8 \%$ in France, $10 \%$ in Germany, $10 \%$ in Italy, and $15 \%$ in the UK. Here I follow Goldberg and Verboven (2001) in the derivation of the first-order conditions and, subsequently, price expressions. The authors derive the first-order conditions accounting for absolute and relative import quotas. I do not take into account import quotas in my estimations, following Brenkers and Verboven (2006a) but allow having conjectural variations parameters in the pricing equation. For homogenous products in case of market power the following equation is written down: $M R=P+\lambda\left(\frac{1}{\alpha}\right) Q$, where $\alpha$ is the price sensitivity parameter, and $\lambda$ is the market conduct parameter. 
$\varphi_{j m t}=\lambda z_{j m t}+\eta_{s}+\eta_{f}+\eta_{m}+\eta_{t}+\eta_{j m t}$

where $\lambda$ is the vector of parameters to be estimated, $\eta_{j m t}$ is an iid disturbance term, and $\eta_{s}$, $\eta_{f}, \eta_{m}, \eta_{t}$ are the fixed effects for production locations, firms, markets, and time, respectively. The fixed effects are important to include into the model to control for systematic differences in the market conduct parameter.

Higher positive values of the conjectures imply more cooperative firm behaviour relative to multi-product Bertrand pricing behaviour. Larger negative values of the conjectures imply more competitive firm behaviour relative to multi-product Bertrand pricing behaviour. In the market conduct equation (11), one would expect a positive relationship between concentration and market conduct and a positive relationship between multimarket contact and market conduct (for the mutual forbearance hypothesis to hold). In addition to the multimarket contact and concentration variables, I include the interaction term between the two and attempt to measure the so-called strategic effects of the multimarket contact, e.g., the distribution of the market power from the more collusive to the more competitive markets. In this case this term should be negative. Concentration and the number of competitors in a geographic-product market are used to distinguish between more and less competitive/collusive markets in the European car market.

\subsection{Testing multimarket contact firms coalitions}

In addition to testing the direct impact of the multimarket contact measure on the market conduct parameter as above (where the so-called "conjectural variation" approach is applied), the collusive assumptions could be tested for multimarket contact coalitions in the supply-side specification (that is, the so-called "menu" approach is rather applied here). The best supplyside model specification can be then selected with the help of a statistical test (e.g., MacKinnon, White and Davidson (1983), Rivers and Vuong (2002)).

The idea behind this approach is that the multimarket contact firms will jointly maximize their profits. The first-order conditions for a multimarket contact firm that internalizes the cross-price effects with its competitors can be written down as follows (as compared to equation (8) above):

$\sum_{k \in F_{M M C_{m t}}, f \in F_{M M C_{m t}}}\left(e_{f m t} p_{k m t}^{w}-e_{f s t} c_{k m t}\right) \frac{\partial s_{k m t}}{\partial p_{j m t}^{w}}+e_{f m t} s_{j m t}=0$

where $M M C_{m t}$ is the coalition of firms in market $m$ in period $t, F_{M M C_{m t}}$ all products of multimarket contact firms, including firm $f$, in market $m$ in period $t$.

The $J_{m t}$ pricing equations can be further expressed as (as compared to equation (9) above):

$p_{m t}=c_{m t}+\left[\Delta \cdot *\left(\Xi^{M M C}\right)\right]^{-1} S_{m t}$

where $\Xi_{i, j}^{M M C}=1$ if $i$ and $j$ are produced by multimarket contact firms that behave collusively and 0 otherwise (the same is true for the own products of the firm). That is, as compared to the approach that I have just discussed in the section above, where I estimate conjectural variation parameters, I test for the assumption that the conjectural variation parameters are equal to 1, i.e., I test for the case of perfect collusion among multimarket contact firms in market $\mathrm{m}$ in period $\mathrm{t}$. 


\section{Data description and estimation procedure}

\subsection{Data description}

The dataset on the European car market is maintained by Penny Goldberg and Frank Verboven $^{27}$. The dataset includes the information on list prices, sales, and technical characteristics of cars during 1970-1999 for five European countries: Belgium, France, Germany, Italy, and the UK. The data are rather aggregate, at the level of a model (e.g., VW Polo). The average number of models per year is about 100 models. The technical characteristics include horsepower, displacement, weight, length, width, height, fuel consumption, acceleration time and maximum speed. In addition, there is some data on such macroeconomic variables as GDP, exchange rates, population, price indexes, and tax rates. Furthermore, there is information on the production location of each model, brand ownership, and market segment. The detailed description of the data sources can be found in particular in Goldberg and Verboven (2001). Some descriptive statistics for the car dataset (in general and across countries) can be found in Table D1 (Appendix D).

\subsection{Estimations steps}

\subsubsection{Demand side}

Demand, pricing and market conduct equations are estimated separately ${ }^{28}$. On the demand side, the two-way error components model is estimated to account for the panel nature of the data similar to Brenkers and Verboven (2006a). The structure of the error term is as follows: $\xi_{j m t}=\xi_{j}+\xi_{m t}+u_{j m t}$, where $\xi_{j}$ does not vary across time (e.g., style), $\xi_{m t}$ can account for macroeconomic fluctuations in market $m$ in period $t$ (captured by market/time fixed effects dummies), $u_{j m t}$ captures the remaining unobserved characteristics. The fixed effects model is estimated. A within-transformation of the data is used to control for the product-fixed effects.

The instruments that I have used in the demand estimation for prices and market shares are standard in the literature (for a more detailed discussion of the instruments see Leheyda (2007a)). Formally, $E\left[u_{j m t} \mid z\right]=0$. The instruments have been constructed at group and subgroup levels: these are the own characteristics of the firm and the sum of characteristics of own and competing products in the market segments and in the subgroups of domestic and foreign producers as well as the number of own and competing products in the market segments and the subgroups of domestic and foreign cars.

The market share for product $\mathrm{j}$ can be written down as:

$S_{j}=\int_{y} \frac{e^{\left(\delta_{j}-\alpha_{i} p_{j}\right) /\left(1-\sigma_{h g}\right)}}{e^{I_{i h g} /\left(1-\sigma_{h g}\right)}} \frac{e^{I_{i h g} /\left(1-\sigma_{g}\right)}}{e^{I_{i g} /\left(1-\sigma_{g}\right)}} \frac{e^{I_{\text {ihg }}}}{e^{I_{i}}} d \widehat{P}^{*}(y)$

where $d \widehat{P}^{*}(y)$ is the distribution of income. It is approximated by the empirical income distribution in each country. The market shares of different types of consumers are added based on how common that type is.

27 The dataset is available at the website of Prof. Frank Verboven.

28 I pursue this approach notwithstanding the possible loss in the efficiency, first of all because of computational tractability. Step-by-step estimation has been pursued in a number of papers. In particular, separate estimation approach for demand, pricing and excess margins equation has been pursued by Slade (2004), only the standard errors in the second step have to be adjusted. The estimation steps for the demand side are described in Nevo (2000). The Matlab algorithm for random coefficients demand model is available from Ariel Nevo's website. I am also very grateful to Prof. Frank Verboven for the opportunity to get acquainted with his Gauss code on the demand equation estimation. 
The above integral has no closed form, therefore, its computation requires aggregation via simulation. This procedure has been suggested by Pakes (1986). The market share is computed for an average consumer in each income class (10 deciles are distinguished), and then the average market share is calculated:

$S_{j}=\frac{1}{N S} \sum_{n s=1}^{N S} \frac{e^{\left(\delta_{j}-\alpha_{i} p_{j}\right) /\left(1-\sigma_{h g}\right)}}{e^{I_{i h g} /\left(1-\sigma_{h g}\right)}} \frac{e^{I_{i h g} /\left(1-\sigma_{g}\right)}}{e^{I_{i g} /\left(1-\sigma_{g}\right)}} \frac{e^{I_{i h g}}}{e^{I_{i}}}$

The following contraction mapping is used to recover the mean utility level $\delta_{j t}$ by minimizing the distance between the observed and predicted sales:

$\delta^{t+1}=\delta^{t}+\left(1-\max \left(\sigma_{1}, \ldots, \sigma_{G}\right)\right)\left(\ln (s)-\ln \left(s\left(\delta^{t}\right)\right)\right)$

The demand side unobservables are afterwards computed conditional on the linear parameters $\widehat{\beta}$ :

$\xi_{j t}=\delta_{j t}(\widehat{\alpha}, \widehat{\sigma})-x_{j} \hat{\beta}$

These unobservables are then interacted with a set of instruments to get a GMM estimator.

One searches for the parameter vector that minimizes the objective function

$\min \bar{\xi}^{\prime} Z \Phi^{-1} Z^{\prime} \bar{\xi}$

where $\Phi$ is a weighting matrix. $\Phi^{-1}=Z^{\prime} Z$ is used as a starting point.

This search is a non-linear search. The linear parameters $\hat{\beta}$ can be expressed as a function of the non-linear parameters $\hat{\alpha}$ and $\hat{\sigma}$

$\widehat{\beta}=\left(X^{\prime} Z \Phi^{-1} Z^{\prime} X\right)^{-1} X^{\prime} Z \Phi^{-1} Z^{\prime} \delta(\widehat{\alpha}, \widehat{\sigma})$

where $\hat{\sigma}$ includes group and subgroup correlation parameters. The non-linear search can be, thus, limited to the non-linear parameters $\alpha$ and $\sigma$.

The quasi-Newton gradient-based algorithm is used as a search method ${ }^{29}$. The asymptotic variance-covariance matrix takes up the following form:

$A v \operatorname{Cov}=\operatorname{inv}\left(\left(Z^{\prime} X G\right)^{\prime} w\left(Z^{\prime} X G\right)\right)$

where $G$ is the gradient of the objective function with respect to price and group and subgroup correlation parameters, and $\mathrm{w}$ is some weighting matrix.

\subsubsection{Substitution patterns}

The two-level nested logit has the assumption that consumers tastes have an extreme value distribution but allows consumer tastes to be correlated (in a restrictive way) across product $\mathrm{j}$ (correlations between groups and subgroups are modelled in a simple way). This allows for more reasonable substitution patterns as compared to a simple logit. Consumer heterogeneity that enters through the price-income coefficient also allows getting more reasonable elasticities and markups as compared to the usual (restricted) two-level nested logit. The calculation of the own- and cross-price elasticities because of additional consumer heterogeneity becomes, however, more burdensome.

29 This method requires the calculation of a Hessian as well as gradients and Jacobians. The secant method (Broyden, Fletcher, Goldfarb, and Shanno) is used to update the Hessian instead of computing it at every iteration. The quasi-Newton methods are similar to Newton methods. They are both based upon the calculation of first and second derivatives. The only difference is that under the quasi-Newton methods the Hessian is not calculated but approximated (Gauss tutorial). 
The own price elasticity $E_{s_{j} / p_{j}}$ of the market share $s_{j}$ of product $j$ (taking into account heterogeneous price-income coefficient) is:

$$
E_{s_{j} / p_{j}}=\frac{\partial s_{j}}{\partial p_{j}} \frac{p_{j}}{s_{j}}=\frac{p_{j}}{s_{j}} \int_{y}-\alpha_{i} s_{i j}\left[\frac{1}{1-\sigma_{h g}}-\left(\frac{1}{1-\sigma_{h g}}-\frac{1}{1-\sigma_{g}}\right) s_{i j / h g}-\frac{\sigma_{g}}{1-\sigma_{g}} s_{i j / g}-s_{i j}\right] d \widehat{P}^{*}(y)
$$

where $s_{i j}, s_{i j / g}, s_{i j / h g}$ are estimated market shares and are defined as above, and where $\alpha_{i}=\frac{1}{y_{i}}$.

The cross-price elasticity $E_{s_{j} / p_{m}}$ of the market share of product $j$ with respect to the price of product $m p_{m}$, when $j$ and $m$ belong to the same subgroup, is given by:

$$
E_{s_{j} / p_{m}}=\frac{\partial s_{j}}{\partial p_{m}} \frac{p_{m}}{s_{j}}=\frac{p_{m}}{s_{j}} \int_{y} \alpha_{i} s_{i j}\left[\left(\frac{1}{1-\sigma_{h g}}-\frac{1}{1-\sigma_{g}}\right) s_{i j / h g}+\frac{\sigma_{g}}{1-\sigma_{g}} s_{i m / g}-s_{i m}\right] d \widehat{P}^{*}(y)
$$

The cross-price elasticity $E_{s_{j} / p_{k}}$ of the market share of product $j$ with respect to the price of product $k p_{k}$, when $k$ belongs to a different subgroup in the same group, is given by:

$$
E_{s_{j} / p_{k}}=\frac{\partial s_{j}}{\partial p_{k}} \frac{p_{k}}{s_{j}}=\frac{p_{k}}{s_{j}} \int_{y} \alpha_{i} s_{i j}\left[\frac{\sigma_{g}}{1-\sigma_{g}} s_{i k / g}-s_{i k}\right] d \widehat{P}^{*}(y)
$$

The cross-price elasticity $E_{s_{j} / p_{l}}$ of the market share of product $j$ with respect to the price of product $l p_{l}$, when 1 belongs to a different group, is given by:

$$
E_{s_{j} / p_{l}}=\frac{\partial s_{j}}{\partial p_{l}} \frac{p_{l}}{s_{j}}=\frac{p_{l}}{s_{j}} \int_{y} \alpha_{i} s_{i l} s_{i j} d \hat{P}^{*}(y)
$$

Each individual has a different price sensitivity, which is averaged to a mean price sensitivity using the individual probabilities of purchase as weights. The integrals have to be calculated by simulation using the knowledge of the distribution of different types of consumers.

\subsubsection{Estimation of conduct parameters}

Conduct parameters for a product could be more precisely calculated once the marginal costs were known. Then having the information on the market shares and elasticities, the conduct parameters could be estimated from the first-order conditions. The pricing equation (9) is difficult to estimate at individual level for heterogenous products in practice. Nevo (1998) show the problem of identification of the conjectural variations parameters in the simplest case of two single-product firms. That is why, to calculate the market conduct, or conjectural variations parameters (which are difficult to identify otherwise at individual level for heterogenous products), I follow Brenkers and Verboven (2006a) approach and construct them after having estimated the demand side assuming that the marginal costs of producing a product $j$ in a given country (subgroup $h g$ group $g$ ) are the same as those in a reference country, which is taken to be Belgium (subgroup $h g$ group $g$ ):

$$
\left(p-\Omega^{-1} s\right)_{\text {Belgium }}=\left(p-\Omega^{-1} s\right)_{\text {Germany }}
$$


$\Omega$ may be written down as $\Delta \varphi$, which is an element-by-element multiplication of two matrices of two dimensions.

Replacing zeros for competing products in subgroup $h g$ group $g$ of product $j$ I define matrix $(\Delta \varphi)_{f}$ as:

$$
(\Delta \varphi)_{f}=\left(\begin{array}{ccc}
\phi \frac{\partial s\left(J_{1}^{f}\right)}{\partial p\left(J_{1}^{f}\right)} & \ldots & \phi \frac{\partial s\left(J_{k(f)}^{f}\right)}{\partial p\left(J_{1}^{f}\right)} \\
\vdots & \ddots & \vdots \\
\phi \frac{\partial s\left(J_{1}^{f}\right)}{\partial p\left(J_{k(f)}^{f}\right)} & \cdots & \phi \frac{\partial s\left(J_{k(f)}^{f}\right)}{\partial p\left(J_{k(f)}^{f}\right)}
\end{array}\right)
$$

where $\phi_{i j}=1$ if the products $i$ and $j$ are produced by the same firm, and $\phi_{i j}=\varphi_{j}$ if the products are produced by different firms in subgroup $h g$ group $g$ in market $m$ in period $t$, and $J_{k(f)}$ is the number of products in subgroup $h g$ of group $g$.

The implied $\varphi$ for Belgium will be, thus, set to zero by default. Marginal costs could be different across countries, or market conduct could be different across countries. Because of these considerations it is important to perform sensitivity analysis with estimating only the hedonic pricing equation with multimarket contact and concentration measures in addition to the market conduct equation with multimarket contact and concentration measures.

\subsubsection{Supply side}

For the pricing/market conduct equations estimations, the data are pooled for all countries, and the equation is estimated using OLS, including fixed effects, and with robust standard errors to account for possible autocorrelation and heteroscedasticity (Huber-White sandwich estimator of the variance). In case of market conduct equations, the standard errors have to be adjusted as the dependent variable is estimated from the above step. Consumer list prices are recalculated into wholesale prices taking into account the information on VAT across countries as well as information on dealer markups ${ }^{30}$. In case of pricing equations the product characteristics enter the supply equation in the logarithmic form.

\section{Estimation results}

\subsection{Demand side}

The results from the demand-side estimations can be found in Table 1. The price is expressed in destination currency, including VAT and dealer markup. Horsepower, width and height have got positive and statistically significant signs. Thus, consumers have preferences for large and powerful cars. Fuel efficiency has got an expected negative and statistically significant sign, i.e., consumers will buy rather fuel-efficient vehicles. Dummy for a foreign car producer is negative and statistically significant. Therefore, consumers may have higher preferences towards domestic car brands. 
Table 1: European car market: demand estimation results (two-level nested logit) Nests: market segment, producer origin

\begin{tabular}{lll}
\hline \hline $\begin{array}{l}\text { Dependent variable: } \\
\text { In(sj)-In(s0) }\end{array}$ & $\begin{array}{l}\text { Estimation method: } \\
\text { No. observations: 11549 }\end{array}$ \\
Sample period: 1970-1999 & \multicolumn{2}{l}{} \\
\hline & coefficient & t-statistics \\
horsepower & 0.01 & 3.82 \\
fuel efficiency & -0.03 & -3.13 \\
width & 0.03 & 6.90 \\
height & 0.01 & 2.95 \\
foreign car & -0.72 & -13.10 \\
price-income & 3.00 & 5.97 \\
Sub-group correlation parameter $\left(\sigma_{h g}\right)$ & \\
subcompact & 0.88 & 24.08 \\
compact & 0.74 & 18.73 \\
intermediate & 0.64 & 15.40 \\
standard & 0.82 & 18.75 \\
luxury & 0.30 & 3.37 \\
Group correlation parameter & $\left(\sigma_{g}\right)$ & \\
subcompact & 0.34 & 6.95 \\
compact & 0.67 & 13.17 \\
intermediate & 0.51 & 10.69 \\
standard & 0.74 & 14.35 \\
luxury & 0.04 & 0.36 \\
\hline \hline
\end{tabular}

Source: own estimations

Note: market/time fixed effects are included but are not reported.

The signs of the group and subgroup correlation parameters are in general consistent with a priori expectations. They are higher in the smaller car market segments, where the car customers are expected to be more homogenous (their preferences will be more correlated). The only exception is the standard market segment group correlation coefficient, which is difficult to interpret.

The group correlation parameters are lower than the subgroup correlation parameters, and both groups of parameters are between 0 and 1, which is consistent with random consumer utility maximization. The only problem is a low and statistically insignificant sign of the luxury segment group coefficient. The statistical significance and expected signs of the group and subgroup correlation parameters support the importance of the two principles of differentiation in the car market, namely market segment and producer origin.

The price-income coefficient, which captures the country-dependent effects of car prices on demand and allows for a more flexible demand model, is statistically significant and has got an expected negative sign.

The average own-price elasticities of demand and the estimates of price-cost margins under single-product and multi-product (firm) Bertrand-Nash pricing assumptions can be found in Table 2. Their pattern is in general consistent with a priori expectations, with the exception of probably the standard market segment, but this result may have been already anticipated from the group and subgroup correlation parameters estimates for this market segment. I find the lowest price elasticities in the luxury car market segment and the highest in the subcompact market segment. The difference between the price-cost margins under single-product and multi-product pricing assumptions is rather small since due to model aggregation many firms 
have got just one brand in a market segment and the cross-price elasticities with respect to the own products in the other market segments are usually found to be low.

Table 2: European car market: own-price elasticities and price-cost margins (averages for market segments)

\begin{tabular}{llll}
\hline \hline & Own-price elasticity & Price-cost margins & \\
\hline & & single-product & multi-product \\
subcompact & -4.73 & 0.07 & 0.10 \\
compact & -2.70 & 0.11 & 0.12 \\
intermediate & -1.83 & 0.13 & 0.14 \\
standard & -2.64 & 0.05 & 0.05 \\
luxury & -1.19 & 0.14 & 0.14 \\
\hline \hline
\end{tabular}

Source: own estimations

I have found the lowest own-price elasticities for the cars in Germany, followed by Belgium and France, and the highest elasticities in Italy and the UK. This pattern of the elasticities can be linked to different per capita income levels: the lower own-price elasticity of demand is expected with the higher per capita income (high-income consumers are less priceresponsible). The lowest nominal GDP per capita in common currency is observed in Italy and the UK, while Germany has got the highest per capita incomes. Goldberg and Verboven (2001) find the lowest own-price elasticities for Italy, followed by Germany, France, Belgium, and the highest own-price elasticities in the UK. Their demand model is, however, different from the demand model estimation in this paper. Irandoust (1996) finds lower price elasticities in Japan, Germany and France than in the UK, Italy, Sweden and the US. Bourdet (1988) also finds higher own-price elasticities for the cars in Italy and the UK than in France. Elasticities may be also driven by consumer brand loyalty (as compared to income-driven elasticities), which one would have expected for example for Italy, where domestic brand loyalty for Fiat is perceived to be high, but this pattern (namely low own-price elasticities) has not been found in the obtained results.

\subsection{Supply side and testing for mutual forbearance hypothesis}

In this section I present the empirical results of testing for the mutual forbearance hypothesis in the European car market. The below presented several hypotheses have been formulated on the basis of the research objectives of this study (I have done this for the better presentation of the results in this Section):

Hypothesis H1: General overlap of the markets leads to more cooperative firm behaviour.

Hypothesis H2: For the mutual forbearance to hold, it may be not just enough to be present in several markets. It could be important for firms to have significant shares in those markets (impact of share-weighted multimarket contact measure). The effect of the multimarket contact on the firm behaviour is stronger in the more concentrated market.

Hypothesis H3: Concentration contributes to higher prices.

Hypothesis H4: I test directly for the impact of the "spheres of influence" on the firm behaviour considering the multimarket contact firms coalitions. The respect of the "spheres of influence" leads to more cooperative behaviour.

Hypothesis H5: The strategic effects of the multimarket contact could be observed, i.e., the redistribution of the market power from the more collusive to the more competitive markets. The result is that the effect of multimarket contact on prices could be weaker in the more concentrated markets. 


\subsubsection{Market conduct equation estimations}

The following market conduct equations are estimated: base, with both multimarket contact and concentration (number of competitors) measures, and with an interaction term between multimarket contact and concentration (number of competitors) variables. The number of markets in which a firm is present and the number of multiple contacts for a firm with its competitors have got a statistically insignificant effect on the market conduct parameter (see Table 3). The impact of the concentration on the market conduct is, however, negative and statistically significant. The lower concentration ratios are, the larger the number of firms that are present in the market is, the more competitively the firms are expected to behave relative to the Bertrand assumption. The constructed conjectures are found to be the lowest for France, Germany and Italy, and do not differ much in magnitude. France is the most concentrated market based on $\mathrm{C} 1$ concentration ratio, and Italy is the most concentrated market on the basis of $\mathrm{C} 4$ and $\mathrm{C} 7$ concentration ratios. Given this descriptive statistics, the found relationship between market conduct and concentration may be not that surprising ${ }^{31}$.

Table 3: European car market: market conduct estimations (1)

\begin{tabular}{lllllll}
\hline Variable & Sp1 & Sp2 & Sp3 & Sp4 & Sp5 & Sp6 \\
\hline MMC1 & -0.001 & -0.001 & -0.001 & & & \\
MMC2 & & & & 0.0004 & 0.0003 & 0.0003 \\
C1 & $-0.007^{* * *}$ & & $-0.007^{* * *}$ & & \\
C4 & & $-0.02^{* * * *}$ & & & $-0.02^{* * *}$ & \\
C8 & & & $-0.04 * * *$ & & & $-0.04^{* * *}$ \\
\hline R2 & 0.49 & 0.49 & 0.49 & 0.49 & 0.49 & 0.49 \\
\hline \hline
\end{tabular}

Source: own estimations

Note: Fixed effects (firm dummies, market segment dummies, market/time fixed effects) are included but are not reported. ***, **, * mean statistical significance at $1 \%, 5 \%$, and $10 \%$ significance level, respectively. Explanations: MMC1 (number of markets in which a firm is present), MMC2 (number of multiple contacts).

The simple count multimarket contact measure has got a statistically significant negative effect when C-1 concentration ratio is included (see Table 4) and the share-weighted multimarket contact measure has got a statistically significant positive effect in all specifications. The values are, however, very low in magnitudes. The higher the simple count measure in the contacts markets is, the lower is the market conduct parameter in the home market. This result is somewhat difficult to interpret as related to the mutual forbearance hypothesis. It should be noted also that there has been evolving theoretical literature that multimarket contact may actually raise the intensity of competition (e.g., Thomas and Willig, 2006). The higher the share-weighted measure due to high market shares in the contact markets is, the higher is the market conduct parameter in the market under consideration, the more collusively the firms behave. The concentration variables are statistically significant and negative as they have been also found above.

31 Waldfogel and Wulf (2006) have found a negative effect of C-4 concentration ratio on prices in the radio broadcasting industry. 
Table 4: European car market: market conduct estimations (2)

\begin{tabular}{lllllll}
\hline \hline Variable & Sp7 & Sp8 & Sp9 & Sp10 & Sp11 & Sp12 \\
\hline MMC3 & $-0.02 * * *$ & 0.003 & 0.007 & & & \\
MMC4 & & & & $0.0001 * * *$ & $0.0001 * * *$ & $0.0001 * * *$ \\
C1 & $-0.007 * * *$ & & $-0.008^{* * *}$ & & \\
C4 & & $-0.02 * * *$ & & & $-0.03 * * *$ & \\
C8 & & & $-0.04 * * *$ & & & $-0.05^{* * *}$ \\
\hline R2 & 0.49 & 0.49 & 0.49 & 0.49 & 0.49 & 0.49 \\
\hline \hline
\end{tabular}

Source: own estimations

Note: Fixed effects (firm dummies, market segment dummies, market/time fixed effects) are included but are not reported. $* * *, * *, *$ mean statistical significance at 1\%, 5\%, and 10\% significance level, respectively. Explanations: MMC3 (simple count multimarket contact measure), MMC4 (share-weighted multimarket contact measure).

I have also estimated specifications for the supply side, where instead of the concentration variables I include the number of competitors in the market (see Table 5). The number of competitors is positive and statistically significant in almost all specifications. The larger the number of competitors is in the market, the larger reactions of them are expected to the actions of the other firms. The sign and significance of the multimarket contact measures is similar as in case of including concentration measures.

Table 5: European car market: market conduct estimations (3)

\begin{tabular}{llllll}
\hline Variable & Sp13 & Sp14 & Sp15 & Sp16 & Sp17 \\
\hline MMC1 & & -0.001 & & & \\
MMC2 & & & 0.0003 & & \\
MMC3 & & & & $-0.02^{* *}$ & \\
MMC4 & & & & $0.0001^{* * *}$ \\
No. Comp & $0.02^{* * *}$ & $0.02^{* * *}$ & $0.02^{* * *}$ & 0.01 & $0.05^{* * *}$ \\
\hline R2 & 0.49 & 0.49 & 0.49 & 0.49 & 0.49 \\
\hline \hline
\end{tabular}

Source: own estimations

Note: Fixed effects (firm dummies, market segment dummies, market/time fixed effects) are included but are not reported. $* * *, * *, *$ mean statistical significance at $1 \%, 5 \%$, and $10 \%$ significance level, respectively. Explanations: MMC1 (number of markets in which a firm is present), MMC2 (number of multiple contacts), MMC3 (simple count multimarket contact measure), MMC4 (share-weighted multimarket contact measure). 'No.Comp' stands for the number of competitors.

When the interaction term between multimarket contact and concentration is added (see Table 6), the negative sign of the interaction term is obtained, also statistically significant, which may speak in favour of the presence of the multimarket contact strategic effects. High multimarket contact combined with high market concentration leads to the lower market reactions of the firms. 
Table 6: European car market: market conduct estimations (4)

\begin{tabular}{lllllll}
\hline Variable & Sp18 & Sp19 & Sp20 & Sp21 & Sp22 & Sp23 \\
\hline MMC1 & $0.03^{* * *}$ & $0.06^{* * *}$ & $0.30^{* * *}$ & & & \\
MMC2 & & & & $0.004^{* * *}$ & $0.008^{* * *}$ & $0.02 * * *$ \\
C1 & $0.007^{* * *}$ & & & $0.009^{* * *}$ & & \\
C4 & & $-0.01^{* * *}$ & & $-0.008^{* *}$ & \\
C8 & & & & & 0.001 \\
MMCc1 & $-0.08^{* * *}$ & & & $-0.009^{* * *}$ & & \\
MMCc4 & & $-0.07^{* * *}$ & & & $-0.01 * * *$ & \\
MMCc8 & & & $-0.31^{* * *}$ & & & $-0.02^{* * *}$ \\
\hline R2 & 0.49 & 0.49 & 0.49 & 0.49 & 0.49 & 0.49 \\
\hline \hline
\end{tabular}

Source: own estimations

Note: Fixed effects (firm dummies, market segment dummies, market/time fixed effects) are included but are not reported. $* * *, * *$, mean statistical significance at $1 \%, 5 \%$, and $10 \%$ significance level, respectively. Explanations: MMC1 (number of markets in which a firm is present), MMC2 (number of multiple contacts).

When the interaction term is added in the regressions with simple and share-weighted multimarket contact measures, the sign of the interaction term is sensitive towards specifications and can be either positive or negative (see Table 7). If it is negative, this may be interpreted as the presence of the strategic effects due to the multimarket contact. If it is positive one could argue that the effect of the multimarket contact on the firm behaviour is stronger in the more concentrated market.

Table 7: European car market: market conduct estimations (5)

\begin{tabular}{lllllll}
\hline \hline Variable & Sp24 & Sp25 & Sp26 & Sp27 & Sp28 & Sp29 \\
\hline MMC3 & 0.01 & $-0.10^{* *}$ & $-1.28^{* * *}$ & & & \\
MMC4 & & & & $-0.0004^{* * *}$ & $-0.0004^{*}$ & $0.01 * * *$ \\
C1 & -0.0001 & & $-0.02^{* * *}$ & & \\
C4 & & $-0.04^{* * *}$ & & $-0.03 * * *$ & \\
C8 & & & $-0.20^{* * *}$ & & & $0.03 *$ \\
MMCc1 & $-0.06^{* * *}$ & & & $0.0007^{* * *}$ & & \\
MMCc4 & & $0.11^{* *}$ & & & $0.0005^{* *}$ & \\
MMCc8 & & & $1.30 * * *$ & & & $-0.01^{* * * *}$ \\
\hline R2 & 0.49 & 0.49 & 0.49 & 0.49 & 0.49 & 0.49 \\
\hline \hline
\end{tabular}

Source: own estimations

Note: Fixed effects (firm dummies, market segment dummies, market/time fixed effects) are included but are not reported. ***,**,* mean statistical significance at $1 \%, 5 \%$, and $10 \%$ significance level, respectively. Explanations: MMC3 (simple count multimarket contact measure), MMC4 (share-weighted multimarket contact measure).

I have also estimated the market conduct specification with the interaction term between the number of competitors in a market and multimarket contact measures in that market (see Table 8). The interaction term is only positive and statistically significant in case of the multimarket contact measures at the firm level. This may be interpreted as the evidence for the presence of the strategic effects due to multimarket contact. 
Table 8: European car market: market conduct estimations (6)

\begin{tabular}{lllll}
\hline \hline Variable & Sp30 & Sp31 & Sp32 & Sp33 \\
\hline MMC1 & $-0.03^{* * *}$ & & & \\
MMC2 & & $-0.002^{* * *}$ & & \\
MMC3 & & -0.02 & $0.0001^{* * *}$ \\
MMC4 & & & 0.01 & $0.05^{* * *}$ \\
No. Comp & $-0.02^{*}$ & $-0.03^{* *}$ & -0.0001 & 0.000 \\
MMCnoComp & $0.002^{* * *}$ & $0.0003^{* * *}$ & 0.49 & 0.49 \\
\hline R2 & 0.49 & 0.49 & 0.49 \\
\hline \hline
\end{tabular}

Source: own estimations

Note: Fixed effects (firm dummies, market segment dummies, market/time fixed effects) are included but are not reported. $* * *, * *, *$ mean statistical significance at $1 \%, 5 \%$, and $10 \%$ significance level, respectively. Explanations: MMC1 (number of markets in which a firm is present), MMC2 (number of multiple contacts), MMC3 (simple count multimarket contact measure), MMC4 (share-weighted multimarket contact measure). 'No. Comp' stands for the number of competitors.

To sum up, it is rather difficult to interpret the whole picture about the multimarket contact effects in the European automobile markets on the basis of the market conduct equation estimations. Multimarket contact has been found positive and statistically significant only in case of share-weighted multimarket contact measure. Negative impact of simple count measure has been found. The impact of concentration on the market conduct parameters is negative and statistically significant. The number of competitors is positively and statistically significantly related to the conjectural variation parameters. Some evidence has been found about the existence of the strategic effects of the multimarket contact: higher multimarket contact and concentration in the market contribute to the larger deviations from noncooperative pricing assumption, but alone both result in lower market reactions (after the interaction term is added). A firm with higher multiple multiple market presence will set lower prices in the more concentrated markets.

The above discussion (corresponding to the research objectives and the respective hypotheses) has been summarized in Table 9.

Table 9: European car market: summary of the evidence on mutual forbearance hypothesis (market conduct equation)

\begin{tabular}{|c|c|c|}
\hline & & Supported/Not supported/Inconclusive \\
\hline H1 & general overlap & $\begin{array}{l}\text { not supported: } \\
\text { negative impact of simple count measure, } \\
\text { insignificant firm-level measures }\end{array}$ \\
\hline $\mathrm{H} 2$ & concentration matters & $\begin{array}{l}\text { supported: } \\
\text { positive impact of share-weighted measure }\end{array}$ \\
\hline $\mathrm{H} 3$ & concentration & not supported \\
\hline $\mathrm{H} 4$ & "spheres of influence" & supported (indirectly) \\
\hline $\mathrm{H} 5$ & strategic effects & supported \\
\hline
\end{tabular}

Source: on the basis of own estimations

\subsubsection{Pricing equation estimations}

In addition to the estimation of the market conduct equation, I study the effect of the multimarket contact and concentration directly on prices. This is done within the hedonic pricing model. The general reduced form for the pricing equation can be written down as $p_{i}=c_{i}+k_{i} p_{i}$, where $k_{i}$ is a percentage markup. The following hedonic regression can be estimated for the European car market, where the price is expressed as a linear function of the cost and market power parameters: 
$\ln \left(p_{i m t}\right)=x_{i m t} \gamma+z_{i m t} \beta+\alpha_{s}+\alpha_{f}+\alpha_{m}+\alpha_{t}+\alpha_{i m t}$

where $x_{i}$ are the product characteristics other than price, $z_{i}$ are the parameters that measure the extent the prices diverge away from marginal costs, e.g., concentration, multimarket contact, etc., $\gamma$ and $\beta$ are the vectors of parameters to be estimated, $\alpha_{s}, \alpha_{f}, \alpha_{m}, \alpha_{i}$ are the fixed effects for production locations, firms, markets, and time, respectively, and $\alpha_{i m t}$ is an iid error term.

I expect the coefficient on the concentration variable in the pricing equation to be positive (the higher the market concentration is, the higher the prices can be charged). If the multimarket contact hypothesis is correct, I expect the positive coefficient on the multimarket contact variables. The coefficient on the interaction term between multimarket contact and concentration can be either positive or negative. If it is positive that could be interpreted that profits are higher in the markets where high firm concentration and high multimarket contact coincide. If the negative effect is found that may be attributed to the presence of the strategic effects due to the multimarket contact, i.e., the redistribution of the market power from the more collusive to the more competitive markets.

Prices, concentration and multimarket contact (also market conduct) may be rather endogenously determined. Thus, concentration and multimarket contact variables need to be instrumented in the pricing/market conduct equations. Some endogeneity may be captured by introducing market fixed effects. This is the strategy that I pursue in this paper (it has been rather difficult to find appropriate instruments).

Similar to the market conduct equation, several specifications for the pricing side have been estimated: base, with both multimarket contact and concentration (number of competitors) measures, and with an interaction term between concentration (number of competitors) and multimarket contact measures.

As for the first two variables to measure multimarket contact (i.e., the number of markets in which a firm is present, and the number of multiple contacts for a firm), they have been found to be positive and statistically significant (see Table 10), although their impact is quite low in magnitude. Thus, the higher multiple presence of a firm as well as the higher number of pairwise contacts may lead to higher prices.

As for the concentration ratios, only $\mathrm{C} 4$ has been found to be statistically significant, and higher in magnitude than the multimarket contact measure coefficient ${ }^{32}$. That is, concentration may facilitate higher prices and profits in the automobile markets.

Fixed effects allow estimating whether there are significant price differences across markets after adjusting for car model specification differences. Market-time fixed effects are the highest in Germany and the UK. Fixed effects for the market segments are the lowest in the subcompact and standard market segments.

32 This may be also the most adequate and suitable concentration measure for the automobile market. 
Table 10: European car market: supply-side estimations (pricing equation (1))

\begin{tabular}{llllllll}
\hline \hline Variable & Sp1 & Sp2 & Sp3 & Sp4 & Sp5 & Sp6 & Sp7 \\
\hline horse & $0.50^{* * *}$ & $0.50^{* * *}$ & $0.50^{* * *}$ & $0.50^{* * *}$ & $0.50^{* * *}$ & $0.50^{* * *}$ & $0.50^{* * *}$ \\
weight & $0.42^{* * *}$ & $0.42^{* * *}$ & $0.42^{* * *}$ & $0.42^{* * *}$ & $0.42^{* * *}$ & $0.42^{* * *}$ & $0.42^{* * *}$ \\
width & -0.06 & -0.06 & -0.05 & -0.06 & -0.06 & -0.05 & -0.06 \\
height & -0.02 & -0.04 & -0.04 & -0.02 & -0.02 & -0.02 & -0.02 \\
const & $3.34^{* * *}$ & $3.40^{* * *}$ & $3.24 * * *$ & $3.32^{* * *}$ & $3.41^{* * *}$ & $3.26^{* * *}$ & $3.33^{* * *}$ \\
mmc1 & & $0.002^{* * *}$ & $0.002^{* * *}$ & $0.002^{* * *}$ & & & \\
mmc2 & & & & & $0.0002^{* * *}$ & $0.0002^{* * *}$ & $0.0002^{* * *}$ \\
c1 & & -0.004 & & & -0.005 & & \\
c4 & & & $0.09^{* * *}$ & & & $0.09 * * *$ & \\
c8 & & & & 0.05 & & & 0.05 \\
\hline R2 & 0.97 & 0.97 & 0.97 & 0.97 & 0.97 & 0.97 & 0.97 \\
\hline \hline
\end{tabular}

Source: own estimations

Note: Fixed effects (firm dummies, market segment dummies, market/time fixed effects) are included but are not reported. Prices and car characteristics are expressed in logarithms. $* * *, * * *$ mean statistical significance at $1 \%, 5 \%$, and $10 \%$ significance level, respectively. Explanations: MMC1 (number of markets in which a firm is present), MMC2 (number of multiple contacts).

The simple multimarket contact measure has been found to be positive and statistically significant (see Table 11). The sign and statistical significance of the share-weighted multimarket contact measure is not so straightforward. The quantitative impact of the multimarket contact measures on prices is quite low.

The share-weighted multimarket contact measure, which is constructed at the geographicproduct market level, could be interpreted in the following way: the slack in the other markets (market power in the non-home markets as measured by concentration) due to multimarket contact enhances collusion in a market under consideration. This measure captures the tradeoff between the benefit of the aggressive action in the focal market and the cost of retaliation in the other contact markets. This measure was found to be negative and not statistically significant in case of $\mathrm{C} 1$ and $\mathrm{C} 8$ ratios. It is positive and statistically significant in case of $\mathrm{C} 4$ ratio, but very low in magnitude. So when I account for concentration in the contact markets, the multimarket contact seems not to have any significant economic effect on prices.

Table 11: European car market: supply-side estimations (pricing equation (2))

\begin{tabular}{lllllll}
\hline Variable & Sp8 & Sp9 & Sp10 & Sp11 & Sp12 & Sp13 \\
\hline horse & $0.50^{* * *}$ & $0.50^{* * *}$ & $0.50^{* * *}$ & $0.50^{* * *}$ & $0.50^{* * *}$ & $0.50^{* * *}$ \\
weight & $0.42^{* * *}$ & $0.42^{* * *}$ & $0.42^{* * *}$ & $0.42^{* * *}$ & $0.42^{* * *}$ & $0.42^{* * *}$ \\
width & -0.05 & -0.04 & -0.05 & -0.06 & -0.05 & -0.05 \\
height & -0.02 & -0.02 & -0.02 & -0.02 & -0.02 & -0.02 \\
const & $3.25 * * *$ & $3.16^{* * *}$ & $3.30^{* * *}$ & $3.34 * * *$ & $3.18^{* * *}$ & $3.24 * * *$ \\
mmc3 & $0.004 * * *$ & $0.003^{* * *}$ & $0.004 * * *$ & & & \\
mmc4 & & & & -0.000 & $0.000^{* *}$ & $-0.0002^{*}$ \\
c1 & -0.01 & & & -0.001 & & \\
c4 & & $0.06^{* * *}$ & & & $0.09 * * *$ & \\
c8 & & & -0.04 & & & $0.06 *$ \\
\hline R2 & 0.97 & 0.97 & 0.97 & 0.97 & 0.97 & 0.97 \\
\hline \hline
\end{tabular}

Source: own estimations

Note: Fixed effects (firm dummies, market segment dummies, market/time fixed effects) are included but are not reported. Prices and car characteristics are expressed in logarithms. $* * *, * * *$ mean statistical significance at $1 \%, 5 \%$, and $10 \%$ significance level, respectively. Explanations: MMC3 (simple count multimarket contact measure), MMC4 (share-weighted multimarket contact measure).

I have also included the number of competitors in a market as a measure of competition intensity (see Table 12). It has been found negative and statistically significant. This could 
also shed light whether the entry of foreign producers, although small ones, has increased competition in the automobile markets. An increase in the number of competitors is correlated with a decrease in the price of products. The number of competitors might be a more suitable measure of market segment competition intensity (internal factor) as compared to the concentration measure.

Table 12: European car market: supply-side estimations (pricing equation (3))

\begin{tabular}{llllll}
\hline \hline Variable & Sp14 & Sp15 & Sp16 & Sp17 & Sp18 \\
\hline horse & $0.50^{* * *}$ & $0.50^{* * *}$ & $0.50^{* * *}$ & $0.50^{* * *}$ & $0.50 * * *$ \\
weight & $0.42^{* * *}$ & $0.42^{* * *}$ & $0.42^{* * *}$ & $0.42^{* * *}$ & $0.42^{* * *}$ \\
width & -0.04 & -0.05 & -0.05 & -0.04 & -0.04 \\
height & -0.02 & -0.03 & -0.03 & -0.02 & -0.01 \\
const & $3.26 * * *$ & $3.31^{* * *}$ & $3.32^{* * *}$ & $3.23 * * *$ & $3.19 * * *$ \\
mmc1 & & $0.002^{* * *}$ & & & \\
mmc2 & & $0.0002^{* * *}$ & & \\
mmc3 & & & $0.002 * * *$ & \\
mmc4 & & & & $-0.00001 * * *$ \\
No. comp & $-0.005^{* * *}$ & $-0.004 * * *$ & $-0.004 * * *$ & $-0.003 * * *$ & $-0.007 * * *$ \\
\hline R2 & 0.97 & 0.97 & 0.97 & 0.97 & 0.97 \\
\hline \hline
\end{tabular}

Source: own estimations

Note: Fixed effects (firm dummies, market segment dummies, market/time fixed effects) are included but are not reported. Prices and car characteristics are expressed in logarithms. ${ }^{* *}, * *, *$ mean statistical significance at $1 \%, 5 \%$, and $10 \%$ significance level, respectively. Explanations: MMC1 (number of markets in which a firm is present), MMC2 (number of multiple contacts), MMC3 (simple count multimarket contact measure), MMC4 (share-weighted multimarket contact measure). 'No. comp' stands for the number of firms in a geographic-product market.

When the interaction term between concentration and multimarket contact is added to study the strategic effects of the multimarket contact (see Table 13), the sign of the interaction term is statistically significant and positive when $\mathrm{C} 1$ and $\mathrm{C} 4$ concentration measures are included ${ }^{33}$. This may be interpreted as that the multimarket contact measured at the firm level combined with higher concentration in a given market contributes to higher prices in the market under consideration. That is, multimarket contact leads to more collusion in the more concentrated markets.

Table 13: European car market: supply-side estimations (pricing equation (4))

\begin{tabular}{lllllll}
\hline \hline Variable & Sp19 & Sp20 & Sp21 & Sp22 & Sp23 & Sp24 \\
\hline MMC1 & 0.00 & $-0.005^{* * *}$ & $0.009^{* *}$ & & & \\
MMC2 & & & & -0.00 & $-0.001^{* * *}$ & 0.0005 \\
C1 & $-0.07^{* * *}$ & & $-0.11^{* * *}$ & & \\
C4 & & -0.05 & & $-0.14^{* * *}$ & \\
C8 & & & $0.18^{* *}$ & & 0.10 \\
MMCc1 & $0.004^{* * *}$ & & & $0.001^{* * *}$ & & \\
MMCc4 & & $0.008^{* * *}$ & & & $0.001^{* * *}$ & \\
MMCc8 & & & $-0.01^{*}$ & & & -0.0003 \\
\hline R2 & 0.97 & 0.97 & 0.97 & 0.97 & 0.97 & 0.97 \\
\hline \hline
\end{tabular}

Source: own estimations

Note: Fixed effects (firm dummies, market segment dummies, market/time fixed effects) are included but are not reported. Prices and car characteristics are expressed in logarithms. $* * *, * * *$ mean statistical significance at $1 \%, 5 \%$, and $10 \%$ significance level, respectively. Explanations: MMC1 (number of markets in which a firm is present), MMC2 (number of multiple contacts). Product characteristics are included but are not reported.

33 Jans and Rosenbaum (1996) have also found that multimarket contact and concentration have become statistically insignificant after the interaction term has been included. The interaction term itself was statistically significant and positive. 
The interaction term is statistically significant and negative for the simple count and shareweighted multimarket contact measures (See Table 14). Thus, I can argue that there is some evidence on existence of the strategic effects of the multimarket contact, i.e., the redistribution of the market power from the more collusive to the more competitive markets.

Table 14: European car market: supply-side estimations (pricing equation (5))

\begin{tabular}{lllllll}
\hline \hline Variable & Sp25 & Sp26 & Sp27 & Sp28 & Sp29 & Sp30 \\
\hline MMC3 & $0.06^{* * *}$ & -0.0001 & $0.04^{* * *}$ & & & \\
MMC4 & & & & $0.00005^{* * *}$ & $0.0001^{* * *}$ & $0.0005^{* * *}$ \\
C1 & 0.04 & & & $0.09^{* * *}$ & \\
C4 & & 0.02 & & $0.17^{* * *}$ & \\
C8 & & & $0.36^{* * *}$ & & \\
MMCc1 & $-0.005^{*}$ & & & $-0.00008^{* * *}$ & & $0.39 * * *$ \\
MMCc4 & & 0.004 & & $-0.0001^{* * *}$ & \\
MMCc8 & & & $-0.04^{* * *}$ & & & $-0.0005^{* * *}$ \\
\hline R2 & 0.97 & 0.97 & 0.97 & 0.97 & 0.97 & 0.97 \\
\hline \hline
\end{tabular}

Source: own estimations

Note: Fixed effects (firm dummies, market segment dummies, market/time fixed effects) are included but are not reported. Prices and car characteristics are expressed in logarithms. $* * *, * * *$ mean statistical significance at $1 \%, 5 \%$, and $10 \%$ significance level, respectively. Explanations: MMC3 (simple count multimarket contact measure), MMC4 (share-weighted multimarket contact measure). Product characteristics are included but are not reported.

I have also estimated the pricing equation with the interaction term between multimarket contact measures and the number of competitors in a market (see Table 15). It is negative and statistically significant, which may be interpreted that prices are lower in the markets characterized by higher multimarket contact and larger number of competitors (thus, higher competition intensity). This could be interpreted as some evidence in favour of the presence of the strategic effects due to multimarket contact.

Table 15: European car market: supply-side estimations (pricing equation (6))

\begin{tabular}{lllll}
\hline \hline Variable & Sp31 & Sp32 & Sp33 & Sp34 \\
\hline MMC1 & $0.006^{* * *}$ & & & \\
MMC2 & & $0.0008^{* * *}$ & & \\
MMC3 & & & $0.008^{* * *}$ & \\
MMC4 & & & $-0.000^{* * *}$ \\
No. Comp & $0.003^{* * *}$ & $0.006^{* * *}$ & $0.005^{* * *}$ & $-0.008^{* * *}$ \\
MMCnoComp & $-0.0004^{* * *}$ & $-0.00006^{* * *}$ & $-0.0008^{* * *}$ & $-0.000^{* * *}$ \\
\hline R2 & 0.97 & 0.97 & 0.97 & 0.97 \\
\hline
\end{tabular}

Source: own estimations

Note: Fixed effects (firm dummies, market segment dummies, market/time fixed effects) are included but are not reported. Prices and car characteristics are expressed in logarithms. $* * *, * * *$ mean statistical significance at $1 \%, 5 \%$, and $10 \%$ significance level, respectively. Explanations: MMC1 (number of markets in which a firm is present), MMC2 (number of multiple contacts), MMC3 (simple count multimarket contact measure), MMC4 (share-weighted multimarket contact measure). 'No. Comp' stands for the number of competitors in a market. Product characteristics are included but are not reported.

To sum up, in general multimarket contact is positively related to prices (in most specifications) - a result, which is consistent with mutual forbearance reducing competition. Greater levels of mulimarket contact move prices above marginal costs. However, although the relationship is statistically significant, the multimarket contact effect has little economic influence on the prices of the car producers. Higher concentration leads to higher prices. Multimarket contact firms forbear from retaliating more in a concentrated market. Some evidence has been found about the existence of the strategic multimarket contact effects: higher multimarket contact and concentration contribute to lower prices. The summary of the found effects is given in Table 16. 
Table 16: European car market: summary of the evidence on the mutual forbearance hypothesis (pricing equation)

\begin{tabular}{lll}
\hline \hline & & $\begin{array}{l}\text { Supported/Not } \\
\text { supported/Inconclusive }\end{array}$ \\
\hline H1 & general overlap & Supported \\
H2 & conc. matters & Supported \\
H3 & concentration & Supported \\
H4 & "spheres of influence" & Supported (implicitly) \\
H5 & strategic effects & Supported \\
\hline \hline
\end{tabular}

Source: on the basis of own estimations

\subsubsection{Results from testing coalitions of multimarket firms}

The construction of the multimarket contact measures allows me to study the general effect of the multimarket contact presence, i.e., the extent of the market overlap in the industry, on facilitating collusive behaviour as well as the role of concentration. To some extent, the impact of the "spheres of influence" might have been captured through the construction of the share-weighted multimarket contact measure. To test explicitly for the effectiveness of the "territorial interests", or "spheres of influence" (i.e., Hypothesis H4) I have tried to point out the so-called multimarket contact firms coalitions. These coalitions have been pointed out on the basis of the constructed multimarket contact measures and on the basis of the discussed picture of multiple market presence in the European car market. The idea has been to test for collusive behaviour among these firms as it has been explained above (see Section 4.3).

The firms that are present in the largest number of markets and have got the largest number of multiple contacts over the considered period of time are VW, Fiat, GM, Ford and Peugeot. This coalition of firms could be treated as a multimarket contact firms coalition, and the collusive assumption among the firms in this coalition could be tested as a potential equilibrium outcome.

Not only the diversification aspect matters (to support collusion due to multimarket contact it is not enough to be present in several markets) but also the ability of the firms to use it in the creation of the transferrable slack should be taken into account. It is unlikely that the firms with a small market share will be able to generate the necessary slack (which is usually fostered by market concentration), which could be transferred to the other markets through the multimarket contact. On the basis of the above described picture of multiple market presence by the automobile companies, several potential multimarket coalitions can be pointed out. The firms that have more than 5\% market share in each geographic market are Ford, GM, Peugeot, Renault, and VW. The firms that have more than 5\% market share in each or at least four product markets are Fiat, Ford, GM, and VW, with 1\% market share these are Fiat, Ford, GM, Peugeot, Renault, and VW. Firms that are present in all geographic-product markets and have more than $1 \%$ share in each geographic-product market are Fiat, Ford, GM, and VW.

Small firms like Daihatsu are unlikely to be engaged into implicit collusive arrangements with large players like VW. Such arrangements are most likely to be among the "influential" rivals. These "influential" players are likely to respect each other's "territorial interests". That is why, in addition I have considered defining an "influential firm" for each geographicproduct market and for each year (i.e., a firm with the highest market share), and then testing collusive behaviour among such firms. This would allow me to test directly for the presence of the "spheres of influence" that could foster collusive behaviour. On the basis of such analysis, I have found that the same firms seem to dominate the markets during the observed period of time: Alfa Romeo (later belongs to Fiat), Fiat, VW, BMW, Mercedes, Peugeot, Renault, Ford, GM, and Rover (later belongs to BMW). 
Under this approach (testing multimarket contact firms coalitions) I do not consider the possibility that there could be different degrees of cooperative behaviour across the markets. Basically I try to differentiate between the two extreme cases: no collusion at all (as represented by single-product, or multi-product assumptions), or collusive behaviour between multimarket contact firms in all markets, which I attribute to multimarket contact presence.

The following candidates for the equilibrium firm interactions in the European car market have been considered: A1: single-product assumption, A2: multiproduct (brand) assumption, A3: multiproduct (firm) assumption, A4: collusive assumption for firms that have more than $5 \%$ market share in each geographic market: Ford, GM, Peugeot, Renault and VW and singleproduct assumption for all other firms, A5: collusive assumption for firms that have more than 5\% market share in each geographic market: Ford, GM, Peugeot, Renault and VW and multi-product (brand) assumption for all other firms, A6: collusive assumption for firms that have more than 5\% market share in each product market: Fiat, Ford, GM and VW and singleproduct assumption for all other firms, A7: collusive assumption for firms that have more than 5\% market share in each product market: Fiat, Ford, GM and VW and multi-product (brand) assumption for all other firms, A8: collusive assumption for firms that have more than $1 \%$ market share in each market: Fiat, Ford, GM, VW, Peugeot and Renault and singleproduct assumption for all other firms, A9: collusive assumption for firms that have more than 1\% market share in each market: Fiat, Ford, GM, VW, Peugeot and Renault and multiproduct (brand) assumption for all other firms, A10: collusive assumption for firms that have "spheres of influence": Alfa Romeo, Fiat, VW, BMW, Mercedes, Peugeot, Renault, GM, Ford and Rover and single-product assumption for all other firms, A11: collusive assumption for firms that have "spheres of influence": Alfa Romeo, Fiat, VW, BMW, Mercedes, Peugeot, Renault, GM, Ford and Rover and multi-product (brand) assumption for all other firms, A12: collusive assumption for firms that are present in the largest number of markets and have the highest number of multiple contacts: VW, Fiat, GM, Ford and Peugeot, and single-product assumption for all other firms, A13: collusive assumption for firms that are present in the largest number of markets and have the highest number of multiple contacts: VW, Fiat, GM, Ford and Peugeot, and multi-product (brand) assumption for all other firms.

On the basis of the multimarket contact firms coalitions that have been pointed out above I have tested for the best supply-side specification (i.e., the specification that best fits the data). I present and discuss the results from several testing procedures: information criteria, test for non-nested hypothesis (MacKinnon, White, and Davidson, 1983) and model selection test (Rivers and Vuong, 2002).

As it can be seen from Table 17, the single-product and multi-product (brand) BertrandNash assumptions have got the lowest information criteria and sum of squared residuals (there is only a slight difference in the markups under these two assumptions). There appears also little difference between multi-product (brand) and multiproduct (firm) assumptions, which could shed more light on the intrabrand competition within an automobile manufacturer group. No multimarket contact firms coalition can be supported on the basis of these criteria. 
Table 17: European car market: information criteria and sum of squared residuals (SSR) for different supply side specifications

\begin{tabular}{llll}
\hline \hline Specifications & AIC & BIC & SSR \\
\hline A1 & 9429.46 & 10054.58 & 1507.53 \\
A2 & 9426.52 & 10051.64 & 1507.15 \\
A3 & 9516.45 & 10141.57 & 1518.93 \\
A4 & 9798.20 & 10423.32 & 1556.44 \\
A5 & 9758.53 & 10383.65 & 1551.11 \\
A6 & 9990.87 & 10615.99 & 1582.63 \\
A7 & 9984.40 & 10609.52 & 1581.74 \\
A8 & 9803.40 & 10428.52 & 1557.15 \\
A9 & 9802.63 & 10427.75 & 1557.04 \\
A10 & 9717.68 & 10342.80 & 1545.63 \\
A11 & 9718.82 & 10343.94 & 1545.78 \\
A12 & 10029.1 & 10654.22 & 1587.88 \\
A13 & 10027.65 & 10652.77 & 1587.68 \\
\hline \hline
\end{tabular}

Source: own estimations Note: 'AIC' stands for Akaike information criterion, 'BIC' stands for Bayesian information criterion, and 'SSR' stands for the squared sum of residuals.

In addition I have conducted the test for non-nested hypotheses by MacKinnon, White and Davidson (1983) (see Tables 18a,b). The intuition behind this test is that if the price-cost margin from a given model has a statistically significant impact on the price-cost margin from another model, that means that the latter model should be rejected. This test is very easy to implement in practice. Within this approach, the two non-nested models are embedded into a more general artificial model. On the basis of the test results, it is, however, difficult to choose the 'best' supply-side specification. When the alternative assumptions are A4-A9, all the null hypothesis are rejected, i.e., these should be the preferred specifications (but they perform only slightly better as compared to the other specifications). Given that the difference between single- and multi-product (brand) assumptions is small, basically for the A4-A9 assumptions the plausibility of the three coalitions of multimarket contact firms should be investigated: 1) Ford, GM, Peugeot, Renault, and VW; 2) Ford, GM, VW, and Fiat, and 3) Ford, GM, Peugeot, Renault, VW, and Fiat. The open question is how to choose among these "best" supply-side specifications.

Table 18a: European car market: results of the test for the non-nested hypotheses (MacKinnon, White and Davidson, 1983)

\begin{tabular}{llllllll}
\hline \hline$H 0 / H 1$ & $A 1$ & $A 2$ & $A 3$ & $A 4$ & $A 5$ & $A 6$ & $A 7$ \\
\hline A1 & & 8.58 & 11.16 & 12.79 & 13.89 & 13.54 & 13.92 \\
A2 & -4.64 & & 8.60 & 12.90 & 12.02 & 11.62 & 12.10 \\
A3 & 1.73 & 1.47 & & 12.99 & 10.79 & 8.13 & 9.01 \\
A4 & -10.04 & -9.98 & -9.92 & & & -4.38 & -4.33 \\
A5 & -9.91 & -8.68 & -1.32 & 24.39 & & 3.88 & 4.21 \\
A6 & -1.25 & -2.10 & -6.86 & 9.19 & 7.94 & & 5.65 \\
A7 & -1.61 & -2.53 & -7.68 & 9.28 & 7.70 & -5.52 & \\
A8 & -4.57 & -5.24 & -7.49 & -8.44 & -2.09 & -5.94 & -5.61 \\
A9 & -4.75 & -5.45 & -7.76 & -8.44 & -2.38 & -6.23 & -5.93 \\
A10 & -10.05 & -10.65 & -12.29 & -10.22 & -9.77 & -11.28 & -11.12 \\
A11 & -10.04 & -10.65 & -12.28 & -10.22 & -9.76 & -11.27 & -11.12 \\
A12 & -2.90 & -3.81 & -7.82 & 5.22 & 4.90 & -5.58 & -4.81 \\
A13 & -3.16 & -4.13 & -8.30 & 5.27 & 4.65 & -6.23 & -5.59 \\
\hline \hline
\end{tabular}

Source: own estimations 
Table 18b: European car market: results of the test for the non-nested hypotheses (MacKinnon, White and Davidson, 1983) (continuation)

\begin{tabular}{lllllll}
\hline \hline H0/H1 & A8 & A9 & A10 & A11 & A12 & A13 \\
\hline A1 & 16.95 & 17.16 & 21.30 & 21.31 & 14.83 & 15.13 \\
A2 & 15.70 & 19.95 & 20.46 & 20.47 & 13.18 & 13.54 \\
A3 & 13.37 & 13.67 & 18.96 & 18.96 & 10.26 & 10.79 \\
A4 & 12.43 & 12.43 & 14.62 & 14.62 & 0.21 & 0.28 \\
A5 & 13.21 & 13.53 & 19.68 & 19.69 & 7.67 & 8.00 \\
A6 & 12.55 & 12.85 & 18.83 & 18.83 & 7.98 & 8.66 \\
A7 & 12.31 & 12.66 & 18.79 & 18.80 & 7.22 & 8.04 \\
A8 & & 4.57 & 15.49 & 15.49 & -4.76 & -4.33 \\
A9 & -4.48 & & 15.35 & 15.36 & -5.15 & -4.76 \\
A10 & -11.28 & -11.07 & & -0.35 & -10.87 & -10.70 \\
A11 & -11.27 & -11.07 & 0.41 & & -10.87 & -10.70 \\
A12 & 11.00 & 11.39 & 18.35 & 18.35 & & 5.29 \\
A13 & 10.64 & 11.11 & 18.28 & 18.29 & -5.18 & \\
\hline \hline
\end{tabular}

Source: own estimations

Note: t-statistics are given in the cells.

The results of Rivers and Vuong (2002) test could not shed more light on the above results. I have failed to select any supply-side specification on the basis of this test.

To sum up, on the basis of the statistical procedures that I have done it has been difficult to choose the model that best describes the firms' equilibrium interactions. That is why, I have to rely on the results from the estimation of market conduct and pricing equations estimations in the above sections to draw some conclusions about the effect of multimarket contact on the firm behaviour in the automobile markets.

\section{Conclusions}

The paper has been an attempt to analyze the conduct behaviour of the automotive firms in the European car market in a systematic way. I have extended the earlier models for the European car market in particular by augmenting the supply side through explicitly considering the factors that contribute to market conduct and pricing behaviour of the automotive firms. Most previous automotive industry studies have concentrated on explaining the international price differentials in the European car market. The focus of this paper has been to study the impact of the internal (concentration, number of competitors in a market) and external (multimarket contact) factors on the firm behaviour.

In addition, this study has been motivated by the presence of extensive multimarket contact in the automobile industry, which is generally argued to foster collusive behaviour and which has not received interest in the previous automotive studies. Industry consolidation has raised the level of the multimarket contact. The concentration ratios for the total European car market have stayed on average at the same level or declined during the considered period of time, while the multimarket contact has increased. The number of competitors has also grown, in particular due to the entrance of Japanese competitors.

Finally, the study has been motivated by the lack of conclusive empirical evidence (in general, not only for automobile markets) on the mutual forbearance hypothesis. It has been first formulated by Edwards (1955), i.e., the extended interdependence when firms meet each other in several markets may lead to tacitly collusive arrangements between the firms. The hypothesis has been formally described for the first time by Bernheim and Whinston (1990). The estimation of the conjectures equations helps me to see whether they can be really 
attributable to the multimarket contact, while some studies just estimated conjectures and attributed them to the mutual forbearance presence (e.g., Gelfand and Spiller, 1987).

It has been found that the general overlap of the markets may lead to more cooperative firm behaviour. For the mutual forbearance to hold, it may be, however, not just enough to be present in several markets. It could be important for firms to have "spheres of influence" in those markets. The effect of the multimarket on the firm behaviour is stronger in the more concentrated market. Concentration alone also contributes to higher prices. The strategic effects of the multimarket contact could be observed in the European car market, i.e., the redistribution of the market power from the more collusive to the more competitive markets. The result is that multimarket contact may lead to lower prices in the more concentrated markets. I have tested directly for the impact of the "spheres of influence" on the firm behaviour considering multimarket contact firms coalitions. However, it was difficult to choose the best supply-side model on the basis of the statistical procedures that I have applied. Thus, to sum up, the results of the study reveal some weak quantitative effect of multimarket contact on pricing/market conduct in the European car market as well as provide some evidence on designing strategic policies by the automotive firms and shifting their market power across the markets, in which they operate.

Because of weak economic impact of multimarket contact on competition, one may argue that multimarket contact notwithstanding its extensive presence in the automobile industry does not play a large role. The results of the study may, therefore, raise the question whether sector differences (e.g., industry structure, demand growth prospects) could account for the different effect of multimarket contact on competitive behaviour. In particular, the economic effects of the multimarket contact have been found to be much stronger for airlines, hotels, mobile telephone markets, etc. (e.g., Evans and Kessides (1994), Jans and Rosenbaum (1996), Parker and Roller (1997), Fernandez and Marin (1998)). In those industries a larger number of markets is observed. As compared to the other multimarket contact studies (that focus on local/regional geographical markets), I have focused on the combination of both geographic and product dimensions of markets to measure the degree of multimarket linkages for the automotive firms and study the impact of this degree on the firm behaviour. It should be noted that some studies report the economic significance of the effect similar to mine, especially when similar multimarket contact measures are constructed (e.g., Heggestad and Rhoades (1978), Waldfogel and Wulf (2006)). However, the studies by Evans and Kessides (1994) and Jans and Rosenbaum (1996) that use similar multimarket contact measures show much stronger economic effect of multimarket contact on prices. As compared to my study on the mutual forbearance hypothesis for the US car industry (Leheyda, 2007a), I was able to get more conclusive evidence on the multimarket contact effects in general. In addition, I could find some support for the presence of the strategic effects due to the multimarket contact, i.e., the redistribution of the market power from the more collusive to the more competitive markets.

Alternatively, one may argue that the construction of the multimarket contact measures as well as pointing out multimarket contact firms coalitions may be not suitable for studying the multimarket contact effect on the firm behaviour in the automobile industry and that some other approach could be thought of to investigate this issue more profoundly.

The "ideal" test to study multimarket contact effects on collusive behaviour would be to contrast the pricing behaviour in a single-product (e.g., two firms in one market M1) and a multiproduct context (e.g., these two firms move together to another market M1+M2) to test for incremental effects in the firm behaviour. In addition, one can take some period of time and compare the break-down of collusive prices in M1 world and M1+M2 world, and if this period of break-downs under the latter scenario is shorter, then this is a hard test for showing that the multimarket contact effect leads to more collusion. This situation could be difficult to 
find in terms of the necessary data in general and for the automobile market in particular. That is why, I have been made restricted to applying the suggested in this paper methods to try to identify the effects of the presence of the multimarket situations on the firm behaviour in the automotive industry. The "ideal" and the developed in this paper methodologies could be applied in the context of other industries and markets.

\section{References}

Alley, W. A. (1997), Partial Ownership Arrangements and Collusion in the Automobile Industry, Journal of Industrial Economics, 45(2), 191-205.

Areeda, P. and D. Turner (1979), Conglomerate Interdependence and Effects on Interindustry Competition as Grounds for Condemnation, University of Pennsylvania Law Review, Vol. CXXVII, 1082-1103.

AutomobilProduktion (2005), Internationale Verflechtungen der Automobilhersteller, Sonderausgabe, Dezember 2005.

Bernheim, D. B. and M. D. Whinston (1990), Multimarket Contact and Collusive Behaviour, RAND Journal of Economics, 21(1), 1-26.

Berry, S. (1992), Estimation of a Model of Entry in the Airline Industry, Econometrica, Vol. 60, 889-917.

Bourdet, Y. (1988), International Integration, Market Structure and Prices, London and New York: Routledge.

Brander, J. A. and A. Zhang (1990), Market Conduct in the Airline Industry: an Empirical Investigation, RAND Journal of Economics, 21(4), 567-583.

Brenkers, R. and F. Verboven (2006a), Liberalizing a Distribution System: the European Car Market, Journal of the European Economic Association, 4(1), 216-251.

Brenkers, R. and F. Verboven (2006b), Market Definition with Differentiated Products Lessons from the Car Market, in: Choi J. P. (Eds.), Recent Developments in Antitrust: Theory and Evidence, MIT Press.

Bresnahan, T. F. (1989), Empirical Studies of Industries with Market Power, in Schmalensee, R. and R. D. Willig (Eds.), Handbook of Industrial Organization, Volume II, Elsevier Science Publishers B.V.

Bresnahan, T. F. and P. C. Reiss (1990), Entry in Monopoly Markets, Review of Economic Studies, Vol. 57, 531-553.

Degryse, H. and F. Verboven (2000), Car Price Differentials in the European Union: an Economic Analysis, An investigation for the Competition Directorate General of the European Commission, Center for Economic Policy Research, London.

European Commission (2004), Commission Report Highlights Changing Competition from China, IP/04/1400, Brussels, November 25.

Evans, W. N. and I. N. Kessides (1994), Living by the "Golden Rule": Multimarket Contact in the U.S. Airline Industry, Quarterly Journal of Economics, 109(2), 341-366.

Gaulier, G. and S. Haller (2000), The Convergence of Automobile Prices in the European Union: An Empirical Analysis for the Period 1993-1999, Working Paper CEPII No 14, November.

Gelfand, M. D. and P. T. Spiller (1987), Entry Barriers and Multiproduct Oligopolies: Do they Forbear or Spoil?, International Journal of Industrial Organization, Vol. 5, 101-113. 
Gimeno, J. (1999), Reciprocal Threats in Multimarket Rivalry: Staking Out "Spheres of Influence" in the US Airline Industry, Strategic Management Journal, 20(2), 101-128.

Gimeno, J. and C. Y. Woo (1999), Multimarket Contact, Economies of Scope, and Firm Performance, Academy of Management Journal, 42(3), 239-259.

Ginsburgh, V. (1994), Price Discrimination in the European Car Market, Cahiers du CERO, 36, 153-181.

Goldberg, P. K. and F. Verboven (2001), The Evolution of Price Dispersion in the European Car Market, Review of Economic Studies, 68(4), 811-848.

Goldberg, P. K. and F. Verboven (2005), Market Integration and Convergence to the Law of One Price: Evidence from the European Car Market, Journal of International Economics, 65(1), pp. 49-73.

Jans, I. and D. I. Rosenbaum (1996), Multimarket Contact and Pricing: Evidence from the US Cement Industry, International Journal of Industrial Organization, 15, 391-412.

Jayachandran, S., J. Gimeno and P. R. Varadarajan (1999), The Theory of Multimarket Contact Competition: a Synthesis and Implications for Marketing Strategy, Journal of Marketing, 63, 49-66.

Jaumandreu, J. and J. Lorences (2002), Modelling Price Competition Across Many Markets (An Application to the Spanish Loans Market), European Economic Review, 46, 93-115.

Jaumandreu, J. and M. J. Moral (2001), The Demand for Cars: A Discrete Choice Model with Income Effects, Mimeo, September.

Jaumandreu, J. and M. J. Moral (2006), Identifying Behaviour in a Multiproduct Oligopoly: Incumbents Reaction to Tariffs Dismantling, Munich Personal RePEc Archive (MPRA) Paper No 1248.

Irandoust, M. (1996), An Empirical Analysis of Market Performance in the Car Industry, Open Economies Review, 7, 327-348.

Feinberg, R. M. (1985), "Sales-at-Risk": a Test of the Mutual Forbearance Theory of Conglomerate Behaviour, Journal of Business, 58(2), 225-241.

Fernandez, N. and P. L. Marin (1998), Market Power and Multimarket Contact: Some Evidence from the Spanish Hotel Industry, Journal of Industrial Organization, 46(3), 301315.

Heggestad, A. A. and S. A. Rhoades (1978), Multi-Market Interdependence and Local Market Competition in Banking, Review of Economics and Statistics, 60(4), 523-532.

Kaiser, U. and W. Sofka (2006), The Pulse of Liability of Foreignness: Dynamic Legitimacy and Experience Effects in the German Car Market, ZEW Discussion Paper No 06-070.

Kay, J. A. (1990), Identifying the Strategic Market, Business Strategy Review, Spring 1990.

Kirman, A. and N. Schueller (1990), Price Leadership and Discrimination in the European Car Market, Journal of Industrial Economics, 39(1), 69-91.

Leheyda, N. (2007a), Market Power, Multimarket Contact and Pricing: Some Evidence from the US Automobile Market, Mimeo, CDSE (University of Mannheim)/ZEW.

Leheyda, N. (2007b), Private Incentives to Innovate: Effects of New Products and BrandName Reputation, Mimeo, CDSE (University of Mannheim)/ZEW.

Lutz, M. (2000), EU Commission Versus Volkswagen: New Evidence on Price Differentiation in the European Car Market, Review of Industrial Organization, 17, 313-323. 
Lutz, M. (2004), Pricing in Segmented Markets, Arbitrage Barriers, and the Law of One Price: Evidence from the European Car Market, Review of International Economics, 12(3), 456-475.

MacKinnon, J. G., H. White and R. Davidson (1983), Tests for Model Specification in the Presence of Alternative Hypotheses: Some Further Results, Journal of Econometrics, 21, 5370 .

Mariuzzo, F. (2005), The Effect of Differences in Buyer and Non-Buyer Characteristics of Equilibrium Price Elasticities: an Empirical Study on the Italian Automobile Market, Trinity Economic Papers No. 2005/14, Trinity College of Dublin, Ireland.

Nevo, A. (1998), Identification of the Oligopoly Solution Concept in a DifferentiatedProducts Industry, Economics Letters, 59, 391-395.

Mazzeo, M. J. (2002), Product Choice and Oligopoly Market Structure, RAND Journal of Economics, 33, 221-242.

Mertens, Y. and V. Ginsburgh (1985), Product Differentiation and Price Discrimination in the European Community: The Case of Automobiles, Journal of Industrial Economics, Vol. 34, 151-165.

Neven, D. and L.-H. Röller (1999), An Aggregate Structural Model of Competition in the European Banking Industry, International Journal of Industrial Organization, 17, 1059-1074.

Nevo, A. (1998), Identification of the Oligopoly Solution Concept in a DifferentiatedProducts Industry, Economics Letters, 59, 391-395.

Ono, H., T. Nakazato and C. Davis (2004), Partial Ownership Arrangements in the Japanese Automobile Industry: 1990-2000, Journal of Applied Economics, VII(2), 355-367.

Pakes, A. (2003), Common Sense and Simplicity in Empirical Industrial Organization, Mimeo, Harvard University.

Pakes, A., M. Ostrovsky, and S. Berry (2003), Simple Estimators for the Parameters of Discrete Dynamic Models (with Entry/Exit Examples), Mimeo, Harvard University.

Pakes, A., J. Porter, and C. Wolfram (2003), Cost Functions from Profit Maximization Conditions: the Electric Utility Case, Mimeo, Harvard University.

Pazo, C. M., and J. Jaumandreu (1999), An Empirical Oligopoly Model of a Regulated Market, International Journal of Industrial Organization, 17, 25-57.

Reinaud, G. (2001), Hard Times for the Automobile Industry? Overcapacity and Downturn in the Markets, Mimeo.

Reiss, P. C., and F. A. Wolak (2004), Structural Econometric Modeling: Rationales and Examples of Industrial Organization, Mimeo, Stanford University. Prepared for the Handbook of Econometrics, Vol. 5.

Rhys, D. G. (1972), Economies of Scale in the Motor Industry, Bulletin of Economic Research, 24(2), 87.

Scott, J. T. (1982), Multimarket Contact and Economic Performance, Review of Economics and Statistics, 64(3), 368-375.

Seim, K. (2002), Geographic Differentiation and Firms' Entry Decisions: the Video Retail Industry, Mimeo, Stanford University, Graduate School of Business.

Slade, M. E. (2004), Market Power and Joint Dominance in the U.K. Brewing, Journal of Industrial Economics, LII(1), 133-163. 
Sudhir, K. (2001), Competitive Pricing Behaviour in the Auto Market: A Structural Analysis, Marketing Science, 20(1), 42-60.

Tolliday, S. (1988), Competition and the Workplace in the British Automobile Industry, 19451988, Business and Economic History, Second Series, Vol. 17.

Verboven, F. (1996), International Price Discrimination in the European Car Market, RAND Journal of Economics, 27(2), 240-268.

Verboven, F. (1998), Localized Competition, Multimarket Operation, and Collusive Behaviour, International Evonomic Review, 39(2), 371-398.

Waldfogel, J. and J. Wulf (2006), Measuring the Effect of Multimarket Contact on Competition: Evidence from Mergers Following Radio Broadcast Ownership Deregulation, Contributions to Economic Analysis and Policy, Vol. 5, No. 1, Article 17.

\section{Appendix A. Multimarket contact measures}

\subsection{Simple multimarket contact measure}

The simple count measure is constructed in the following way ${ }^{34}$. It is assumed that there are $k=1, \ldots, K$ geographic-product markets and $n=1, \ldots, N$ automotive manufacturers. In geographic-product market $k$ there are $N_{k}$ automotive firms. Let $D_{n k}$ be a dummy variable, which is equal to 1 if firm $n$ is present in market $k$ and zero otherwise. Matrix $A=\left(a_{i j}\right)$ should be constructed with $a_{i j}=\sum_{k=1}^{K} D_{i k} D_{j k}$. This is a symmetric matrix, where the diagonal elements $a_{i i}$ are the number of markets in which the firm $i$ is present, and the off-diagonal elements $a_{i j}$ are the number of markets in which both firms $i$ and $j$ are present:

$A=\left(\begin{array}{ccc}a_{11} & \cdots & a_{1 N} \\ \vdots & \ddots & \vdots \\ a_{N 1} & \cdots & a_{N N}\end{array}\right)$

I calculate the average multimarket contact per firm-pair in market $k$ in the following way:

$$
\text { AverMarketContact }_{k}=\sum_{i=1}^{N-1} \sum_{j=i+1}^{N} a_{i j} D_{i k} D_{j k} /\left(N_{k}\left(N_{k}-1\right) / 2\right)
$$

where $N_{k}$ is the number of firms in market under consideration $k . N_{k}\left(N_{k}-1\right)$ is the total number of possible pairs of firms in this market.

The example below (see Table 19) shows the construction of such a measure for a particular geographic-product market in a particular year (Italy, standard, 1999).

\footnotetext{
$34 \quad$ Simple count and market-share weighted measures have been constructed in particular by Evans and
} Kessides (1992) and Jans and Rosenbaum (1996). 
Table 19: European car market: example of construction of a multimarket-contact measure at the geographic-product market level

\begin{tabular}{|c|c|c|c|c|c|c|c|c|c|}
\hline & בBMW & Fiat & Ford & Honda & $\overline{G M}$ & Peugeot & $\overline{V W W}$ & Daewoo & Sum \\
\hline BMW & 19 & 19 & 19 & 13 & 19 & 13 & 19 & 17 & 119 \\
\hline Fiat & & 25 & 25 & 14 & 25 & 19 & 25 & 18 & 126 \\
\hline Ford & & & 25 & 14 & 25 & 19 & 25 & 18 & 101 \\
\hline Honda & & & & 14 & 14 & 13 & 14 & 12 & 53 \\
\hline GM & & & & & 25 & 19 & 25 & 18 & 62 \\
\hline Peugeot & & & & & & 19 & 19 & 18 & 37 \\
\hline VW & & & & & & & 25 & 18 & 18 \\
\hline Daewoo & & & & & & & & 18 & \\
\hline Sum & & & & & & & & & 516 \\
\hline MMC & & & & & & & & & 18.43 \\
\hline
\end{tabular}

Source: own estimations

The diagonal elements in the above Table are the number of geographic-product markets, in which a firm is present. The off-diagonal elements show the number of geographic-product markets in which both firms meet each other. The number of these contacts (off-diagonal elements) is aggregated for each firm and is given in the last column. The contacts are aggregated for all firms (516) and then they are divided by the number of possible firm pairs in this market $\left(N_{k}\left(N_{k}-1\right) / 2=28\right)$ to get the multimarket contact measure of 18.43 for Italy's standard market segment in 1999.

This measure is calculated for each geographic-product market and for each year (which is extremely time-consuming). If there is only one automotive firm in the market, the measure will be equal to zero.

The impact of this measure on the firm behaviour may be interpreted in the following way: facing a trade-off between the benefit of the aggressive action in the focal market (i.e., the market under consideration) and the cost of the rival retaliation in the other contact markets, the firms may tend to behave less aggressively.

\subsection{Share-weighted multimarket contact measure}

Relatively more important markets could be given some greater weight in the multimarket contact measure, which leads me to the construction of the next measure.

I construct a quadratic weighting multimarket contact measure in the following way. The revenue share of firm $i$ from market $k\left(R_{i k}\right)$ is multiplied by the revenue share of firm $j$ from the same market $k$, which is then used to weight the contribution of the pairwise contact of firms $i$ and $j$ in market $k$. The following matrix is then constructed: $R=\left(r_{i j}\right)$ with $r_{i j}=\sum_{k=1}^{K} R_{i k} R_{j k}$. This is a symmetric matrix.

I calculate the average revenue-weighted market contact in the following way:

AverMarket Re venueContact $_{k}=\sum_{i=1}^{N-1} \sum_{j=i+1}^{N} r_{i j} D_{i k} D_{j k} /\left(N_{k}\left(N_{k}-1\right) / 2\right)$

The construction of this measure is similar to the construction of the simple multimarket contact measure, except for the fact that the measure is weighted by the market shares of the firm. 
The interpretation of this measure is similar to the one of the simple multimarket contact measure above. If this measure value is small, the potential cost of retaliation is low as compared to the benefit of the aggressive behaviour in the focal/home market (i.e., the market under consideration). If it is high, the multimarket contact may exert large influence upon the focal market behaviour, and higher prices in that market should be observed. This measure captures that in the more concentrated markets the firms might have more to lose, thus, they may withhold from competitive behaviour. 


\section{Appendix B. European car market: general descriptive statistics (concentration, multiple market presence and ownership)}

Graph B1: European car market: development of concentration ratios (one-firm (C1), fourfirm (C4), seven-firm (C7)) over time at country market level

European car market: development of concentration over time

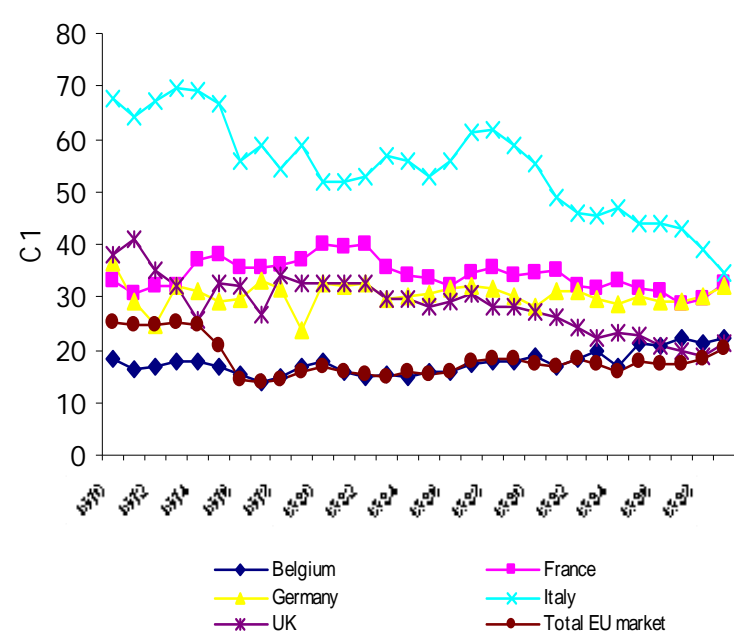

European car market: development of concentration over time

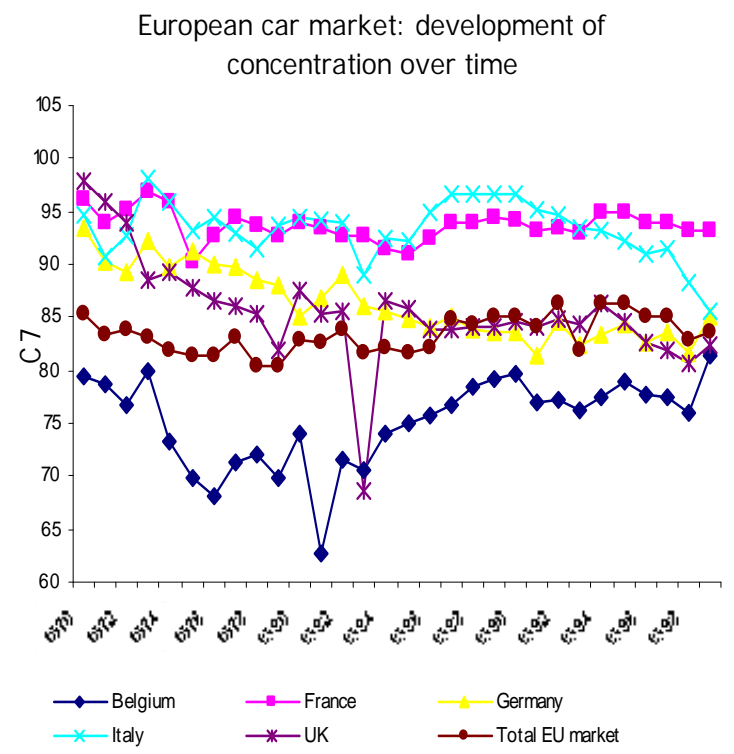

Source: European car market database, own calculations
European car market: development of concentration over time

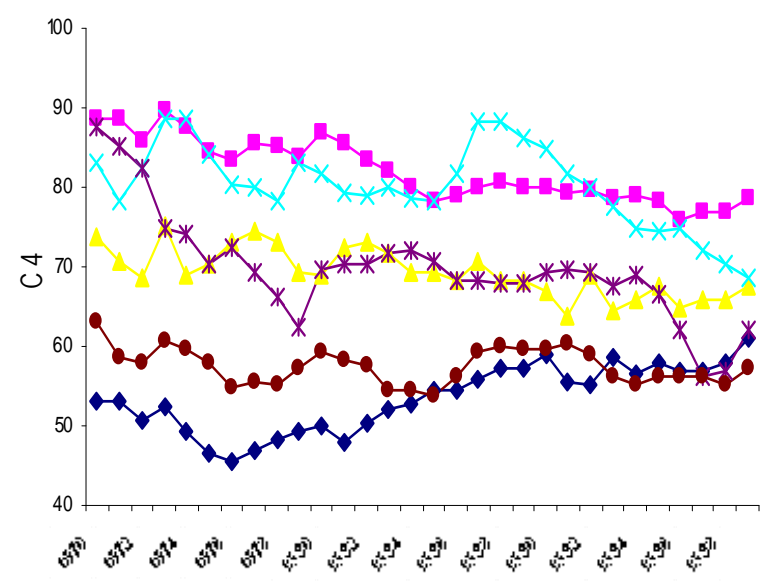

$\rightarrow$ Belgium $\rightarrow$-France $\longrightarrow$ Germary $\rightarrow$ * Italy $\rightarrow$ * UK $\rightarrow$-Total EU market

Source: European car matket datase, own calculations 
Table B2: European car market: purchase taxes on new vehicles, 1999

\begin{tabular}{|c|c|c|c|}
\hline Country & VAT (\%) & Purchase taxes & $\begin{array}{l}\text { Registration fees } \\
\text { (in local currency) }\end{array}$ \\
\hline Belgium & 21 & Based on capacity and age & $2500 \mathrm{FB}$ \\
\hline France & 20.6 & None & $\begin{array}{l}\text { Local tax } 102 \text { to } 195 \mathrm{FF} \\
\text { (+ parafiscal charges) }\end{array}$ \\
\hline Germany & 16 & None & $50 \mathrm{DM}$ \\
\hline Italy & 20 & $\begin{array}{l}\text { Provincial, based on fiscal } \\
\text { power }\end{array}$ & 300000 to $720000 \mathrm{~L}$ \\
\hline $\begin{array}{l}\text { United } \\
\text { Kingdom } \\
\end{array}$ & 17.5 & None & None \\
\hline
\end{tabular}

Source: Gaulier and Haller (2000) 
Table B3: European car market: shares in a firm's total European sales, 1970 as compared to 1999

\begin{tabular}{|c|c|c|c|c|c|c|c|c|c|c|c|c|}
\hline & Belgium & & France & & Germany & & Italy & & $U K$ & & 'Spheres & uence' \\
\hline & 1970 & 1999 & 1970 & 1999 & 1970 & 1999 & 1970 & 1999 & 1970 & 1999 & 1970 & 1999 \\
\hline Alfa Romeo & 2.32 & & 6.38 & & 10.50 & & 79.01 & & 1.78 & & Italy & \\
\hline BMW & 5.93 & 3.88 & 5.30 & 8.52 & 80.07 & 45.90 & 5.89 & 12.01 & 2.80 & 29.69 & Germany & Germany \\
\hline Daihatsu & & 1.70 & & & & 68.03 & & 5.35 & & 24.92 & & Germany \\
\hline Fiat & 3.43 & 2.15 & 20.76 & 10.68 & 11.57 & 10.54 & 62.57 & 68.98 & 1.66 & 7.65 & Italy & Italy \\
\hline Ford & 4.97 & 4.11 & 6.74 & 13.75 & 32.30 & 28.33 & 10.08 & 17.41 & 45.91 & 36.40 & UK & UK \\
\hline Honda & 18.22 & 4.19 & 45.07 & 7.69 & 36.71 & 29.64 & & 10.67 & & 47.81 & France & UK \\
\hline DeTomaso & & & & & & & 100.00 & & & & Italy & \\
\hline Hyundai & & 4.30 & & 5.87 & & 22.47 & & 37.81 & & 29.55 & & Italy \\
\hline $\mathrm{Kia}$ & & 8.07 & & 5.88 & & 66.83 & & 16.80 & & 8.30 & & Germany \\
\hline Mazda & & 7.02 & & & & 67.06 & & 4.10 & & 15.94 & & Germany \\
\hline Mercedes & 3.91 & 3.37 & 5.28 & 7.54 & 85.29 & 66.52 & 4.65 & 11.83 & 0.88 & 10.74 & Germany & Germany \\
\hline Mitsubishi & & 13.22 & & 3.25 & & 60.18 & & 4.11 & & 19.23 & & Germany \\
\hline Nissan & 100.00 & 4.79 & & 9.47 & & 27.21 & & 18.17 & & 40.37 & Belgium & UK \\
\hline GM & 4.83 & 4.34 & 4.93 & 10.78 & 63.59 & 42.88 & 8.34 & 15.93 & 18.31 & 26.07 & Germany & Germany \\
\hline Peugeot & 5.54 & 5.82 & 81.06 & 49.43 & 10.91 & 10.96 & 2.49 & 12.75 & & 21.04 & France & France \\
\hline Renault & 5.28 & 4.77 & 61.96 & 49.09 & 22.06 & 19.20 & 6.05 & 11.82 & 4.65 & 15.12 & France & France \\
\hline FujiHi & & 100.00 & & & & & & & & & & Belgium \\
\hline Rover & 2.72 & & 3.61 & & 2.46 & & 0.33 & & 90.89 & & UK & \\
\hline Saab & 56.73 & & & & 43.27 & & & & & & Belgium & \\
\hline Suzuki & & 8.97 & & 11.51 & & 39.89 & & 10.60 & & 29.03 & & Germany \\
\hline Toyota & 87.57 & 8.94 & & 11.80 & & 30.48 & & 20.05 & 12.43 & 28.73 & Belgium & Germany \\
\hline VW & 3.60 & 5.03 & 2.93 & 12.63 & 80.43 & 55.07 & 8.77 & 14.94 & 4.28 & 12.33 & Germany & Germany \\
\hline Volvo & 26.81 & & 13.29 & & 27.78 & & 3.89 & & 28.22 & & UK & \\
\hline DAF & 21.34 & & 21.11 & & 33.53 & & 11.72 & & 12.30 & & Germany & \\
\hline TalbotSimca & 5.71 & & 35.61 & & 15.94 & & 16.54 & & 26.21 & & France & \\
\hline TalbotMatra & 5.92 & & 94.08 & & & & & & & & France & \\
\hline Daewoo & & 4.13 & & 10.18 & & 9.52 & & 51.86 & & 24.31 & & Italy \\
\hline Daimler (Smart) & & & & 7.29 & & 67.95 & & 24.76 & & & & Germany \\
\hline Total market sales & 4.66 & 4.57 & 21.91 & 19.85 & 34.36 & 34.26 & 23.15 & 20.74 & 15.93 & 20.58 & Germany & Germany \\
\hline
\end{tabular}

Source: European car market database, own calculations

Note: 'Spheres of influence' ('market dependence') are defined as those geographical markets where a firm has the highest market share in a firm's total European sales. 
Table B4: European car market: shares of a firm in total market sales, 1970 as compared to 1999

\begin{tabular}{|c|c|c|c|c|c|c|c|c|c|c|c|c|c|c|}
\hline & \multicolumn{2}{|c|}{ Belgium } & \multicolumn{2}{|c|}{ France } & \multicolumn{2}{|c|}{ Germany } & \multicolumn{2}{|l|}{ Italy } & \multicolumn{2}{|l|}{$U K$} & \multicolumn{2}{|c|}{ Europe } & \multicolumn{2}{|c|}{ 'Spheres of influence' } \\
\hline & 1970 & 1999 & 1970 & 1999 & 1970 & 1999 & 1970 & 1999 & 1970 & 1999 & 1970 & 1999 & 1970 & 1999 \\
\hline Alfa Romeo & 0.77 & & 0.45 & & 0.47 & & 5.26 & & 0.17 & & 1.54 & & Italy & \\
\hline Daihatsu & & 0.07 & & & & 0.38 & & 0.05 & & 0.23 & & 0.47 & & Germany \\
\hline BMW & 2.46 & 4.86 & 0.47 & 2.45 & 4.49 & 7.67 & 0.49 & 3.31 & 0.34 & 8.25 & 1.93 & 5.72 & Germany & Germany \\
\hline Fiat & 18.45 & 4.91 & 23.70 & 5.62 & 8.43 & 3.21 & 67.63 & 34.71 & 2.61 & 3.88 & 25.02 & 10.44 & Italy & Italy \\
\hline Ford & 10.28 & 10.71 & 2.96 & 8.26 & 9.05 & 9.86 & 4.19 & 10.01 & 27.73 & 21.09 & 9.62 & 11.92 & UK & UK \\
\hline Honda & 0.21 & 1.07 & 0.11 & 0.45 & 0.06 & 1.01 & & 0.60 & & 2.72 & 0.05 & 1.17 & Belgium & UK \\
\hline Hyundai & & 0.83 & & 0.26 & & 0.58 & & 1.60 & & 1.26 & & 0.88 & & Italy \\
\hline DeTomaso & & & & & & & 3.76 & & & & 0.87 & & Italy & \\
\hline Kia & & 0.47 & & & & 0.52 & & 0.22 & & 0.11 & & 0.27 & & Germany \\
\hline Mazda & & 1.84 & & 0.36 & & 2.35 & & 0.24 & & 0.93 & & 1.20 & & Germany \\
\hline Mercedes & 2.55 & 3.85 & 0.73 & 1.98 & 7.56 & 10.14 & 0.61 & 2.98 & 0.17 & 2.73 & 3.04 & 5.22 & Germany & Germany \\
\hline Mitsubishi & & 1.64 & & 0.09 & & 0.99 & & 0.11 & & 0.53 & & 0.57 & & Belgium \\
\hline Nissan & 1.02 & 2.54 & & 1.16 & & 1.93 & & 2.12 & & 4.76 & 0.05 & 2.42 & Belgium & UK \\
\hline GM & 11.10 & 11.58 & 2.41 & 6.62 & 19.81 & 15.27 & 3.86 & 9.37 & 12.30 & 15.45 & 10.70 & 12.20 & Germany & UK \\
\hline Peugeot & 7.29 & 16.70 & 22.67 & 32.68 & 1.95 & 4.20 & 0.66 & 8.07 & & 13.42 & 6.13 & 13.13 & France & France \\
\hline Renault & 13.25 & 10.48 & 33.04 & 24.84 & 7.50 & 5.63 & 3.06 & 5.72 & 3.41 & 7.38 & 11.68 & 10.05 & France & France \\
\hline FujiHi & & 0.04 & & & & & & & & & & 0.00 & & Belgium \\
\hline Rover & 3.90 & & 1.10 & & 0.48 & & 0.09 & & 38.14 & & 6.69 & & UK & \\
\hline Saab & 0.21 & & & & 0.02 & & & & & & 0.02 & & Belgium & \\
\hline Suzuki & & 0.62 & & 0.18 & & 0.37 & & 0.16 & & 0.45 & & 0.32 & & Belgium \\
\hline Toyota & 3.59 & 4.54 & & 1.38 & & 2.07 & & 2.25 & 0.15 & 3.24 & 0.19 & 2.32 & Belgium & Belgium \\
\hline VW & 12.06 & 22.06 & 2.08 & 12.76 & 36.51 & 32.25 & 5.91 & 14.46 & 4.19 & 12.02 & 15.60 & 20.06 & Germany & Germany \\
\hline Volvo & 2.96 & & 0.31 & & 0.42 & & 0.09 & & 0.91 & & 0.51 & & Belgium & \\
\hline DAF & 2.87 & & 0.60 & & 0.61 & & 0.32 & & 0.48 & & 0.63 & & Belgium & \\
\hline TalbotSimca & 7.00 & & 9.28 & & 2.65 & & 4.08 & & 9.39 & & 5.71 & & France, UK & \\
\hline TalbotMatra & 0.02 & & 0.08 & & & & & & & & 0.02 & & France & \\
\hline Daewoo & & 1.18 & & 0.67 & & 0.36 & & 3.28 & & 1.55 & & & & Italy \\
\hline Daimler & & & & 0.23 & & 1.22 & & 0.74 & & & & 0.62 & & Germany \\
\hline Total market sales & 100.0 & & 100.0 & & 100.0 & & 100.0 & & 100.0 & & 100.0 & & & \\
\hline C-1 & 18.45 & 22.06 & 33.04 & 32.68 & 36.51 & 32.25 & 67.63 & 34.71 & 38.14 & 21.09 & 25.02 & 20.06 & & \\
\hline C-4 & 53.09 & 61.06 & 88.69 & 78.54 & 73.80 & 67.51 & 82.99 & 68.55 & 87.57 & 61.99 & 63.00 & 57.31 & & \\
\hline C-7 & 79.44 & 81.30 & 96.14 & 93.24 & 93.35 & 85.01 & 94.68 & 85.66 & 97.78 & 82.38 & 85.44 & 83.51 & & \\
\hline
\end{tabular}


Table B5: European car market: shares of a firm in market segment sales, 1970 as compared to 1999

\begin{tabular}{|c|c|c|c|c|c|c|c|c|c|c|c|c|c|c|}
\hline & \multicolumn{2}{|c|}{ Subcompact } & \multicolumn{2}{|c|}{ Compact } & \multicolumn{2}{|c|}{ Intermediate } & \multicolumn{2}{|c|}{ Standard } & \multicolumn{2}{|c|}{ Luxury } & \multicolumn{2}{|l|}{ Total } & \multicolumn{2}{|c|}{$\begin{array}{l}\text { 'Spheres of influence' } \\
\text { (market share dominance) }\end{array}$} \\
\hline & 1970 & 1999 & 1970 & 1999 & 1970 & 1999 & 1970 & 1999 & 1970 & 1999 & 1970 & 1999 & 1970 & 1999 \\
\hline Alfa Romeo & & & 3.89 & & 5.94 & & & & & & 1.54 & & Intermediate & \\
\hline BMW & & 0.14 & 1.89 & 4.92 & 4.26 & & 4.83 & 44.06 & 12.30 & 22.11 & 1.93 & 5.72 & Luxury & Standard \\
\hline Daihatsu & & 0.50 & & & & 0.03 & & & & & & 0.19 & & Subcompact \\
\hline Fiat & 39.14 & 18.46 & 7.51 & 4.89 & 24.97 & 3.80 & 12.44 & 12.90 & 0.99 & 6.61 & 25.02 & 10.44 & Subcompact & Subcompact \\
\hline Ford & & 11.32 & 16.40 & 15.05 & 32.70 & 13.06 & 19.64 & 5.05 & & 3.40 & 9.62 & 11.93 & Intermediate & Compact \\
\hline Honda & 0.11 & 0.28 & & 2.29 & & & & 5.63 & & & 0.05 & 1.17 & Subcompact & Standard \\
\hline Hyundai & & 1.03 & & 1.00 & & 0.94 & & & & & & 0.88 & & Subcompact \\
\hline DeTomaso & 1.77 & & & & & & & & & & 0.87 & & Subcompact & \\
\hline $\mathrm{Kia}$ & & 0.31 & & 0.09 & & 0.62 & & & & & & 0.27 & & Intermediate \\
\hline Mazda & & 0.55 & & 1.77 & & 2.32 & & & & & & 1.20 & & Intermediate \\
\hline Mercedes & & & & 5.66 & & & & & 82.06 & 62.79 & 3.04 & 5.22 & Luxury & Luxury \\
\hline Mitsubishi & & & & 0.56 & & 2.01 & & & & & & 0.57 & & Compact \\
\hline Nissan & 0.10 & 3.20 & & 1.70 & & 3.45 & & & & 0.37 & 0.05 & 2.43 & Subcompact & Intermediate \\
\hline GM & & 10.18 & 26.02 & 16.82 & 0.72 & 12.07 & 30.70 & 11.07 & 4.65 & 2.83 & 10.70 & 12.20 & Standard & Compact \\
\hline Peugeot & 4.82 & 17.28 & 6.66 & 7.06 & 7.52 & 22.23 & 11.03 & 1.21 & & & 6.13 & 13.13 & Standard & Intermediate \\
\hline Renault & 18.87 & 16.11 & 9.40 & 7.15 & & 8.04 & & 3.16 & & & 11.68 & 10.05 & Subcompact & Subcompact \\
\hline Rover & 9.48 & & 4.85 & & & & 6.31 & & & & 6.69 & & Subcompact & \\
\hline Saab & & & & & & & 0.14 & & & & 0.02 & & Standard & \\
\hline Suzuki & & 0.45 & & & & 0.58 & & & & & & 0.29 & & Intermediate \\
\hline Toyota & & 2.24 & 0.74 & 2.63 & & 3.40 & & 0.19 & & & 0.19 & 2.32 & Compact & Intermediate \\
\hline VW & 17.24 & 14.46 & 17.88 & 27.13 & 13.47 & 26.45 & 10.60 & 16.38 & & 1.89 & 15.60 & 20.07 & $\begin{array}{l}\text { Subcompact, } \\
\text { compact }\end{array}$ & $\begin{array}{l}\text { Compact, } \\
\text { intermediate }\end{array}$ \\
\hline Volvo & & & & & & & 4.16 & & & & 0.51 & & Standard & \\
\hline DAF & 1.27 & & & & & & & & & & 0.63 & & Subcompact & \\
\hline TalbotSimca & 7.20 & & 4.75 & & 10.42 & & & & & & 5.71 & & Intermediate & \\
\hline TalbotMatra & & & & & & & 0.16 & & & & 0.02 & & Standard & \\
\hline Daewoo & & 1.86 & & 1.27 & & 1.01 & & 0.35 & & & & 1.31 & & Subcompact \\
\hline Daimler & & 1.63 & & & & & & & & & & 0.62 & & Subcompact \\
\hline $\begin{array}{l}\text { Total } \\
\text { segment } \\
\text { sales }\end{array}$ & 100.0 & 100.0 & 100.0 & 100.0 & 100.0 & 100.0 & 100.0 & 100.0 & 100.0 & 100.0 & 100.0 & 100.0 & & \\
\hline
\end{tabular}

Source: European car market database, own calculations 
Table B6: European car market: shares of a firm in a firm's sales, 1970 as compared to 1999

\begin{tabular}{|c|c|c|c|c|c|c|c|c|c|c|c|c|}
\hline & \multicolumn{2}{|c|}{ Subcompact } & \multicolumn{2}{|c|}{ Compact } & \multicolumn{2}{|c|}{ Intermediate } & \multicolumn{2}{|c|}{ Standard } & \multicolumn{2}{|l|}{ Luxury } & \multicolumn{2}{|c|}{$\begin{array}{l}\text { 'Spheres of influence' } \\
\text { (market dependence) }\end{array}$} \\
\hline & 1970 & 1999 & 1970 & 1999 & 1970 & 1999 & 1970 & 1999 & 1970 & 1999 & 1970 & 1999 \\
\hline Alfa Romeo & & & 64.8 & & 35.2 & & & & & & Compact & \\
\hline BMW & & 0.95 & 25.1 & 25.93 & 20.2 & & 31.0 & 51.48 & 23.7 & 21.64 & Standard & Standard \\
\hline Daihatsu & & 97.21 & & & & 2.79 & & & & & & Subcompact \\
\hline Fiat & 76.89 & 66.89 & 7.69 & 14.12 & 9.13 & 7.18 & 6.15 & 8.26 & 0.15 & 3.55 & Subcompact & Subcompact \\
\hline Ford & & 35.89 & 43.69 & 38.07 & 31.06 & 21.60 & 25.24 & 2.83 & & 1.60 & Compact & Compact \\
\hline Honda & 100.00 & 9.07 & & 58.83 & & & & 32.10 & & & Subcompact & Compact \\
\hline Hyundai & & 44.47 & & 34.51 & & 21.02 & & & & & & Subcompact \\
\hline DeTomaso & 100.00 & & & & & & & & & & Subcompact & \\
\hline $\mathrm{Kia}$ & & 43.96 & & 10.59 & & 45.45 & & & & & & Intermediate \\
\hline Mazda & & 17.41 & & 44.44 & & 38.15 & & & & & & Compact \\
\hline Mercedes & & & & 32.66 & & & & & 100.00 & 67.34 & Luxury & Luxury \\
\hline Mitsubishi & & & & 29.80 & & 70.20 & & & & & & Intermediate \\
\hline Nissan & 100.00 & 49.95 & & 21.15 & & 28.04 & & & & 0.86 & Subcompact & Subcompact \\
\hline GM & & 31.55 & 62.30 & 41.58 & 0.61 & 19.50 & 35.47 & 6.07 & 1.61 & 1.30 & Compact & Compact \\
\hline Peugeot & 38.67 & 49.78 & 27.85 & 16.21 & 11.22 & 33.39 & 22.25 & 0.62 & & & Subcompact & Subcompact \\
\hline Renault & 79.37 & 60.64 & 20.63 & 21.47 & & 15.78 & & 2.11 & & & Subcompact & Subcompact \\
\hline Rover & 69.72 & & 18.61 & & & & 11.67 & & & & Subcompact & \\
\hline Saab & & & & & & & 100.00 & & & & Standard & \\
\hline Suzuki & & 59.93 & & & & 40.17 & & & & & & Subcompact \\
\hline Toyota & & 36.46 & 100.00 & 34.10 & & 28.88 & & 0.56 & & & Compact & Subcompact \\
\hline VW & 54.32 & 27.25 & 29.39 & 40.78 & 7.89 & 25.99 & 8.40 & 5.46 & & 0.53 & Subcompact & Compact \\
\hline Volvo & & & & & & & 100.00 & & & & Standard & \\
\hline DAF & 100.00 & & & & & & & & & & Subcompact & \\
\hline TalbotSimca & 61.99 & & 21.33 & & 16.68 & & & & & & Subcompact & \\
\hline TalbotMatra & & & & & & & 100.00 & & & & Standard & \\
\hline Daewoo & & 53.83 & & 29.20 & & 15.20 & & 1.77 & & & & Subcompact \\
\hline Daimler & & 100.00 & & & & & & & & & & Subcompact \\
\hline $\begin{array}{l}\text { Total } \\
\text { segment sales }\end{array}$ & 49.15 & 37.83 & 25.64 & 30.16 & 9.14 & 19.72 & 12.37 & 6.69 & 3.71 & 5.60 & Subcompact & Subcompact \\
\hline
\end{tabular}

Source: European car market database, own estimations 
Table B7: European car market: geographic-product market presence (defined by shares of a firm in a market segment ('market-share dominance')), 1999

\begin{tabular}{|c|c|c|c|c|c|c|c|}
\hline & $B M W$ & Daihatsu & Fiat & Ford & Honda & Hyundai & Kia \\
\hline \multicolumn{8}{|l|}{ Belgium (BE) } \\
\hline Subcompact & 0.07 & 0.25 & 6.67 & 9.44 & 0.49 & 0.72 & 1.02 \\
\hline Compact & 1.68 & & 3.09 & 10.52 & 1.69 & 1.17 & 0.05 \\
\hline Intermediate & 0.00 & & 1.90 & 13.47 & & 0.88 & 0.67 \\
\hline Standard & 39.40 & & 14.67 & 7.54 & 4.53 & & \\
\hline Luxury & 24.60 & & 6.59 & 11.22 & & & \\
\hline \multicolumn{8}{|l|}{ France (FR) } \\
\hline Subcompact & & & 8.41 & 6.58 & 0.15 & 0.15 & \\
\hline Compact & 3.16 & & 3.64 & 13.72 & 1.03 & 0.54 & \\
\hline Intermediate & & & 1.04 & 7.35 & & 0.26 & \\
\hline Standard & 33.53 & & 11.76 & 1.91 & 3.81 & & \\
\hline Luxury & 22.29 & & 6.20 & 5.94 & & & \\
\hline \multicolumn{8}{|c|}{ Germany (DE) } \\
\hline Subcompact & 0.28 & 1.50 & 7.48 & 12.25 & 0.58 & 0.65 & 0.64 \\
\hline Compact & 1.48 & & 1.34 & 11.61 & 1.60 & 0.52 & 0.23 \\
\hline Intermediate & & 0.08 & 1.60 & 10.27 & & 1.12 & 1.36 \\
\hline Standard & 51.94 & & 4.52 & 4.13 & 3.25 & & \\
\hline Luxury & 22.77 & & 1.52 & 2.14 & & & \\
\hline \multicolumn{8}{|l|}{$\operatorname{Italy}(I T)$} \\
\hline Subcompact & 0.06 & 0.09 & 42.73 & 7.96 & 0.31 & 2.15 & 0.24 \\
\hline Compact & 5.03 & & 18.46 & 17.08 & 1.45 & 1.09 & \\
\hline Intermediate & & & 22.24 & 10.70 & & 1.18 & 0.75 \\
\hline Standard & 28.78 & & 48.74 & 4.58 & 1.77 & & \\
\hline Luxury & 16.90 & & 31.91 & 3.09 & & & \\
\hline \multicolumn{8}{|l|}{$U K$} \\
\hline Subcompact & 0.32 & 0.69 & 6.38 & 22.48 & & 0.85 & 0.32 \\
\hline Compact & 12.83 & & 2.94 & 21.64 & 5.05 & 2.08 & \\
\hline Intermediate & & & 1.31 & 24.58 & & 1.24 & \\
\hline Standard & 44.16 & & 5.60 & 8.55 & 15.19 & & \\
\hline Luxury & 24.12 & & 1.44 & 5.70 & & & \\
\hline \multicolumn{8}{|l|}{ Total market } \\
\hline Subcompact & 0.14 & 0.50 & 18.46 & 11.32 & 0.28 & 1.03 & 0.31 \\
\hline Compact & 4.92 & & 4.89 & 15.05 & 2.29 & 1.00 & 0.09 \\
\hline Intermediate & 0.00 & 0.03 & 3.80 & 13.06 & & 0.94 & 0.62 \\
\hline Standard & 44.06 & & 12.90 & 5.05 & 5.63 & & \\
\hline Luxury & 22.11 & & 6.61 & 3.40 & & & \\
\hline $\begin{array}{l}\text { 'Spheres } \\
\text { of influence' }\end{array}$ & $\begin{array}{l}\text { BEstand*, } \\
\text { DEstand, } \\
\text { UKstand }\end{array}$ & DEsubc & $\begin{array}{l}\text { ITsubc, } \\
\text { ITstan, } \\
\text { ITlux } \\
\end{array}$ & $\begin{array}{l}\text { UKsubc, } \\
\text { UKcomp, } \\
\text { UKinte }\end{array}$ & UKstan & ITsubc & DEinte \\
\hline
\end{tabular}

Source: European car market database, own calculations

Note: * stan, subc, lux, comp, inte stand for standard, subcompact, luxury, compact and intermediate market segments, respectively. 
Table B7: European car market: geographic-product market presence (defined by shares of a firm in a market segment ('market-share dominance')), 1999 (continuation)

\begin{tabular}{|c|c|c|c|c|c|c|c|}
\hline & Mazda & Mercedes & Mitsubishi & Nissan & $\overline{G M}$ & Peugeot & Renault \\
\hline \multicolumn{8}{|l|}{ Belgium (BE) } \\
\hline Subcompact & 1.61 & \multirow{3}{*}{3.69} & & 2.62 & 11.52 & 21.61 & 14.67 \\
\hline Compact & 2.54 & & 0.92 & 2.81 & 17.03 & 10.51 & 13.44 \\
\hline Intermediate & 2.09 & & 5.57 & 3.28 & 6.08 & 28.00 & 5.37 \\
\hline Standard & & \multirow{2}{*}{\multicolumn{2}{|c|}{50.85}} & & 8.63 & 2.24 & 3.98 \\
\hline Luxury & & & & 0.58 & 4.80 & & \\
\hline \multicolumn{8}{|l|}{ France (FR) } \\
\hline Subcompact & 0.16 & \multirow{3}{*}{3.06} & & 1.09 & 6.69 & 31.92 & 31.75 \\
\hline Compact & 0.58 & & 0.14 & 0.91 & 8.71 & 20.23 & 20.98 \\
\hline Intermediate & 0.61 & & 0.26 & 1.81 & 4.77 & 53.35 & 17.05 \\
\hline Standard & & \multirow{3}{*}{\multicolumn{2}{|c|}{61.52}} & & 6.60 & 7.50 & 25.60 \\
\hline Luxury & & & & & 2.56 & & \\
\hline \multicolumn{6}{|l|}{ Germany (DE) } & & \\
\hline Subcompact & 1.44 & \multirow{3}{*}{9.14} & & 2.74 & 14.79 & 8.50 & 13.33 \\
\hline Compact & 2.91 & & 0.91 & 1.51 & 20.96 & 2.09 & 4.05 \\
\hline Intermediate & 4.62 & & 3.22 & 3.27 & 14.57 & 6.40 & 4.39 \\
\hline Standard & & \multirow{3}{*}{\multicolumn{2}{|c|}{69.63}} & & 11.29 & 0.46 & 0.13 \\
\hline Luxury & & & & 0.37 & 1.25 & & \\
\hline \multicolumn{7}{|l|}{ Italy (IT) } & \\
\hline Subcompact & 0.21 & \multirow{3}{*}{4.93} & & 2.68 & 7.40 & 9.78 & 9.46 \\
\hline Compact & 0.33 & & 0.29 & 0.82 & 17.23 & 3.50 & \\
\hline Intermediate & 0.39 & & 0.42 & 3.74 & 8.34 & 15.35 & 3.19 \\
\hline Standard & & \multirow{3}{*}{\multicolumn{2}{|c|}{45.38}} & & 3.75 & 0.32 & \\
\hline Luxury & & & & & 1.72 & & \\
\hline \multicolumn{6}{|l|}{$U K$} & & \\
\hline Subcompact & 0.40 & \multirow{3}{*}{2.25} & & 7.54 & 13.69 & 20.12 & 10.10 \\
\hline Compact & 1.39 & & 0.34 & 2.93 & 14.72 & 8.55 & 6.79 \\
\hline Intermediate & 1.50 & & 1.89 & 5.34 & 19.04 & 16.88 & 7.49 \\
\hline Standard & & \multirow{3}{*}{\multicolumn{2}{|c|}{55.51}} & & 19.04 & & 0.28 \\
\hline Luxury & & & & 0.95 & 10.98 & & \\
\hline \multicolumn{6}{|l|}{ Total market } & & \\
\hline Subcompact & 0.55 & \multirow{3}{*}{5.66} & & 3.20 & 10.18 & 17.28 & 16.11 \\
\hline Compact & 1.77 & & 0.56 & 1.70 & 16.82 & 7.06 & 7.15 \\
\hline Intermediate & 2.32 & & 2.01 & 3.45 & 12.07 & 22.23 & 8.04 \\
\hline Standard & & \multirow{2}{*}{\multicolumn{2}{|c|}{62.79}} & & 11.07 & 1.21 & 3.16 \\
\hline Luxury & & & & 0.37 & 2.83 & & \\
\hline $\begin{array}{l}\text { 'Spheres } \\
\text { of influence' }\end{array}$ & DEinte* & luxury & BEinte & UKsubc & $\begin{array}{l}\text { DEcomp, } \\
\text { UKinte, } \\
\text { UKstan }\end{array}$ & $\begin{array}{l}\text { BEinte, } \\
\text { FRsubc, } \\
\text { FRinte }\end{array}$ & $\begin{array}{l}\text { FRsubc, } \\
\text { FRcomp } \\
\text { FRstan }\end{array}$ \\
\hline
\end{tabular}

Source: European car market database, own calculations

Note: * stan, subc, lux, comp, inte stand for standard, subcompact, luxury, compact and intermediate market segments, respectively. 
Table B7: European car market: geographic-product market presence (defined by shares of a firm in a market segment ('market-share dominance')), 1999 (continuation)

\begin{tabular}{|c|c|c|c|c|c|c|}
\hline & FujiHI & Suzuki & Toyota & $\overline{V V W}$ & Daewoo & $\overline{\text { Daimler }}$ \\
\hline \multicolumn{7}{|l|}{ Belgium (BE) } \\
\hline Subcompact & 0.14 & 0.99 & 4.24 & 22.44 & 1.49 & \\
\hline Compact & & & 5.34 & 24.30 & 1.21 & \\
\hline Intermediate & & 1.41 & 6.04 & 24.02 & 1.22 & \\
\hline Standard & & & 0.42 & 18.04 & 0.56 & \\
\hline Luxury & & & & 1.36 & & \\
\hline \multicolumn{7}{|l|}{ France (FR) } \\
\hline Subcompact & & 0.17 & 1.54 & 10.31 & 0.59 & 0.48 \\
\hline Compact & & & 1.31 & 20.96 & 1.03 & \\
\hline Intermediate & & 0.43 & 1.46 & 11.07 & 0.53 & \\
\hline Standard & & & & 8.70 & 0.61 & \\
\hline Luxury & & & & 1.49 & & \\
\hline \multicolumn{7}{|l|}{ Germany (DE) } \\
\hline Subcompact & & 0.77 & 2.29 & 27.17 & 0.58 & 4.99 \\
\hline Compact & & & 2.31 & 38.98 & 0.37 & \\
\hline Intermediate & & 0.86 & 3.21 & 44.61 & 0.43 & \\
\hline Standard & & & 0.19 & 24.10 & & \\
\hline Luxury & & & & 2.32 & & \\
\hline \multicolumn{7}{|l|}{ Italy (IT) } \\
\hline Subcompact & & 0.13 & 2.26 & 9.54 & 3.72 & 1.30 \\
\hline Compact & & & 2.82 & 23.96 & 3.02 & \\
\hline Intermediate & & 0,80 & 2.83 & 26.60 & 3.47 & \\
\hline Standard & & & & 10.45 & 1.61 & \\
\hline Luxury & & & & 0.99 & & \\
\hline \multicolumn{7}{|l|}{$U K$} \\
\hline Subcompact & & 0.88 & 2.70 & 11.50 & 2.04 & \\
\hline Compact & & & 3.31 & 13.37 & 1.80 & \\
\hline Intermediate & & & 5.40 & 14.21 & 1.13 & \\
\hline Standard & & & 0.41 & 6.77 & & \\
\hline Luxury & & & & 1.31 & & \\
\hline \multicolumn{7}{|l|}{ Total } \\
\hline Subcompact & & 0.45 & 2.24 & 14.46 & 1.86 & 1.63 \\
\hline Compact & & 0.00 & 2.63 & 27.13 & 1.27 & \\
\hline Intermediate & & 0.58 & 3.40 & 26.45 & 1.01 & \\
\hline Standard & & & 0.19 & 16.38 & 0.35 & \\
\hline Luxury & & & & 1.89 & & \\
\hline $\begin{array}{l}\text { 'Spheres } \\
\text { of influence' }\end{array}$ & & BEinte & BEinte & $\begin{array}{l}\text { DEcomp, } \\
\text { DEinte, } \\
\text { ITinte }\end{array}$ & ITinte & DEsubc \\
\hline
\end{tabular}

Source: European car market database, own calculations

Note: * stan, subc, lux, comp, inte stand for standard, subcompact, luxury, compact and intermediate market segments, respectively. 
Table B8: European car market: geographic-product market presence (share of a market segment in the total sales of a firm ('market dependence')), 1999

\begin{tabular}{|c|c|c|c|c|c|c|c|}
\hline & BMW & Daihatsu & Fiat & Ford & Honda & "Hyundai & Kia \\
\hline \multicolumn{8}{|l|}{ Belgium (BE) } \\
\hline Subcompact & 0.02 & 1.70 & 0.85 & 1.05 & 0.56 & 1.09 & 5.07 \\
\hline Compact & 0.46 & & 0.47 & 1.40 & 2.28 & 2.12 & 0.28 \\
\hline Intermediate & 0.00 & & 0.20 & 1.22 & & 1.09 & 2.72 \\
\hline Standard & 2.40 & & 0.49 & 0.22 & 1.35 & & \\
\hline Luxury & 0.99 & & 0.15 & 0.22 & & & \\
\hline \multicolumn{8}{|l|}{ France (FR) } \\
\hline Subcompact & & & 7.50 & 5.14 & 1.16 & 1.56 & \\
\hline Compact & 2.58 & & 1.63 & 5.39 & 4.12 & 2.90 & \\
\hline Intermediate & & & 0.47 & 2.90 & & 1.41 & \\
\hline Standard & 4.34 & & 0.84 & 0.12 & 2.41 & & \\
\hline Luxury & 1.59 & & 0.24 & 0.20 & & & \\
\hline \multicolumn{8}{|l|}{ Germany (DE) } \\
\hline Subcompact & 0.41 & 65.24 & 6.02 & 8.63 & 4.18 & 6.20 & 20.17 \\
\hline Compact & 3.14 & & 1.56 & 11.83 & 16.65 & 7.16 & 10.31 \\
\hline Intermediate & & 2.79 & 1.09 & 6.16 & & 9.11 & 36.36 \\
\hline Standard & 28.85 & & 1.38 & 1.10 & 8.82 & & \\
\hline Luxury & 13.50 & & 0.50 & 0.61 & & & \\
\hline \multicolumn{8}{|l|}{ Italy (IT) } \\
\hline Subcompact & 0.12 & 5.35 & 48.23 & 7.86 & 3.17 & 28.79 & 10.43 \\
\hline Compact & 4.23 & & 8.51 & 6.89 & 5.94 & 5.95 & \\
\hline Intermediate & & & 4.85 & 2.04 & & 3.07 & 6.37 \\
\hline Standard & 5.18 & & 4.81 & 0.40 & 1.56 & & \\
\hline Luxury & 2.48 & & 2.56 & 0.22 & & & \\
\hline \multicolumn{8}{|l|}{$U K$} \\
\hline Subcompact & 0.40 & 24.92 & 4.29 & 13.22 & & 6.82 & 8.30 \\
\hline Compact & 15.52 & & 1.95 & 12.56 & 29.84 & 16.38 & \\
\hline Intermediate & & & 0.57 & 9.28 & & 6.34 & \\
\hline Standard & 10.69 & & 0.74 & 0.99 & 17.97 & & \\
\hline Luxury & 3.08 & & 0.10 & 0.35 & & & \\
\hline $\begin{array}{l}\text { Total firm } \\
\text { sales }\end{array}$ & 100 & 100 & 100 & 100 & 100 & 100 & 100 \\
\hline $\begin{array}{l}\text { 'Spheres of } \\
\text { influence' }\end{array}$ & DEstan & DEsubc & ITsubc & $\begin{array}{l}\text { DEcomp, } \\
\text { UKsubc, } \\
\text { UKcomp }\end{array}$ & UKcomp & ITsubc & DEinte \\
\hline
\end{tabular}

Source: European car market database, own calculations

Note: ${ }^{*}$ stan, subc, lux, comp, inte stand for standard, subcompact, luxury, compact and intermediate market segments, respectively. 
Table B8: European car market: geographic-product market presence (share of a market segment in the total sales of a firm ('market dependence')), 1999 (continuation)

\begin{tabular}{|c|c|c|c|c|c|c|c|}
\hline & Mazda & Mercedes & $\begin{array}{l}\text { Mitsu } \\
\text { bishi }\end{array}$ & Nissan & $\overline{~ G M}$ & Peugeot & $\overline{\text { Renault }}$ \\
\hline \multicolumn{8}{|l|}{ Belgium (BE) } \\
\hline Subcompact & 1.77 & \multirow{3}{*}{1.12} & & 1.43 & 1.25 & 2.18 & 1.93 \\
\hline Compact & 3.36 & & 2.59 & 1.84 & 2.21 & 1.27 & 2.12 \\
\hline Intermediate & 1.89 & & 10.64 & 1.46 & 0.54 & 2.31 & 0.58 \\
\hline Standard & & \multirow{3}{*}{\multicolumn{2}{|c|}{2.25}} & & 0.25 & 0.06 & 0.14 \\
\hline Luxury & & & & 0.06 & 0.09 & & \\
\hline \multicolumn{6}{|l|}{ France (FR) } & & \\
\hline Subcompact & 1.23 & \multirow{3}{*}{2.74} & & 4.18 & 5.11 & 22.64 & 29.42 \\
\hline Compact & 2.27 & & 1.13 & 1.76 & 3.34 & 7.22 & 9.78 \\
\hline Intermediate & 2.38 & & 2.12 & 3.52 & 1.84 & 19.15 & 8.00 \\
\hline Standard & & \multirow{3}{*}{\multicolumn{2}{|c|}{4.80}} & & 0.40 & 0.42 & 1.89 \\
\hline Luxury & & & & & 0.09 & & \\
\hline \multicolumn{6}{|l|}{ Germany (DE) } & & \\
\hline Subcompact & 10.08 & \multirow{3}{*}{21.28} & & 9.50 & 10.18 & 5.44 & 11.14 \\
\hline Compact & 29.46 & & 19.46 & 7.55 & 20.88 & 1.93 & 4.90 \\
\hline Intermediate & 27.52 & & 40.72 & 9.63 & 8.53 & 3.48 & 3.12 \\
\hline Standard & & \multirow{2}{*}{\multicolumn{2}{|c|}{45.24}} & & 2.94 & 0.11 & 0.04 \\
\hline Luxury & & & & 0.52 & 0.35 & & \\
\hline \multicolumn{8}{|l|}{ Italy (IT) } \\
\hline Subcompact & 2.02 & \multirow{3}{*}{4.54} & & 13.03 & 7.14 & 8.78 & \multirow{2}{*}{11.09} \\
\hline Compact & 1.33 & & 2.43 & 1.64 & 6.79 & 1.28 & \\
\hline Intermediate & 0.75 & & 1.69 & 3.51 & 1.56 & 2.66 & 0.72 \\
\hline Standard & & \multirow{3}{*}{\multicolumn{2}{|c|}{7.29}} & & 0.32 & 0.03 & \\
\hline Luxury & & & & & 0.12 & & \\
\hline \multicolumn{6}{|l|}{$U K$} & & \\
\hline Subcompact & 2.31 & \multirow{3}{*}{2.98} & & 21.80 & 7.87 & 10.75 & 7.05 \\
\hline Compact & 8.02 & & 4.20 & 8.37 & 8.35 & 4.51 & 4.68 \\
\hline Intermediate & 5.61 & & 15.04 & 9.91 & 7.03 & 5.79 & 3.36 \\
\hline Standard & & & & & 2.16 & & 0.04 \\
\hline Luxury & & 7.76 & & 0.29 & 0.66 & & \\
\hline $\begin{array}{l}\text { Total firm } \\
\text { sales }\end{array}$ & 100 & 100 & 100 & 100 & 100 & 100 & 100 \\
\hline $\begin{array}{l}\text { 'Spheres of } \\
\text { influence' }\end{array}$ & $\begin{array}{l}\text { DEcomp, } \\
\text { DEinte }\end{array}$ & DElux & DEinte & UKsubc & DEcomp & $\begin{array}{l}\text { FRsubc, } \\
\text { FRinte }\end{array}$ & FRsubc \\
\hline
\end{tabular}

Source: European car market database, own calculations

Note: * stan, subc, lux, comp, inte stand for standard, subcompact, luxury, compact and intermediate market segments, respectively. 
Table B8: European car market: geographic-product market presence (share of a market segment in the total sales of a firm ('market dependence')), 1999 (continuation)

\begin{tabular}{|c|c|c|c|c|c|c|c|}
\hline & FujiHI & Suzuki & Toyota & $V W$ & Daewoo & Daimler & $\begin{array}{l}\text { Total } \\
\text { segment } \\
\text { sales }\end{array}$ \\
\hline \multicolumn{8}{|l|}{$\begin{array}{l}\text { Belgium } \\
(B E)\end{array}$} \\
\hline Subcompact & 100.00 & 4.58 & 2.42 & 1.48 & 1.51 & & 1.33 \\
\hline Compact & & & 3.65 & 1.92 & 1.47 & & 1.59 \\
\hline Intermediate & & 5.33 & 2.81 & 1.29 & 1.01 & & 1.08 \\
\hline Standard & & & 0.06 & 0.31 & 0.15 & & 0.35 \\
\hline Luxury & & & & 0.02 & & & 0.23 \\
\hline \multicolumn{8}{|l|}{ France (FR) } \\
\hline Subcompact & & 5.68 & 6.18 & 4.78 & 4.22 & 7.29 & 9.31 \\
\hline Compact & & & 2.65 & 4.89 & 3.70 & & 4.68 \\
\hline Intermediate & & 7.05 & 2.97 & 2.60 & 1.92 & & 4.71 \\
\hline Standard & & & & 0.32 & 0.35 & & 0.74 \\
\hline Luxury & & & & 0.03 & & & 0.41 \\
\hline \multicolumn{8}{|l|}{$\begin{array}{l}\text { Germany } \\
(D E)\end{array}$} \\
\hline Subcompact & & 22.66 & 8.27 & 11.37 & 3.71 & 67.95 & 8.40 \\
\hline Compact & & & 12.10 & 23.61 & 3.45 & & 12.16 \\
\hline Intermediate & & 21.44 & 9.86 & 15.89 & 2.36 & & 7.15 \\
\hline Standard & & & 0.25 & 3.82 & & & 3.18 \\
\hline Luxury & & & & 0.39 & & & 3.39 \\
\hline \multicolumn{8}{|l|}{ Italy (IT) } \\
\hline Subcompact & & 5.38 & 11.44 & 5.60 & 33.47 & 24.76 & 11.78 \\
\hline Compact & & & 5.84 & 5.74 & 11.09 & & 4.81 \\
\hline Intermediate & & 6.35 & 2.77 & 3.02 & 6.03 & & 2.28 \\
\hline Standard & & & & 0.54 & 1.27 & & 1.03 \\
\hline Luxury & & & & 0.04 & & & 0.84 \\
\hline \multicolumn{8}{|l|}{$U K$} \\
\hline Subcompact & & 21.52 & 8.15 & 4.02 & 10.93 & & 7.01 \\
\hline Compact & & & 9.86 & 4.61 & 9.50 & & 6.92 \\
\hline Intermediate & & & 10.47 & 3.19 & 3.88 & & 4.50 \\
\hline Standard & & & 0.24 & 0.47 & & & 1.39 \\
\hline Luxury & & & & 0.05 & & & 0.73 \\
\hline $\begin{array}{l}\text { Total firm } \\
\text { sales }\end{array}$ & 100 & 100 & 100 & 100 & 100 & 100 & 100 \\
\hline $\begin{array}{l}\text { 'Spheres } \\
\text { of } \\
\text { influence' }\end{array}$ & BEsubc & $\begin{array}{l}\text { DEsubc, } \\
\text { DEinte, } \\
\text { UKsubc }\end{array}$ & $\begin{array}{l}\text { DEcomp, } \\
\text { ITsubc, } \\
\text { UKinte }\end{array}$ & DEcomp & ITsubc & DEsubc & \\
\hline
\end{tabular}

Source: European car market database, own calculations

Note: * stan, subc, lux, comp, inte stand for standard, subcompact, luxury, compact and intermediate market segments, respectively. 
Table B9: European car market: automotive manufacturer groups

\begin{tabular}{|c|c|}
\hline $\begin{array}{l}\text { Firm (equivalent } \\
\text { to corporate } \\
\text { group) }\end{array}$ & Brands \\
\hline Alfa Romeo & Alfa Romeo (till 1986 (including 1986)) \\
\hline BMW & BMW, Rover Triumph (1994-1999) \\
\hline Daihatsu & Daihatsu (starting 1979) \\
\hline Fiat & $\begin{array}{l}\text { 1970: Citroen, Fiat, Lancia, Autobianchi; 1971: Citroen, Fiat, } \\
\text { Lancia; 1972-1974: Citroen, Fiat, Lancia, Autobianchi; 1975: } \\
\text { Citroen, Fiat, Lancia; 1976-1986: Fiat, Lancia; 1987-1989: } \\
\text { AlfaRomeo, Fiat, Lancia; 1990-1996: Alfa Romeo, Fiat, Lancia, } \\
\text { Innocenti; 1997-1999: Alfa Romeo, Fiat, Lancia }\end{array}$ \\
\hline Ford & Ford, Volvo (1999) \\
\hline Honda & Honda \\
\hline Hyundai & Hyundai (starting 1980) \\
\hline DeTomaso & Innocenti (1970-1989) \\
\hline $\mathrm{Kia}$ & Kia (starting 1993) \\
\hline Mazda & Mazda (starting 1972) \\
\hline Mercedes & Mercedes \\
\hline Mitsubishi & Mitsubishi (starting 1976) \\
\hline Nissan & NissanDatsun \\
\hline GM & OpelVauxhall, Saab (starting 1990) \\
\hline Peugeot & Peugeot, Citroen (starting 1976), Talbot (1980-1986) \\
\hline Renault & Renault \\
\hline Rover & $\begin{array}{l}\text { RoverTriumph (1970-1993), Rover (1970-1979), Triumph (1970- } \\
\text { 1979), Princess (1976-1979) }\end{array}$ \\
\hline Saab & Saab (1970-1989) \\
\hline Seat & Seat (1983-1985) \\
\hline Fujuhi & Subaru (starting 1979) \\
\hline Suzuki & Suzuki (starting 1981) \\
\hline Toyota & Toyota \\
\hline VW & Audi, Volkswagen, Seat (starting 1986), Skoda (starting 1993) \\
\hline Volvo & Volvo (1970-1998) \\
\hline Yugo & Yugo (1981-1991) \\
\hline Daewoo & Daewoo (starting 1995) \\
\hline Daimler & MMC (1998-1999) \\
\hline DAF & DAF (1970-1975) \\
\hline TalbotSimca & TalbotHillmanChrysler (1970-1979), TalbotSimca (1970-1977), \\
\hline HillmanSunbeam & TalbotSimca (1978-1979), TalbotMatra (1978-1979) \\
\hline TalbotMatra & TalbotMatra (1970-1977) \\
\hline Lancia & Lancia (1971) \\
\hline
\end{tabular}

Source: European car market database, own calculations 
Table B10: European car market: cross-ownership changes

\begin{tabular}{ll}
\hline \hline $\begin{array}{l}\text { Firm (equivalent to corporate } \\
\text { group) }\end{array}$ & Brands \\
\hline Ford Group & Mazda (33\%) \\
GM Group & Subaru $(20 \%)$, Suzuki $(20 \%)$, Isuzu $(12 \%)$, Fiat (10\%) \\
RenaultNissan Group & Nissan $(44 \%)$ \\
Toyota & Daihatsu (52\%) \\
DaimlerChrysler & Mitsubishi $(24.7 \%)$ \\
Hyundai & Kia $(60 \%)$ \\
\hline \hline
\end{tabular}

Source: Deustche Bank (2004)

Note: The shares are given as of 2004; they may have been changing over time. 


\section{Appendix C. European car market: descriptive statistics for concentration ratios and multimarket contact measures}

Table C1: European car market: descriptive statistics for multimarket contact measures (averages across years and firms))

\begin{tabular}{|c|c|c|c|c|}
\hline \multirow[t]{2}{*}{ Firm } & \multicolumn{2}{|c|}{$\begin{array}{l}\text { Number of markets in which a firm } \\
\text { is present }\end{array}$} & \multicolumn{2}{|c|}{ Number of multiple contacts } \\
\hline & mean & std. dev. & mean & std. dev. \\
\hline Alfa Romeo & 12.74 & 0.12 & 126.86 & 1.88 \\
\hline BMW & 15.54 & 0.20 & 131.40 & 2.52 \\
\hline Daihatsu & 4.20 & 0.12 & 53.42 & 1.56 \\
\hline Fiat & 21.99 & 0.08 & 202.15 & 1.14 \\
\hline Ford & 19.00 & 0.11 & 200.28 & 1.71 \\
\hline Honda & 12.72 & 0.24 & 138.51 & 2.37 \\
\hline Hyundai & 9.46 & 0.29 & 123.52 & 4.15 \\
\hline De Tomaso & 2.26 & 0.14 & 19.21 & 1.34 \\
\hline Kia & 8.96 & 0.35 & 122.22 & 5.14 \\
\hline Mazda & 12.79 & 0.12 & 152.25 & 1.84 \\
\hline Mercedes & 5.46 & 0.09 & 28.07 & 1.52 \\
\hline Mitsubishi & 9.53 & 0.11 & 117.5 & 1.33 \\
\hline Nissan & 15.64 & 0.12 & 174.04 & 1.62 \\
\hline GM & 21.91 & 0.12 & 210.28 & 1.78 \\
\hline Peugeot & 19.73 & 0.02 & 208.83 & 0.64 \\
\hline Renault & 17.32 & 0.12 & 183.46 & 1.72 \\
\hline Rover & 14.84 & 0.12 & 155.93 & 1.80 \\
\hline Saab & 5.72 & 0.29 & 54.38 & 2.26 \\
\hline Seat & 5.18 & 0.27 & 53.29 & 3.21 \\
\hline Fujihi & 1.59 & 0.09 & 20.34 & 1.16 \\
\hline Suzuki & 6.58 & 0.29 & 80.18 & 4.00 \\
\hline Toyota & 14.42 & 0.12 & 166.44 & 1.71 \\
\hline VW & 20.90 & 0.07 & 213.94 & 1.10 \\
\hline Volvo & 13.14 & 0.23 & 125.64 & 2.37 \\
\hline Yugo & 2.71 & 0.10 & 28.86 & 1.13 \\
\hline Daewoo & 14.36 & 0.56 & 185.44 & 7.30 \\
\hline Daimler & 2.5 & 0.50 & 37.50 & 7.50 \\
\hline DAF & 4.79 & 0.12 & 36.86 & 1.08 \\
\hline Talbotsimca & 14.03 & 0.16 & 121.94 & 2.10 \\
\hline Talbotmatra & 3.17 & 0.16 & 27.91 & 1.69 \\
\hline Lancia & 8.00 & 0.00 & 71.00 & 0.00 \\
\hline
\end{tabular}


Table C2: European car market: descriptive statistics for multimarket contact measures and number of competitors (averages across years and geographic-product markets))

\begin{tabular}{lllllll}
\hline \hline Firm & \multicolumn{2}{l}{ Simple count } & \multicolumn{2}{l}{ Share-weighted } & \multicolumn{2}{l}{ No. of competitors } \\
\hline & mean & std. dev. & mean & std. dev. & mean & std. dev. \\
Belgium: compact & 10.69 & 0.08 & 740.19 & 8.14 & 14.47 & 0.08 \\
Belgium: intermediate & 11.88 & 0.05 & 810.88 & 10.48 & 12.86 & 0.09 \\
Belgium: luxury & 9.93 & 0.21 & 1866.22 & 92.68 & 5.85 & 0.11 \\
Belgium: standard & 11.41 & 0.13 & 938.40 & 16.70 & 12.59 & 0.10 \\
Belgium: subcompact & 9.99 & 0.08 & 770.99 & 5.69 & 12.33 & 0.07 \\
France: compact & 12.36 & 0.07 & 889.63 & 6.96 & 12.95 & 0.06 \\
France: intermediate & 13.20 & 0.06 & 992.52 & 12.46 & 11.53 & 0.10 \\
France: luxury & 10.08 & 0.28 & 2738.35 & 179.06 & 5.14 & 0.13 \\
France: standard & 12.14 & 0.15 & 1142.59 & 22.60 & 11.01 & 0.10 \\
France: subcompact & 11.96 & 0.12 & 1043.22 & 10.36 & 10.39 & 0.05 \\
Germany: compact & 11.99 & 0.08 & 849.39 & 6.28 & 12.93 & 0.07 \\
Germany: intermediate & 12.76 & 0.09 & 943.21 & 14.07 & 11.65 & 0.11 \\
Germany: luxury & 10.08 & 0.22 & 1976.58 & 74.06 & 5.65 & 0.12 \\
Germany: standard & 12.16 & 0.12 & 1079.97 & 15.53 & 10.72 & 0.08 \\
Germany: subcompact & 11.60 & 0.09 & 965.55 & 11.02 & 10.90 & 0.09 \\
Italy: compact & 13.53 & 0.09 & 1282.32 & 16.58 & 10.48 & 0.11 \\
Italy: intermediate & 14.07 & 0.09 & 1412.00 & 27.84 & 9.68 & 0.14 \\
Italy: luxury & 9.34 & 0.28 & 2138.78 & 76.93 & 5.05 & 0.10 \\
Italy: standard & 12.66 & 0.16 & 1420.79 & 20.08 & 8.86 & 0.07 \\
Italy: subcompact & 11.81 & 0.10 & 1227.70 & 14.60 & 9.49 & 0.09 \\
UK: compact & 11.49 & 0.09 & 794.58 & 4.77 & 13.32 & 0.08 \\
UK: intermediate & 12.32 & 0.05 & 863.61 & 11.10 & 12.49 & 0.11 \\
UK: luxury & 9.69 & 0.23 & 2136.97 & 146.41 & 5.71 & 0.14 \\
UK: standard & 11.67 & 0.15 & 1020.77 & 19.30 & 11.56 & 0.11 \\
UK: subcompact & 11.36 & 0.09 & 933.01 & 8.00 & 11.21 & 0.08 \\
\hline \hline & & & & & &
\end{tabular}

Source: own estimations 
Table C3: European car market: descriptive statistics for concentration ratios (across geographic-product markets)

\begin{tabular}{llllllll}
\hline \hline & No. obs. & C1 & & C4 & & C8 & \\
\hline & & mean & std. dev. & mean & std. dev. & mean & std. dev. \\
Belgium: compact & 618 & 23.13 & 0.18 & 60.96 & 0.24 & 87.19 & 0.17 \\
Belgium: intermediate & 588 & 24.80 & 0.19 & 67.25 & 0.32 & 90.70 & 0.17 \\
Belgium: luxury & 211 & 61.80 & 0.66 & 96.63 & 0.18 & 100 & 0 \\
Belgium: standard & 514 & 26.89 & 0.33 & 70.66 & 0.31 & 91.89 & 0.35 \\
Belgium: subcompact & 742 & 24.44 & 0.12 & 66.73 & 0.18 & 93.18 & 0.11 \\
France: compact & 541 & 33.44 & 0.27 & 80.36 & 0.19 & 95.47 & 0.08 \\
France: intermediate & 488 & 48.47 & 0.34 & 88.43 & 0.18 & 97.83 & 0.09 \\
France: luxury & 165 & 63.13 & 0.81 & 97.41 & 0.15 & 100 & 0 \\
France: standard & 426 & 46.05 & 0.48 & 87.44 & 0.18 & 97.69 & 0.08 \\
France: subcompact & 645 & 40.85 & 0.24 & 87.76 & 0.21 & 99.43 & 0.02 \\
Germany: compact & 518 & 40.71 & 0.19 & 80.16 & 0.16 & 93.16 & 0.17 \\
Germany: intermediate & 509 & 43.61 & 0.25 & 83.88 & 0.30 & 95.87 & 0.15 \\
Germany: luxury & 199 & 73.58 & 0.66 & 98.48 & 0.10 & 100 & 0 \\
Germany: standard & 422 & 38.14 & 0.43 & 86.76 & 0.22 & 98.05 & 0.07 \\
Germany: subcompact & 635 & 28.41 & 0.38 & 76.74 & 0.38 & 97.26 & 0.09 \\
Italy: compact & 447 & 38.18 & 0.56 & 81.85 & 0.36 & 97.88 & 0.14 \\
Italy: intermediate & 418 & 42.57 & 0.86 & 83.03 & 0.46 & 97.29 & 0.19 \\
Italy: luxury & 175 & 49.94 & 0.84 & 97.91 & 0.10 & 100 & 0 \\
Italy: standard & 353 & 43.33 & 0.43 & 86.07 & 0.31 & 98.68 & 0.08 \\
Italy: subcompact & 634 & 64.71 & 0.41 & 89.98 & 0.25 & 99.44 & 0.06 \\
UK: compact & 557 & 32.49 & 0.30 & 74.76 & 0.38 & 92.28 & 0.15 \\
UK: intermediate & 531 & 34.81 & 0.51 & 78.98 & 0.32 & 95.34 & 0.12 \\
UK: luxury & 176 & 45.75 & 1.08 & 96.74 & 0.22 & 100 & 0 \\
UK: standard & 439 & 31.36 & 0.58 & 74.56 & 0.52 & 93.82 & 0.23 \\
UK: subcompact & 598 & 31.73 & 0.53 & 72.68 & 0.31 & 97.50 & 0.07 \\
\hline \hline & & & & & & &
\end{tabular}

Source: own calculations

Note: in some geographic-product markets less than three firms can be present. 


\section{Appendix D. European car market: descriptive statistics (dataset)}

Table D1: European car market: descriptive statistics for the European car market

\begin{tabular}{|c|c|c|c|c|}
\hline & mean & std. dev. & min & $\max$ \\
\hline \multicolumn{5}{|c|}{ Total European (No. observations: 11549) } \\
\hline price/income & 0.83 & 0.41 & 0.24 & 6.47 \\
\hline sales & 19813.24 & 37719.92 & 51 & 433694 \\
\hline horsepower & 57.14 & 23.88 & 13 & 169.5 \\
\hline weight & 978.87 & 225.41 & 520 & 1910 \\
\hline width & 164.38 & 9.62 & 122 & 188 \\
\hline height & 140.43 & 4.62 & 117.5 & 173.5 \\
\hline fuel efficiency & 8.18 & 1.72 & 4 & 18.6 \\
\hline $\begin{array}{l}\text { domestic car } \\
\text { dummy }\end{array}$ & 0.19 & 0.39 & 0 & 1 \\
\hline \multicolumn{5}{|c|}{ Belgium (No. observations: 2673) } \\
\hline price/income & 0.72 & 0.34 & 0.25 & 3.45 \\
\hline sales & 3925.42 & 4453.51 & 51 & 62410 \\
\hline horsepower & 56.53 & 23.71 & 13 & 165 \\
\hline weight & 976.00 & 227.46 & 520 & 1750 \\
\hline width & 164.16 & 9.82 & 122 & 188 \\
\hline height & 140.34 & 4.63 & 117.5 & 173.5 \\
\hline fuel efficiency & 8.22 & 1.76 & 4.5 & 18.6 \\
\hline $\begin{array}{l}\text { domestic car } \\
\text { dummy }\end{array}$ & 0 & 0 & 0 & 0 \\
\hline \multicolumn{5}{|c|}{ France (No. observations: 2265) } \\
\hline price/income & 0.75 & 0.32 & 0.27 & 3.59 \\
\hline sales & 23305.81 & 38090.45 & 279 & 300395 \\
\hline horsepower & 56.17 & 23.02 & 13 & 169 \\
\hline weight & 973.02 & 220.39 & 520 & 1750 \\
\hline width & 164.28 & 9.46 & 122 & 188 \\
\hline height & 140.46 & 4.85 & 117.5 & 173.5 \\
\hline fuel efficiency & 8.12 & 1.66 & 4.5 & 15.5 \\
\hline $\begin{array}{l}\text { domestic car } \\
\text { dummy }\end{array}$ & 0.25 & 0.43 & 0 & 1 \\
\hline \multicolumn{5}{|c|}{ Italy (No. observations: 2027) } \\
\hline price/income & 0.99 & 0.49 & 0.28 & 5.35 \\
\hline sales & 24292.14 & 45754.1 & 291 & 433694 \\
\hline horsepower & 57.22 & 24.86 & 13 & 169.5 \\
\hline weight & 978.69 & 229.32 & 520 & 1910 \\
\hline width & 164.06 & 9.99 & 122 & 188 \\
\hline height & 140.63 & 4.68 & 117.5 & 173.5 \\
\hline fuel efficiency & 8.08 & 1.69 & 4.6 & 18 \\
\hline $\begin{array}{l}\text { domestic car } \\
\text { dummy }\end{array}$ & 0.24 & 0.42 & 0 & 1 \\
\hline
\end{tabular}

Source: European car market database, own estimations 
Table D1: European car market: descriptive statistics for the European car market (continuation)

\begin{tabular}{lllll}
\hline \hline & mean & std. dev. & min & max \\
\hline $\begin{array}{l}\text { Germany (No. observations: 2283) } \\
\text { price/income }\end{array}$ & 0.65 & 0.27 & & \\
sales & 31002.55 & 50282.04 & 0.24 & 2.45 \\
horsepower & 57.45 & 24.27 & 13 & 414132 \\
weight & 983.05 & 228.66 & 520 & 169 \\
width & 164.57 & 9.74 & 122 & 1750 \\
height & 140.49 & 4.66 & 117.5 & 188 \\
fuel efficiency & 8.24 & 1.77 & 4 & 173.5 \\
domestic car & 0.27 & 0.44 & 0 & 18 \\
dummy & & & & 1 \\
UK (No. observations: 2301$)$ & & & \\
price/income & 1.05 & 0.45 & 0.32 & \\
sales & 19784.34 & 29875.92 & 296 & 6.47 \\
horsepower & 58.42 & 23.61 & 13 & 193784 \\
weight & 984.00 & 221.13 & 520 & 165 \\
width & 164.82 & 9.06 & 129.5 & 1825 \\
height & 140.27 & 4.29 & 122 & 188 \\
fuel efficiency & 8.22 & 1.68 & 4.5 & 173.5 \\
domestic car & 0.23 & 0.42 & 0 & 18 \\
dummy & & & & 1 \\
\hline \hline
\end{tabular}

Source: European car market database, own estimations 